\title{
Haemoglobin-Loaded Metal Organic Framework-Based Nanoparticles Camouflaged With a Red Blood Cell Membrane as Potential Oxygen Delivery Systems
}

\author{
Liu, Xiaoli; Jansman, Michelle Maria Theresia; Hosta-Rigau, Leticia
}

Published in:

Biomaterials Science

Link to article, DOI:

10.1039/D0BM01118E

Publication date:

2020

Document Version

Peer reviewed version

Link back to DTU Orbit

Citation (APA):

Liu, X., Jansman, M. M. T., \& Hosta-Rigau, L. (2020). Haemoglobin-Loaded Metal Organic Framework-Based Nanoparticles Camouflaged With a Red Blood Cell Membrane as Potential Oxygen Delivery Systems.

Biomaterials Science, 8, 5859-5873. https://doi.org/10.1039/D0BM01118E

\section{General rights}

Copyright and moral rights for the publications made accessible in the public portal are retained by the authors and/or other copyright owners and it is a condition of accessing publications that users recognise and abide by the legal requirements associated with these rights.

- Users may download and print one copy of any publication from the public portal for the purpose of private study or research.

- You may not further distribute the material or use it for any profit-making activity or commercial gain

- You may freely distribute the URL identifying the publication in the public portal 


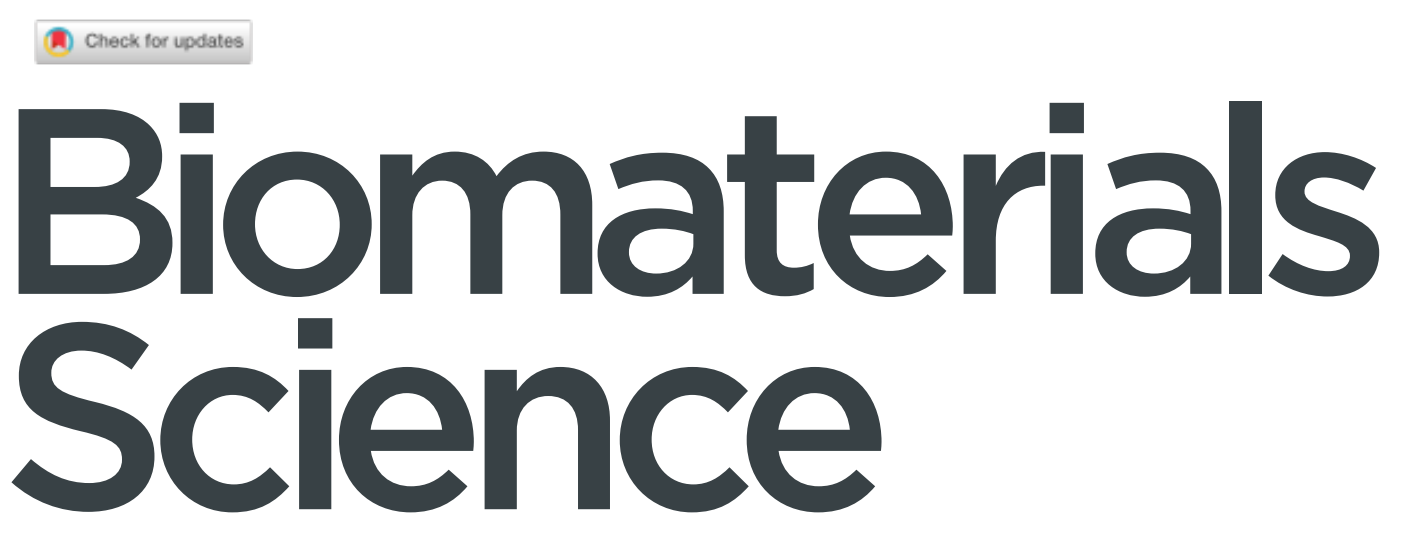

\section{Accepted Manuscript}

This article can be cited before page numbers have been issued, to do this please use: X. Liu, M. M. T. Jansman and L. Hosta-Rigau, Biomater. Sci., 2020, DOI: 10.1039/DOBM01118E.
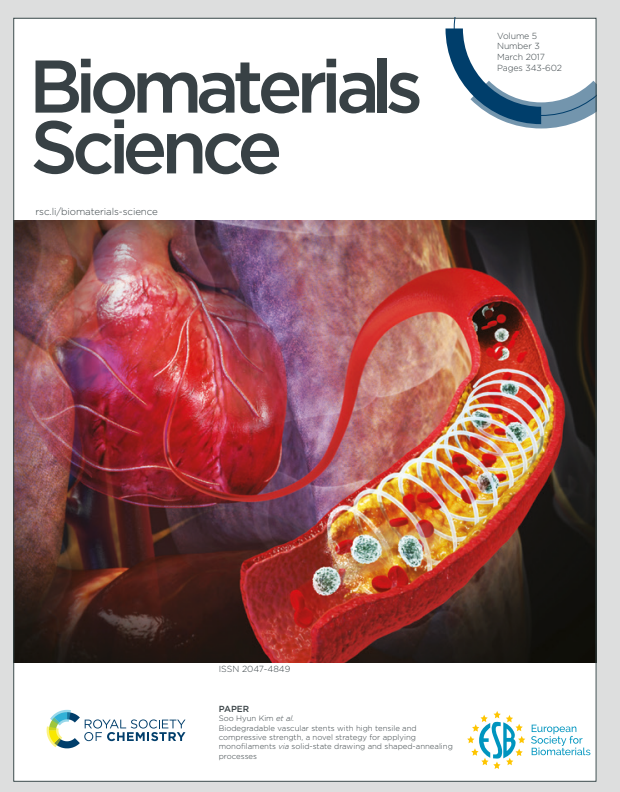

This is an Accepted Manuscript, which has been through the Royal Society of Chemistry peer review process and has been accepted for publication.

Accepted Manuscripts are published online shortly after acceptance, before technical editing, formatting and proof reading. Using this free service, authors can make their results available to the community, in citable form, before we publish the edited article. We will replace this Accepted Manuscript with the edited and formatted Advance Article as soon as it is available.

You can find more information about Accepted Manuscripts in the Information for Authors.

Please note that technical editing may introduce minor changes to the text and/or graphics, which may alter content. The journal's standard Terms \& Conditions and the Ethical guidelines still apply. In no event shall the Royal Society of Chemistry be held responsible for any errors or omissions in this Accepted Manuscript or any consequences arising from the use of any information it contains. 


\title{
Haemoglobin-Loaded Metal Organic Framework- Based Nanoparticles Camouflaged With a Red Blood Cell Membrane as Potential Oxygen Delivery
}

\section{Systems}

Xiaoli Liu, ${ }^{\dagger}$ Michelle M. T. Jansman, ${ }^{\dagger}$ and Leticia Hosta-Rigau ${ }^{\dagger, *}$

$\dagger$ DTU Health Tech, Centre for Nanomedicine and Theranostics, Technical University of Denmark, Nils Koppels Allé, B423, 2800 Kgs. Lyngby, Denmark

\section{KEYWORDS}

Haemoglobin-based oxygen carriers; Metal-organic framework, Poly(dopamine), Red blood cell membrane; Stealth Coatings; Surface modification

\begin{abstract}
Transfusion of donor red blood cells (RBCs) is a crucial methodology required for the treatment of acute trauma, anaemia or for surgical procedures. Due to the many limitations of donor blood, numerous strategies have been explored to develop haemoglobin $(\mathrm{Hb})$-based oxygen carriers to be used as oxygen delivery systems. However, since free Hb suffers from a lack of stability and short circulation times in blood, an encapsulation platform is needed. Herein, we entrap Hb within a type of metal organic framework (MOF)-based nanoparticles (MOF-NPs). By doing so, Hb is protected from misfolding and denaturation, which is a crucial aspect to preserve its excellent oxygen binding and releasing properties. Furthermore, the porous structure of MOF-NPs allows for the diffusion of small molecules (i.e., oxygen) in and out of the system. Our results show that the Hb-loaded MOF-NPs (MOFHb-NPs) are monodisperse and show a small hydrodynamic diameter of $\sim 220 \mathrm{~nm}$. Importantly, the structure and functionality of encapsulated $\mathrm{Hb}$ are well
\end{abstract}


preserved. To achieve long circulation in the blood stream, we functionalize $\mathrm{MOF}^{\mathrm{Hb}}-\mathrm{NPs}_{\mathrm{s}}$ with naturally derived RBC-membranes and compared the stealth properties of the membrane-coated $\mathrm{MOF}^{\mathrm{Hb}}$-NPs to our previously reported PEGylation strategy. Protein adsorption and cell uptake studies demonstrate that both coatings are able to significantly decrease the adsorption of proteins and also diminish their uptake by macrophages and endothelial cells. Furthermore, both types of coatings render $\mathrm{MOF}^{\mathrm{Hb}}-\mathrm{NPs}$ with good biocompatibility and oxygen binding and releasing properties. Overall, this study presents a novel oxygen carrier system which might find applications as a blood surrogate.

\section{Introduction}

Transfusion of packed red blood cells (RBCs) is a crucial clinical procedure widely applied during surgery, natural or man-made disasters (e.g., plane crashes, earthquakes) or battlefield wounds. ${ }^{1}$ Additionally, RBCs transfusions are also required for the treatment of anaemia, haemoglobin $(\mathrm{Hb})$ disorders or for patients receiving antitumor therapy. ${ }^{2,3}$ However, the transfusion of donor RBCs often encounters several difficulties which include risk of bacterial or virus transmission (e.g., HIV, hepatitis or malaria), severe shortage of blood inventory due to RBCs short half-life or logistical constraints. Furthermore, despite rigorous typing and cross matching, mismatched transfusions still occur. Therefore, the development of blood surrogates free from the abovementioned risks has attracted a great deal of attention in the fields of biotechnology and biomedicine.

Being $\mathrm{Hb}$ the main component of RBCs, accounting for their high oxygen-carrying capacity, a lot of effort has been devoted to the development of Hb-based oxygen carriers (HBOCs). However, despite Hb's excellent ability to transport and transfer oxygen and re-stablish oxygen homeostasis in tissues, free $\mathrm{Hb}$ molecules cannot be administered as blood substitutes. Outside RBCs, the $\mathrm{Hb}$ tetramer breaks down into dimers, which results in short circulation times but also in severe adverse effects including renal toxicity, vasoconstriction and haemorrhagic lesions. ${ }^{4,5}$

Therefore, in recent years, several strategies for encapsulating $\mathrm{Hb}$ within different platforms have been explored. Such approaches could provide a suitable environment to maintain Hb's functionality while, at the same time, preventing the dissociation of the Hb tetramer. Among 
others, $\mathrm{Hb}$ has been encapsulated within liposomes, ${ }^{6,7}$ polymersomes ${ }^{8}$ or polymer particles. ${ }^{9,10}$ However, despite the tremendous progress achieved, it is still a challenge to entrap $\mathrm{Hb}$ within a well-defined structure preserving its secondary structure while also enabling the free diffusion of small molecules (i.e., oxygen but also small reducing agents) in an out of the system. Furthermore, difficulties in prolonging their circulation times in the bloodstream are also hampering the transition of these $\mathrm{Hb}$ encapsulating platforms into the clinic. ${ }^{11}$

Metal-organic frameworks (MOFs), which consist of metal ions or clusters connected by organic linkers, are new type of self-assembled materials displaying several unique properties. ${ }^{12-14}$ They feature well-defined, crystalline pore structures with large surface areas and structural flexibility, since they can be fine-tuned by the right choice of organic linkers and metallic compounds. Recently, MOF-based nanoparticles (MOF-NPs), have been widely employed for biomedical applications ${ }^{15-17}$ as a result of their ability to encapsulate different types of biomolecules including vaccines, ${ }^{18}$ enzymes ${ }^{19,20}$ and DNA. ${ }^{21}$ MOF-NPs are also particularly well suited to construct HBOCs. Due to their high void space, they make it possible to encapsulate large amounts of cargo (i.e., $\mathrm{Hb}$ ) which is required to fulfil the high demands of oxygen transport. Additionally, Hb's secondary structure will be preserved since, by matching the pore size, they allow to encapsulate single $\mathrm{Hb}$ molecules within predefined cavities. This is an important aspect since, misfolding or denaturation, will alter Hb's excellent oxygen binding and releasing properties. Moreover, MOFNPs also facilitate the selective transport of small molecules (i.e., $\mathrm{O}_{2}$ but also reducing agents present in plasma) through the protective porous coating. Due to these advantages, Hb has been recently conjugated onto the surface of MOF-NPs by post-modification ${ }^{22}$ and encapsulated within the cages of the so-called zeolitic imidazole framework-8 MOF-NPs. ${ }^{11}$ Herein, we employ the water-stable porous coordination network (PCN)-333(Al) MOF which is based on trivalent metal species (i.e., $\mathrm{Al}^{3+}$ ) and exhibits one of the highest void volumes and largest cages. ${ }^{23}$ Taking into account Hb's large size $(6 \times 6 \times 5 \mathrm{~nm}),{ }^{24} \mathrm{PCN}-333(\mathrm{Al})$ is one of the few reported MOFs that can act as single-molecule traps for $\mathrm{Hb}$, thus minimizing $\mathrm{Hb}$ 's aggregation and leaching. ${ }^{23}$

Since biological RBCs can survive for up to 120 days within the blood stream, ${ }^{25}$ achieving long in vivo circulation times is another key feature when developing oxygen-carriers. Once in the blood stream, uptake by the mononuclear phagocyte system (MPS) is one of the major hurdles that almost all intravenously administered carriers need to overcome. ${ }^{26,27}$ The functionalization of 
nanosized carriers with polyethylene glycol (PEG), is currently considered the gold standard approach to extend their circulation lifetimes. However, PEG immunogenicity is an increasingly recognized issue. The administration of PEGylated drugs or nanoparticles can lead to the production of anti-PEG antibodies, their subsequent recognition by the MPS in the spleen and liver and their following clearance from the circulation. ${ }^{28}$ Thus, alternatives to PEGylation to prolong the nanocarriers circulation time are highly sought after. ${ }^{28,29}$

Biological RBCs are nature's long-circulating vehicles, and their limited immune cell clearance is mainly governed by their cell membranes where a collection of "self-marker" biomolecules are embedded into their lipid bilayer. ${ }^{30,31}$ Thus, a powerful emerging strategy to improve biocompatibility by reducing immunogenicity, is the coating of the nanocarriers by cellular membranes extracted from biological RBCs. ${ }^{32-35}$ Thus, in this work, we i) encapsulate Hb within PCN-333(Al) MOF-based NPs and evaluate the preservation of Hb's structure and functionality, ii) camouflage the resulting Hb-loaded MOF-NPs with biomimetic and naturally derived RBCmembranes (RBC-Ms), iii) evaluate the stealth properties of the RBC-M coating in terms of protein adsorption and cell uptake studies, iv) compare the RBC-M coating to our previously reported PEGylation strategy and, finally, v) confirm preservation oxygen-binding and releasing properties of the coated Hb-loaded MOF-NPs. With such a study, we hope to provide a new kind of oxygen carriers with a high $\mathrm{Hb}$ loading capacity and potential long in vivo circulation to fulfil the demand of oxygen supply in biomedical applications.

\section{Materials and methods}

\subsection{Materials}

Fresh bovine blood (Product No. 77667) was obtained from SSI Diagnostica A/S (Hillerød, Denmark). Human blood was withdrawn from healthy donors in DTU-Health Technology at University of Denmark (Kongens Lyngby, Denmark). The blood withdrawing was performed in accordance with the guidelines from the Regional Research Ethics Committees for the Capital Region of Denmark. All donors provided their informed consent to participate prior collection of 
blood samples. All the operators received appropriate training before the handling of biological materials used in this study.

Sodium chloride $(\mathrm{NaCl})$, toluene, acetone, dopamine (DA), $N, N$ '-Dimethylformamide (DMF), aluminum chloride hexahydrate $\left(\mathrm{AlCl}_{3} \cdot 6 \mathrm{H}_{2} \mathrm{O}\right)$, trifluoroacetic acid (TFA), poly- $L$-lysine (PLL) (Mw 15 - $30 \mathrm{kDa}$ ), 4-(2-hydroxyethyl) piperazine-1-ethane-sulfonic acid (HEPES), HEPES buffer solution (1M, isotonic), phosphate buffered saline (PBS), biotin-N-hydroxysuccinimide (biotinNHS), streptavidin, bovine serum albumin (BSA), fluorescein isothiocyanate (FITC), FITClabelled immunoglobulin G (IgG-FITC), sodium dithionite (SDT), Dulbecco's Modified Eagle's Medium-high glucose (DMEM D5796), penicillin/streptomycin, fetal bovine serum (FBS), trypsin and the human umbilical vein endothelial cell line (HUVEC) were purchased from Merck Life Science A/S (Søborg, Denmark). Polycarbonate porous membrane (1 $\mu \mathrm{m})$ was purchased from GE Healthcare Life Sciences (Brondby, Denmark). 1,1'-dioctadecyl-3,3,3',3'-tetramethylindodicarbocyanine perchlorate (DiD) was purchased from Invitrogen A/S (Taastrup, Denmark). 4,4',4' '-s-triazine-2,4,6-triyl-tribenzoic acid ( $\left.\mathrm{H}_{3} \mathrm{TATB}\right)$ was purchased from ChemScene LLC (Monmouth Junction, NJ, USA). $\alpha$-Methoxy- $\omega$-carboxylic acid succinimidyl ester poly(ethylene glycol) (MeO-PEG-NHS, MwPEG $=2000 \mathrm{Da}$ ) was purchased from Iris Biotech GmbH (Marktredwitz, Germany). Endothelial Cell Medium (ECM) Kit supplemented with 5\% FBS and 1\% endothelial cell growth supplements was purchased from Innoprot (Derio-Biskaia, Spain). PrestoBlue Cell Viability Reagent, and Pierce Bicinchoninic Acid (BCA) Protein Assay Kit were obtained from Thermo Fisher Scientific (Waltham, MA, USA). The macrophage cell line RAW 264.7 was obtained from European Collection of Authenticated Culture Collections (ECACC, Wiltshire, UK).

HEPES buffer is composed of $10 \mathrm{mM}$ HEPES ( $\mathrm{pH} 7.4$ and $\mathrm{pH} 8.5$ ) and was prepared with ultrapure water (Milli-Q (MQ), gradient A 10 system, TOC $<4$ ppb, resistance $18 \mathrm{MV} \mathrm{cm}$, EMD Millipore, USA). HEPES buffer at pH 7.4 was used in all the studies, unless otherwise clarified. The prepared HEPES buffer solutions were used in all the studies except when working with cells were an isotonic HEPES buffer solution from Merck Life Science was used.

BSA was fluorescently labelled with FITC (BSA-FITC) as previously reported. ${ }^{36}$ Briefly, a FITC solution (3.7 mg in $300 \mu \mathrm{L}$ DMSO) was added to a BSA solution (30 mg in $6 \mathrm{~mL} 0.05 \mathrm{M}$ 
$\mathrm{NaHCO}_{3}, \mathrm{pH} 10$ ) in a dropwise fashion. After overnight incubation at room temperature (RT), the excess of FITC was thoroughly removed by dialysis against MQ water for two days. The collected solution was freeze-dried for future use. Hb was fluorescently labelled with FITC (Hb-FITC) following the same aforementioned protocol.

Poly(L-lysine (15-30 kDa))-graft[2.0]-poly(ethylene glycol (2 kDa)) (PLL-g-PEG) was synthetized following a reported procedure. ${ }^{37}$ Briefly, a MeO-PEG-NHS solution $(0.038 \mathrm{mmol}$ in $4 \mathrm{~mL}$ cold HEPES) was added to a PLL solution ( $0.143 \mathrm{mmol}$ in $500 \mu \mathrm{L}$ cold HEPES). The reaction was allowed to proceed for $4 \mathrm{~h}$ at $4{ }^{\circ} \mathrm{C}$ under constant stirring. Finally, the reaction mixture was dialyzed for 2 days against MQ water followed by freeze-drying. The NMR analysis showed a PEG grafting ratio of $50 \%$, indicating that $50 \%$ of the lysine monomers were modified with PEG. (Figure S1, Supporting Information).

\subsection{Hb extraction from bovine blood}

$\mathrm{Hb}$ was extracted from fresh bovine blood by hypotonic haemolysis following a previous study. ${ }^{38}$ Briefly, bovine RBCs were washed with an isotonic saline solution, i.e., $0.9 \% \mathrm{NaCl}(3 \times$, 15 min, $1500 \mathrm{~g}$ ). Next, the bovine RBCs were mixed with MQ water and toluene at a 1:1:0.4 ratio. Following thorough vortexing, the suspension was stored overnight at $4{ }^{\circ} \mathrm{C}$. The suspension was then spun down (20 min, $8000 \mathrm{~g}$ ) and, following filtration through ash-free filtration paper, the stroma-free $\mathrm{Hb}$ was collected and stored at $-80{ }^{\circ} \mathrm{C}$ for future use.

\subsection{Preparation and characterization of Hb-loaded MOF-NPs (MOF $\left.{ }^{\mathrm{Hb}}-\mathrm{NPs}\right)$}

2.3.1. Preparation of MOF-NPs. $12 \mathrm{~mL}$ of an $\mathrm{AlCl}_{3} \cdot 6 \mathrm{H}_{2} \mathrm{O}$ solution ( $3 \mathrm{mg} \mathrm{mL}{ }^{-1}$ in DMF), $12 \mathrm{~mL}$ of a $\mathrm{H}_{3}$ TATB solution ( $1 \mathrm{mg} \mathrm{mL}^{-1}$ in DMF) and $40 \mu \mathrm{L}$ TFA (HPLC grade, purity $>99 \%$ ), were mixed and incubated at $95{ }^{\circ} \mathrm{C}$ for $24 \mathrm{~h}$. The resulting MOF-NPs were collected and washed in DMF $(3 \times, 20 \mathrm{~min}, 15000 \mathrm{~g})$, acetone $(3 \times, 20 \mathrm{~min}, 15000 \mathrm{~g})$ and dried in a vacuum oven for future use.

2.3.2. Preparation of $\mathbf{M O F}^{\mathbf{H b}}$-NPs. The extracted bovine $\mathrm{Hb}$ was dissolved in MQ water at a concentration of $100 \mathrm{mg} \mathrm{mL}^{-1}$. Next, the MOF-NPs were re-suspended in MQ water at a concentration of $1 \mathrm{mg} \mathrm{mL}^{-1}$. Different amounts (i.e., 2, 5, 10, 20, 30, 40 and $60 \mu \mathrm{L}$ ) of Hb solutions at the concentration of $100 \mathrm{mg} \mathrm{mL}^{-1}$ were added to $1 \mathrm{~mL}$ of the MOF-NPs suspension under 
continuous magnetic stirring at $800 \mathrm{rpm}$ for $2 \mathrm{~h}$. Finally, the samples were collected and washed in MQ water $(3 \times, 20 \mathrm{~min}, 15000 \mathrm{~g})$. The $\mathrm{Hb}$ entrapment efficiency (EE) and drug loading (DL) were determined using a BCA assay. The EE was calculated as follows: \% EE = (encapsulated $\mathrm{Hb}$ amount / initial amount of $\mathrm{Hb}) \times 100$. The DL was calculated as follows: $\% \mathrm{DL}=($ encapsulated $\mathrm{Hb}$ amount / total amount of $\left.\mathrm{MOF}^{\mathrm{Hb}}-\mathrm{NPs}\right) \times 100$. The $\mathrm{MOF}^{\mathrm{Hb}}-\mathrm{NPs}$ with the optimal EE and DL were chosen for the following studies.

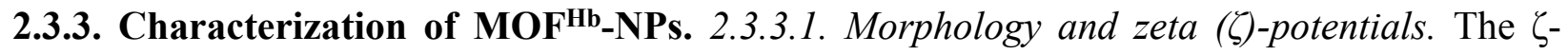
potentials of the $\mathrm{MOF}^{\mathrm{Hb}}-\mathrm{NPs}$ prepared with different initial $\mathrm{Hb}$ amounts were determined using a Zetasizer nano ZS instrument (Malvern Instruments Ltd., UK).

Scanning electron microscopy (SEM, Hitachi High-Tech HITACHI, USA) was employed to evaluate the morphology of both MOF-NPs and $\mathrm{MOF}^{\mathrm{Hb}}$-NPs with the optimal EE and DL. A drop of test sample was dried on a glass slide and mounted on a metal stub with double-sided adhesive tape. Next, the samples were coated under vacuum with gold prior to observation (Sputter Coater 208 HR, Cressington Scientific, UK). The samples were imaged at an operating voltage of $15 \mathrm{keV}$.

2.3.3.2. Fourier-transform infrared (FTIR) spectroscopy. FTIR analysis was performed using a Perkin Elmer Spectrum 100 FT-IR spectrometer (Perkin Elmer Inc., Wellesley, MA) under ambient conditions. The spectra were collected with a resolution of $4 \mathrm{~cm}^{-1}$ within the wavelength range of 400 to $4000 \mathrm{~cm}^{-1}$. Five scans per sample were measured.

2.3.3.3. UV-vis spectra of oxygenation and deoxygenation of $H b$. The UV-Vis spectra of fresh $\mathrm{Hb}$ and $\mathrm{MOF}^{\mathrm{Hb}}$-NPs dissolved/suspended in HEPES buffer were measured on a UV-2600 UV-vis Spectrophotometer (Shimadzu, Japan) in the wavelength range of 350 - $650 \mathrm{~nm}$. The deoxygenated $\mathrm{Hb}\left(\right.$ deoxy-Hb) was obtained by purging the test sample with nitrogen gas $\left(\mathrm{N}_{2}\right)$ for 10 min followed by recording the UV-vis spectrum.

\subsection{Stability over time}

The size stability of MOF-NPs and MOF $\mathrm{Hb}_{-} \mathrm{NPs}$ stored at $4{ }^{\circ} \mathrm{C}$ was determined measuring the hydrodynamic diameter by dynamic light scattering (DLS) using the Zetasizer nano ZS instrument at pre-designed time intervals (i.e. 1, 3, 5, 7, 10 and 14 days). The release behaviour of $\mathrm{Hb}$ from the $\mathrm{MOF}^{\mathrm{Hb}}$-NPs was also studied at $4{ }^{\circ} \mathrm{C}$. For that, aliquots of $1 \mathrm{mg} \mathrm{mL}^{-1}$ suspensions of $\mathrm{MOF}^{\mathrm{Hb}}$ 
NPs were prepared and stored at $4{ }^{\circ} \mathrm{C}$. At each pre-defined time point, 3 aliquots were taken out and the released amount of $\mathrm{Hb}$ in the supernatant following centrifugation (10 min, $15000 \mathrm{~g}$ ) was evaluated using a BCA assay.

\subsection{Surface modification with stealth coatings}

2.5.1. Polydopamine (PDA) coating. The as-prepared $\mathrm{MOF}^{\mathrm{Hb}}-\mathrm{NPs}$ (fabricated from $1 \mathrm{mg} \mathrm{MOF}$ NPs as starting material) were re-suspended in 0.5 mL HEPES buffer ( $\mathrm{pH} 8.5$ ) and mixed with 0.5 $\mathrm{mL}$ of a DA solution (10 mg mL $\mathrm{m}^{-1}$ in HEPES buffer, $\left.\mathrm{pH} 8.5\right) .{ }^{39,40}$ The mixture was rotated for $4 \mathrm{~h}$ at the speed of $40 \mathrm{rpm}$ at RT followed by washing in MQ water $(2 \times, 10 \mathrm{~min}, 15000 \mathrm{~g})$ to obtain PDA coated $\mathrm{MOF}^{\mathrm{Hb}}-\mathrm{NPs}\left(\mathrm{MOF}^{\mathrm{Hb}} / \mathrm{PDA}-\mathrm{NPs}\right)$.

2.5.2. PEGylation. To obtain PEGylated carriers (MOFHb/PEG-NPs), MOFHb/PDA-NPs (prepared from $1 \mathrm{mg}$ of MOF-NPs as starting material) were re-suspended in $0.5 \mathrm{~mL}$ HEPES buffer and mixed with $0.5 \mathrm{~mL}$ of a PLL- $g$-PEG solution ( $2 \mathrm{mg} \mathrm{mL}^{-1}$ in HEPES buffer). The mixture was rotated for $1 \mathrm{~h}$ at the speed of $40 \mathrm{rpm}$ at RT followed by washing with HEPES buffer $(2 \times, 20 \mathrm{~min}$, $15000 \mathrm{~g}$ ). The polydispersity index (PDI) and $\zeta$-potentials of the different NPs (i.e., MOF-NPs, $\mathrm{MOF}^{\mathrm{Hb}}$-NPs, $\mathrm{MOF}^{\mathrm{Hb}} / \mathrm{PDA}-\mathrm{NPs}$ and $\mathrm{MOF}^{\mathrm{Hb}} / \mathrm{PEG}-\mathrm{NPs}$ ) were determined employing the Zetasizer nano ZS instrument.

2.5.3. RBC-M coating. 2.5.3.1. Extraction of RBC-Ms from human blood. The RBC-M were isolated from human blood according to a previous study. ${ }^{33}$ Whole human blood was freshly collected from healthy donors. The whole blood was then spun down $\left(10 \mathrm{~min}, 1500 \mathrm{~g}, 4{ }^{\circ} \mathrm{C}\right)$ to remove the serum and the buffy coat and the resulting RBCs were then washed in ice-cold PBS (3 $\times, 15 \mathrm{~min}, 1500 \mathrm{~g}$ ). The washed RBCs were then subjected to a hypotonic medium treatment (PBS:MQ at a 1:4 v/v ratio on ice bath, $30 \mathrm{~min}$ ) for haemolysis at a 1:10 volume ratio to remove the intracellular contents. The supernatant was subsequently spun down $(4 \times, 20 \mathrm{~min}, 15000 \mathrm{~g}$ at $4{ }^{\circ} \mathrm{C}$ ) and the light-pink RBC ghost pellets were collected.

2.5.3.2. Coating with $R B C-M s$. RBC-M-coated $\left.\mathrm{NPs}_{\text {(MOF }} \mathrm{Hb} / \mathrm{M}-\mathrm{NPs}\right)$ were prepared by mixing either $\mathrm{MOF}^{\mathrm{Hb}}-\mathrm{NPs}$ or $\mathrm{MOF}^{\mathrm{Hb}} / \mathrm{PDA}-\mathrm{NPs}$ (prepared from $1 \mathrm{mg}$ of MOF-NPs as starting material and suspended in $1 \mathrm{~mL}$ of HEPES buffer) with RBC-Ms extracted from $400 \mu \mathrm{L}$ blood. The mixture was sonicated for $10 \mathrm{~s}(70 \%$ amplitude, $1 \mathrm{~s} / 1 \mathrm{~s})$ on an ice bath followed by extrusion through $1 \mu \mathrm{m}$ 
polycarbonate porous membrane to facilitate membrane fusion. An Avanti ${ }^{\circledR}$ Mini-Extruder (Avanti Polar Lipids, Inc., AL, USA) was used. Finally, the coated MOFHb/M-NPs were washed with HEPES buffer solution $(3 \times, 20 \mathrm{~min}, 15000 \mathrm{~g})$.

\subsubsection{Evaluation of the RBC-M coating. The RBC-M coating of $\mathrm{MOF}^{\mathrm{Hb}}-\mathrm{NPs}$ or $\mathrm{MOF}$} NPs was evaluated by fluorescence intensity measurements. To do that, the extracted RBC-Ms were first labelled with a lipophilic far-red fluorescent dye DiD (excitation/emission = 644/665 $\mathrm{nm})$ by adding $10 \mu \mathrm{L}$ of the $\mathrm{DiD}$ fluorophore $\left(1 \mathrm{mg} \mathrm{mL}^{-1}\right.$ in DMSO) to $1 \mathrm{~mL}$ of a RBC-M suspension. The fluorescently labelled RBC-Ms $\left(\mathrm{RBC}_{-} \mathrm{M}^{\mathrm{F}}\right)$ were used to coat both $\mathrm{MOF}^{\mathrm{Hb}}-\mathrm{NPs}$ and $\mathrm{MOF}^{\mathrm{Hb}} / \mathrm{PDA}-\mathrm{NPs}$ following the same procedure as described in section 2.5.3.2. The samples were next analysed by measuring the normalized mean fluorescence intensity (nMFI) by flow cytometry (BD Biosciences, Sparks, MD, USA). While untreated MOF $\mathrm{Hb}_{-N P s}$ and MOF ${ }^{\mathrm{Hb}} / \mathrm{PDA}-$ NPs were used as controls, the physical mixtures of $\mathrm{MOF}^{\mathrm{Hb}}-\mathrm{NPs}$ and $\mathrm{MOF}^{\mathrm{Hb}} / \mathrm{PDA}-\mathrm{NPs}$ with $\mathrm{RBC}$ $\mathrm{M}^{\mathrm{F}}$, respectively, without sonication and extrusion treatment, were also evaluated by flow cytometry. Each condition was evaluated in at least two independent experiments.

A RBC-M coverage assay was also conducted to identify the amount of RBC-M promoting full coverage of the $\mathrm{MOF}^{\mathrm{Hb}} / \mathrm{PDA}-\mathrm{NPs}$. For that, biotin (BT)-labelled MOF $\mathrm{Hb} / \mathrm{PDA}-\mathrm{NPs}\left(\mathrm{MOF}^{\mathrm{Hb}} / \mathrm{BT}\right.$ NPs) were prepared. Specifically, $200 \mu \mathrm{L}$ of biotin-NHS (BT-NHS, $20 \mathrm{mg} \mathrm{mL}^{-1}$ in DMSO) were added to $\mathrm{MOF}^{\mathrm{Hb}} / \mathrm{PDA}-\mathrm{NPs}$ (prepared from $12 \mathrm{mg}$ of MOF-NPs as starting material re-suspended in $12 \mathrm{~mL}$ of HEPES buffer). The BT-NHS esters reacted with amines on the PDA coating layer forming amide bonds and releasing the NHS groups. After reaction for $1 \mathrm{~h}$ at RT, the un-bound BT-NHS was removed by washing with HEPES buffer $(3 \times, 10 \mathrm{~min}, 15000 \mathrm{~g})$. Next, the BTlabelled $\mathrm{MOF}^{\mathrm{Hb}} / \mathrm{BT}-\mathrm{NPs}$ (prepared from $1 \mathrm{mg} \mathrm{mL}^{-1}$ of MOF-NPs in HEPES as the starting material) were incubated with varying amounts of RBC-Ms (i.e., extracted from 17, 25, 50, 100, 200 and $400 \mu \mathrm{L}$ of whole blood). The RBC-M coverage depending on the amount of added RBCMs, was evaluated by incubating $0.5 \mathrm{~mL}$ of coated $\mathrm{MOF}^{\mathrm{Hb}} / \mathrm{BT} / \mathrm{M}-\mathrm{NPs}$ (prepared from $1 \mathrm{mg} \mathrm{mL}^{-1}$ of MOF-NPs in HEPES as the starting material) with $4 \mu \mathrm{L}$ of streptavidin (Strep) solution (1 mg $\mathrm{mL}^{-1}$ in HEPES) for $30 \mathrm{~min}$. Particle aggregation induced by Strep-BT interactions was monitored by DLS using the Zetasizer nano ZS instrument. As controls, the corresponding RBC-M coated $\mathrm{MOF}^{\mathrm{Hb}}$ /BT-NPs without Strep addition were considered. Each condition was evaluated in at least two independent experiments. 


\subsection{Evaluation of the stealth coatings}

2.6.1. Protein adsorption studies. The stealth properties depending on the surface coatings (i.e., PDA, PEG and RBC-M) were assessed in terms of protein adsorption. Suspensions of $\mathrm{MOF}^{\mathrm{Hb}} / \mathrm{PDA}-\mathrm{NPs}, \mathrm{MOF}{ }^{\mathrm{Hb}} / \mathrm{PEG}-\mathrm{NPs}$ and $\mathrm{MOF}^{\mathrm{Hb}} / \mathrm{M}-\mathrm{NPs}$ displaying 100000 events $\mu \mathrm{L}^{-1}$ (as measured by flow cytometry), were incubated in $200 \mu \mathrm{L}$ of an IgG-FITC or BSA-FITC solution (0.5 mg mL-1 in HEPES) at $37{ }^{\circ} \mathrm{C}$ for $4 \mathrm{~h}$ under constant shaking using a thermo-shaker (Grant Bio PHMT-PSC18 thermo-shaker, Grant Instruments Ltd, United Kingdom) at the speed of 1400 rpm. After the incubation time, the samples were washed in HEPES $(2 \times, 5 \mathrm{~min}, 15000 \mathrm{~g})$ to remove the unbound proteins. The MFI due to the adsorbed proteins onto the NPs was analysed by flow cytometry (excitation/emission $=488 / 530 \mathrm{~nm}$ ). At least 20000 events were analysed in two independent experiments.

2.6.2. Cell uptake studies. 2.6.2.1. Cell culture. DMEM cell culture medium supplemented with $10 \%(\mathrm{v} / \mathrm{v}) \mathrm{FBS}, 1 \%(\mathrm{v} / \mathrm{v})$ penicillin/streptomycin $\left(10000 \mathrm{U} \mathrm{mL}^{-1}\right.$ and $10 \mu \mathrm{g} \mathrm{m}^{-1}$, respectively) was used for culturing the mouse macrophage Raw 264.7 cell line. ECM cell culture medium supplemented with $5 \%(\mathrm{v} / \mathrm{v}) \mathrm{FBS}, 1 \%(\mathrm{v} / \mathrm{v})$ penicillin/streptomycin $\left(10000 \mathrm{U} \mathrm{mL}^{-1}\right.$ and $10 \mu \mathrm{g}$ $\mathrm{mL}^{-1}$, respectively) and $1 \%(\mathrm{v} / \mathrm{v})$ endothelial cell growth supplements was used for culturing the endothelial HUVEC cell line. All the cells were cultured in T75 flasks in a humidified incubator with $5 \% \mathrm{CO}_{2}$ supply at $37{ }^{\circ} \mathrm{C}$. The cell media was exchanged 2 - 3 times per week and the cells were sub-cultured when reaching $\sim 80 \%$ confluence. RAW 264.7 cells were detached from the culture flask using a cell scraper while HUVEC cells were detached by treatment with trypsin. Both RAW 264.7 and HUVEC cells were re-suspended in fresh cell media and added into new T75 culture flasks with appropriate amounts (a subcultivation ratio of 1:5 was used for RAW 264.7 cells and a ratio of 1:3 was used for HUVEC cells). Only cells between passages 5 and 18 (for RAW 264.7) and between passages 3 and 14 (for HUVEC) were used in all experiments.

2.6.2.2. Cell uptake/association. For cell uptake assays, 24-well plates were used and the RAW 264.7 and HUVEC cells were seeded in $1 \mathrm{~mL}$ of full cell media at a density of 180000 and 100 000 cells per well, respectively, and allowed to attach for $24 \mathrm{~h}$. Fluorescently labelled MOF $\mathrm{Hb}_{-} \mathrm{NPs}$ (MOF ${ }^{H b}$-FITC-NPs) were prepared using FITC-Hb instead of $\mathrm{Hb}$ following the same protocol as

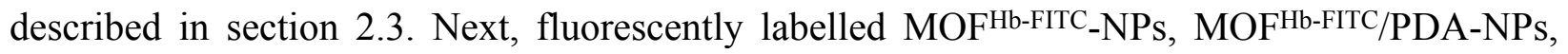


MOFHb-FITC/PEG-NPs or MOFHb-FITC/M-NPs were added to the different wells for $4 \mathrm{~h}$ at $37^{\circ} \mathrm{C}$ and $5 \% \mathrm{CO}_{2}$. A ratio of 100:1 of NPs to cells was used. After incubation, the cells were washed in PBS $(2 \times)$ and detached from the wells employing a cell scrapper (for RAW 264.7) or trypsin (for HUVEC, $100 \mu \mathrm{L}$ per well) and then collected by centrifugation (10 min, $300 \mathrm{~g})$. The cell uptake/association of the different NPs was evaluated by flow cytometry. The cellular uptake efficiency (CUE), which is determined as the percentage of cells with a mean fluorescence intensity higher than the auto fluorescence level of the cells, was assessed. Cells alone were used as controls. At least 5000 events were analysed in each running and each condition was measured in triplicate. The fluorescence intensity (FI) of the FITC-labelled NPs extracted from the same amount of cells was measured using a TECAN Spark multimode plate reader (Tecan Group Ltd., Maennendorf, Switzerland). In brief, the cells were diluted to the same amounts and then sonicated in an ice bath for $10 \mathrm{~s}(70 \%, 1 \mathrm{~s} / 1 \mathrm{~s})$. The resulting cell fragments were separated from the released NPs by spinning down the suspension $\left(5 \mathrm{~min}, 8000 \mathrm{~g}\right.$ ) at $4^{\circ} \mathrm{C}$. Finally, $200 \mu \mathrm{L}$ of the supernatants were transferred to a black 96-well plate and the FI was measured using the plate reader (excitation/emission $=490 / 525 \mathrm{~nm}$ ) and normalized (nFI) to the FI of the cells incubated with MOFHb-FITC-NPs. Each condition was evaluated in at least three independent experiments.

\subsection{Biocompatibility studies}

2.7.1. Cell viability. The cell viability after the cell uptake study was evaluated in 96 -well plates. Cell densities of 30000 and 15000 cells per well for RAW 264.7 and HUVEC cells, respectively, in $200 \mu \mathrm{L}$ of full cell media were employed. After attachment for $24 \mathrm{~h}$, the cells were washed in PBS $(2 \times, 200 \mu \mathrm{L})$ and $200 \mu \mathrm{L}$ of the different NPs (i.e., MOF-NPs, MOF ${ }^{\mathrm{Hb}}-\mathrm{NPs}, \mathrm{MOF}^{\mathrm{Hb}} / \mathrm{PDA}^{-}$ NPs, MOF ${ }^{\mathrm{Hb}} / \mathrm{PEG}-\mathrm{NPs}$ and $\mathrm{MOF}^{\mathrm{Hb}} / \mathrm{M}-\mathrm{NPs}$ ) were added to the different wells at the same ratio used for cell uptake study (i.e., ratio of 100:1 of NPs to cells). After $4 \mathrm{~h}$ incubation, the cells were washed carefully in PBS $(3 \times, 200 \mu \mathrm{L})$ and $100 \mu \mathrm{L}$ of PrestoBlue solution $(10 \% \mathrm{v} / \mathrm{v}$ in fresh full cell media) was added to each well. Following incubation for $1 \mathrm{~h}$ at $37{ }^{\circ} \mathrm{C}$ and $5 \% \mathrm{CO}_{2}, 95 \mu \mathrm{L}$ of each supernatant were transferred to a black 96-well plate and analysed using the plate reader $($ excitation/emission $=535 / 615 \mathrm{~nm})$. Cells only were used as the positive control and PrestoBlue containing cell media only was used as the negative control. The cell viability was calculated as follows: $\%$ cell viability $=($ experimental value - negative control value $) /($ positive control value 
- negative control value) $\times 100$. Each condition was evaluated in triplicate in at least two independent experiments.

2.7.2. Haemolysis rate. The blood compatibility of the NPs depending on the surface coating (i.e., MOF-NPs, $\mathrm{MOF}^{\mathrm{Hb}}$-NPs, MOFHb/PDA-NPs, MOF ${ }^{\mathrm{Hb}} / \mathrm{PEG}-\mathrm{NPs}$ and $\mathrm{MOF}^{\mathrm{Hb}} / \mathrm{M}-\mathrm{NPs}$ ) was evaluated by conducting a haemolysis rate test. First, whole blood collected from healthy donors was washed as described in section 2.5.3.1. Next, the blood cells collected from $1 \mathrm{~mL}$ of whole blood were suspended in $10 \mathrm{~mL}$ isotonic HEPES buffer. Suspensions of the different NPs were incubated with the diluted blood cells at a ratio of 100:1 (NPs : blood cells) using the thermo-shaker at $250 \mathrm{rpm}$ for $4 \mathrm{~h}$ at $37^{\circ} \mathrm{C}$. After incubation, $200 \mu \mathrm{L}$ of the suspensions were spun-down (10 min, $1000 \mathrm{~g}$ ) and the pellet was collected for morphology observation. For that, the pellets were re-suspended in isotonic HEPES buffer and imaged using an Axiovert 25 inverted microscope (Carl Zeiss A/S, Birkerød, Denmark). $200 \mu \mathrm{L}$ of the suspensions were spun down (10 min, $15000 \mathrm{~g})$, the supernatants were collected and the absorbance at $540 \mathrm{~nm}$ was measured using the plate reader. Blood cells in MQ water or isotonic HEPES buffer were used as positive and negative controls, respectively. The haemolysis rate was calculated as follows: \% haemolysis rate $=$ (experimental value - negative control value) / (positive control value - negative control value $) \times 100$. Each condition was evaluated in at least three independent experiments.

\subsection{Functional performance}

The oxygenation and deoxygenation of $\mathrm{Hb}$ within the different MOF-NPs (i.e., $\mathrm{MOF}^{\mathrm{Hb}}-\mathrm{NPs}$, $\mathrm{MOF}^{\mathrm{Hb}} / \mathrm{PDA}, \mathrm{MOF}^{\mathrm{Hb}} / \mathrm{PEG}-\mathrm{NPs}$ and $\mathrm{MOF}^{\mathrm{Hb}} / \mathrm{M}-\mathrm{NPs}$ ) was evaluated by UV-vis spectroscopy (using the $600 \mathrm{UV}$-vis Spectrophotometer) in the wavelength range of 350-650 nm. The NPs were suspended in HEPES buffer and the UV-vis spectra were recorded. Then, $\mathrm{N}_{2}$ was allowed to flow over the samples containing a pinch of oxygen scavenger SDT for $10 \mathrm{~min}$ to obtain NPs loaded with deoxy-Hb, followed by recording the UV-vis spectrum. Next, the NPs were purged with $\mathrm{O}_{2}$ for $10 \mathrm{~min}$, and NPs loaded with oxy-Hb were obtained and their UV-vis spectra recorded. Subsequently, the samples were purged with $\mathrm{N}_{2}$ and $\mathrm{O}_{2}$ and their $\mathrm{UV}$-vis spectra were recorded again. Samples from at least two independent batches have been measured.

\subsection{Statistical analysis}


A Tukey's multiple comparison test $\left(* \mathrm{p} \leq 0.05 ; * * \mathrm{p} \leq 0.001,{ }^{* * *} \mathrm{p} \leq 0.0005, * * * * \mathrm{p} \leq 0.0001\right)$ was employed using GraphPad Prism (8.1.0 (325)) software to assess the statistical differences between the different conditions. A one-way analysis of variance with a confidence level of $95 \%(\alpha=0.005)$ was employed.

\section{Results and discussion}

\subsection{Preparation and characterization of MOF-NPs and $\mathrm{MOF}^{\mathrm{Hb}}-\mathrm{NPs}$}

Water-stable MOFs containing mesocages acting as single molecule traps, show enormous potential to create HBOCs since they afford the encapsulation of single $\mathrm{Hb}$ molecules within individual cages. Such an approach will avoid the dissociation of the $\mathrm{Hb}$ tetramer while also eliminating Hb's aggregation preventing it from misfolding and denaturation. This will, in turn, preserve Hb's excellent oxygen binding and releasing properties. In particular, PCN-333(Al) exhibits large cages $(5.5 \mathrm{~nm})$ fitting the size of individual $\mathrm{Hb}$ molecules $(6 \times 6 \times 5 \mathrm{~nm})$, where the macromolecules could enter the cages while undergoing a partial conformation change. ${ }^{23,41}$ Additionally, PCN-333(Al) also displays one of the highest void volumes among the reported MOFs, which will allow for the encapsulation of the large amounts of $\mathrm{Hb}$ required to meet the high oxygen demands of our body. What is more, PCN-333(Al) also exhibits smaller cages (i.e., medium-sized and small cages of $4.2 \mathrm{~nm}$ and of $1.1 \mathrm{~nm}$, respectively), that will remain empty, thus allowing the diffusion of small compounds (i.e., oxygen but also reducing agents) in and out of the system.

Nano-sized MOF-NPs with a PCN-333(Al) crystalline structure were prepared and Hb was incorporated by post-encapsulation to render $\mathrm{MOF}^{\mathrm{Hb}}-\mathrm{NPs}{ }^{23}$ Bovine $\mathrm{Hb}$, which only requires chloride ion for native operation, was chosen. This will circumvent the complications of allosteric effectors such as 2,3-diphosphoglycerate, which are required for the native operation of human $\mathrm{Hb}^{42}$ In order to identify the optimal EE and DL, MOF-NPs were incubated with increasing amounts of $\mathrm{Hb}$. Figure 1A shows how the EE decreased upon increasing the initial $\mathrm{Hb}$ amounts, ranging from 100\% (when incubating $1 \mathrm{mg}$ of MOF-NPs with $0.2 \mathrm{mg}$ of $\mathrm{Hb}$ ) to $16.3 \%$ (when incubating $1 \mathrm{mg}$ of MOF-NPs with $6 \mathrm{mg}$ of $\mathrm{Hb}$ ). In contrast, the DL increased upon increasing the amount of $\mathrm{Hb}$ until reaching the maximum loading capacity of $\sim 50 \%$ in DL when incubating $1 \mathrm{mg}$ of MOF-NPs with $2 \mathrm{mg}$ of $\mathrm{Hb}$. Therefore, this input amount was chosen for the preparation of 
$\mathrm{MOFHb}_{-} \mathrm{NPs}$ in the subsequent studies. The $\zeta$-potential of the MOFHb-NPs upon increasing the amount of added $\mathrm{Hb}$ was also evaluated (Figure 1B). While empty MOF-NPs displayed a negative $\zeta$-potential $(-10.4 \pm 0.1 \mathrm{mV})$ as a result of the unreacted carboxyl groups of $\mathrm{H}_{3} \mathrm{TATB}$, an increase in $\zeta$-potential could be observed upon increasing the amount of added $\mathrm{Hb}$. A plateau of a $\zeta$-potential of $\sim 12.7 \pm 0.6 \mathrm{mV}$ was reached upon addition of $3 \mathrm{mg}$ of $\mathrm{Hb}$ per $1 \mathrm{mg}$ of MOF-NPs. Due to Hb's isoelectric point of 6.8, the $\mathrm{Hb}$ molecules are positively charged in a MOF-NPs solution ( $\mathrm{pH} \sim 5.6$, Table S1 in Supporting Information) which results on positive $\zeta$-potentials for MOF $\mathrm{Hb}_{-} \mathrm{NPs}_{\text {with }}$ a high DL. Both MOF-NPs and MOF ${ }^{H b}-N P s$ at a DL of 50\% were imaged by SEM in solution. Figure 1C shows that both empty MOF-NPs and $\mathrm{MOF}^{\mathrm{Hb}}-\mathrm{NPs}$ are monodisperse when resuspended in MQ water.

Preservation of Hb's structure is fundamental for oxygen transport. In this study, $\mathrm{Hb}$ was loaded into MOF-NPs by post-encapsulation, and only mild stirring was used to assist with the loading. The influence of the processing procedure on Hb's chemical structure was analysed by FTIR spectroscopy and, as expected, Figure 2A shows how the FTIR spectra of native $\mathrm{Hb}$ and $\mathrm{MOF}^{\mathrm{Hb}}$ NPs are almost identical. The two spectra displayed the characteristic peaks at $1650 \mathrm{~cm}^{-1}$ and 1534 $\mathrm{cm}^{-1}$, which represent the typical amide I and amide II bands of proteins and indicate that the chemical structure of $\mathrm{Hb}$ was well preserved after being loaded into MOF-NPs. While the amide I band dominated by the stretching vibrations of the $\mathrm{C}=\mathrm{O}$, shows the information of the backbone conformation and hydrogen bonding; the amide II band derives from in-plane N-H bending and $\mathrm{C}-\mathrm{N}$ stretching vibrations. As expected, the amide I and amide II bands were not present in the spectrum of empty MOF-NPs.

Preservation of $\mathrm{Hb}$ 's functionality following encapsulation to create $\mathrm{MOF}^{\mathrm{Hb}}-\mathrm{NPs}$ was demonstrated by UV-vis spectroscopy (Figure 2B). After preparation, $\mathrm{MOF}^{\mathrm{Hb}}$-NPs exhibited three main peaks at 414, 541, and $578 \mathrm{~nm}$ (solid red line), which are the characteristic absorption peaks of oxygenated $\mathrm{Hb}(\mathrm{oxy}-\mathrm{Hb})$ (dashed red line). After purging with $\mathrm{N}_{2}$, the Soret peak shifted from $414 \mathrm{~nm}$ to $428 \mathrm{~nm}$, the two peaks at 541 and $578 \mathrm{~nm}$ disappeared while the appearance of peak at $564 \mathrm{~nm}$ (solid green line); which are the characteristic peaks for deoxy-Hb in its free form (dashed green line). Such spectral changes following purging with $\mathrm{N}_{2}$ confirm the MOFHb-NPs ability to bind and release oxygen, in a similar manner than native $\mathrm{Hb}$. 


\subsection{Stability over time}

Size stability over prolonged periods of time is an important aspect to consider for storage purposes when developing nanoparticles for biomedical applications, and it is also a central factor related to their circulation behaviour in vivo. Therefore, the stability of $\mathrm{MOF}^{\mathrm{Hb}}-\mathrm{NPs}$ suspensions in MQ water stored at $4{ }^{\circ} \mathrm{C}$ for up to 14 days was studied by measuring their hydrodynamic diameter. Figure 3A shows how the size of empty MOF-NPs slightly increased from $170 \mathrm{~nm}$ to $200 \mathrm{~nm}$ after the whole storage period. In contrast, the size of the loaded $\mathrm{MOF}^{\mathrm{Hb}}-\mathrm{NPs}$ did not exhibit any substantial increase $(\sim 220 \mathrm{~nm})$ after storage for 14 days. Additionally, both MOF-NPs and $\mathrm{MOF}^{\mathrm{Hb}}$-NPs showed good monodispersity with PDI values smaller than 0.2 for the whole studied period, while a PDI of 0.2 or below indicates acceptable monodisperse NPs for medical applications. ${ }^{43}$ Since the leakage of $\mathrm{Hb}$ from HBOCs can lead to renal toxicity or vasoconstriction, amongst others, ${ }^{44} \mathrm{Hb}$ 's cumulative release over time was also evaluated. Figure 3B shows an initial burst release of $\sim 3 \%$ of $\mathrm{Hb}$ at day 2 with no further release up to 14 days. A total cumulative release of $\sim 6 \%$ could be detected after the whole studied period of 28 days. We hypothesize that the initial burst release could correspond to a small portion of $\mathrm{Hb}$ being physically attached onto the surface of $\mathrm{MOF}^{\mathrm{Hb}}-\mathrm{NPs}$, instead of being encapsulated. In contrast, we attribute the slower and more sustained $\mathrm{Hb}$ cumulative release of $\sim 3 \%$ over the last 14 -day period to the dissociation of the $\mathrm{MOF}^{\mathrm{Hb}}$-NPs porous structure, which is induced by the coordination between water molecules and the metal clusters which results in the distortion of the crystal lattices of the MOF structure. ${ }^{45}$ Such a slow leakage from the mesoporous MOF-NPs as compared to other reported HBOCs would result on a pronounced advantage for their in vivo application. As an example, a $\sim 20 \% \mathrm{Hb}$ release was detected in less than 8 days for the recently reported Hb-loaded mesoporous silica NPs. ${ }^{46}$ While, on a different study, a burst release $\sim 10 \% \mathrm{Hb}$ within only two days was recently reported for a HBOCs consisting of co-precipitated microparticles of $\mathrm{Hb}$ and manganese carbonate. ${ }^{47}$

\subsection{Surface modification with stealth coatings}

In order to fulfil the high oxygen demands of our body, successful HBOCs need to achieve long circulation in the bloodstream. However, any intravenously administered nanocarrier will unavoidably experience a highly complex environment inherently adept to recognize and eliminate external elements. Currently, the coating of the nanocarriers with PEG is the gold standard to 
suppress their uptake by the MPS and prolong their blood circulation time. ${ }^{28}$ However, recent observations of immunological responses resulting from the formation of anti-PEG antibodies, have promoted the search for alternatives to PEG. As such, coating with the membranes of RBCs has recently been proposed as a powerful alternative. By means of a surface makeup involving “self-marker" proteins but also glycans and acidic sialyl moieties, biological RBCs avoid immune responses. ${ }^{31,48}$ Thus, several drug-loaded nanocarriers have been successfully coated by RBC-M demonstrating extended circulation times. ${ }^{49-51}$ To develop a long-circulating HBOCs, we coat the as-prepared $\mathrm{MOF}^{\mathrm{Hb}}$-NPs with $\mathrm{RBC}-\mathrm{M}$ and compare this stealth coating to our previously reported PEGylation strategy. ${ }^{36,39}$

3.3.1. PEGylation. The surface modification of the $\mathrm{MOF}^{\mathrm{Hb}}-\mathrm{NPs}$ was assessed by $\zeta_{\text {-potential }}$ measurements. Figure 4 shows a negative $\zeta$-potential of $-17.6 \pm 2.0 \mathrm{mV}$ for MOF-NPs which increased to $13.7 \pm 1.9 \mathrm{mV}$ following Hb's encapsulation. Prior functionalization with PLL-gPEG, a PDA coating was deposited. While PDA coatings have been previously employed for the fabrication of several nanocarriers, ${ }^{52-54}$ in this case, such a coating is introduced to facilitate the incorporation of positively charged PLL-g-PEG by electrostatic interactions. Moreover, PDA has barely any chemical reaction with Hb's functional groups. Furthermore, we, and others, have demonstrated how PDA can minimize Hb's autoxidation into non-functional metHb. ${ }^{1,40,55-58}$ The $\mathrm{MOF}^{\mathrm{Hb}}$-NPs were incubated in a DA solution in basic conditions and, the deposition of PDA to render $\mathrm{MOF}^{\mathrm{Hb}} / \mathrm{PDA}-\mathrm{NPs}$, was confirmed by the decrease in $\zeta$-potential to $-20.6 \pm 0.5 \mathrm{mV}$. Finally, incubation in a PLL-g-PEG solution resulted in a $\zeta$-potential increase to $7.7 \pm 0.3 \mathrm{mV}$ thus rendering PEGylated MOFHb/PEG-NPs. Importantly, no changes in PDI (below 0.2) could be observed following the different coating steps, thus indicating good colloidal stability for the asprepared NPs.

3.3.2. RBC-M coating. Functionalization of nanocarriers with bio-membranes derived from $\mathrm{RBCs}$, endows the nanocarriers with high biocompatibility, immune-evasion and enables them to avoid clearance by the MPS due to their native long circulation property. ${ }^{34,59}$ Thus, RBC-Ms were extracted from fresh human blood from donors and fluorescently labelled by incubating them with the lipophilic far-red fluorescent DiD dye. The resulting $\mathrm{RBC}-\mathrm{M}^{\mathrm{F}} \mathrm{S}$ were mixed with the $\mathrm{MOF}^{\mathrm{Hb}}$

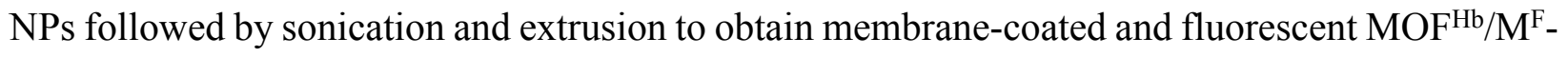
NPs. The association of the RBC-M $\mathrm{M}^{\mathrm{F}}$ with the $\mathrm{MOF}^{\mathrm{Hb}}-\mathrm{NPs}$ was first evaluated by flow cytometry. 
Since the surface charge of the nanocarriers affects the coating with RBC-Ms, ${ }^{60}$ both uncoated MOFHb_NPs (positively charged) and PDA-coated MOFHb/PDA-NPs (negatively charged) were considered. As controls, physical mixtures of RBC-MF and the NPs (both $\mathrm{MOF}^{\mathrm{Hb}}-\mathrm{NPs}_{\text {s }}$ and MOF ${ }^{\mathrm{Hb}} / \mathrm{PDA}-\mathrm{NPs}$ ) without sonication and extrusion were considered (Figure 5Ai). The MFI readings due to the DiD-labelled $\mathrm{RBC}-\mathrm{Ms}$ were normalized to uncoated $\mathrm{MOF}^{\mathrm{Hb}}-\mathrm{NPs}$. Figure 5Aii shows a $\sim 56 \%$ increase in nMFI (dark grey bars) when coating bare $\mathrm{MOF}^{\mathrm{Hb}}-\mathrm{NPs}$ with $\mathrm{RBC}-\mathrm{M}^{\mathrm{F}}$. However, the results were different for PDA-coated $\mathrm{MOF}^{\mathrm{Hb}} / \mathrm{PDA}-\mathrm{NPs}$, which experienced a $244 \%$ increase in nMFI (dark purple bars) which indicates a positive interaction between the $\mathrm{RBC}-\mathrm{M}^{\mathrm{F}}$ and the NPs. This result is in agreement with previous reports demonstrating that a negative surface charge is a major factor facilitating the coating by RBC-Ms. ${ }^{60}$ Importantly, the physical mixtures of the NPs and $\mathrm{RBC}-\mathrm{M}^{\mathrm{F}}$ resulted on a barely noticeable increase in nMFI. Specifically, a $\sim 20 \%$ and $\sim 25 \%$ increase in nMFI was observed in the absence (MOFHb-NPs, light grey bars) and presence (MOF ${ }^{\mathrm{Hb}} / \mathrm{PDA}-\mathrm{NPs}$, light purple bars) of a PDA layer. The MOF $\mathrm{Hb} / \mathrm{M}-\mathrm{NPs}$ were also characterized by SEM. MOF ${ }^{\mathrm{Hb}}-\mathrm{NPs}$ without a PDA layer shows large aggregates following coating with RBC-Ms (Figure 5Aiii) as a result of the disturbed RBC-M interaction with the NPs. In contrast, MOFHb/PDA-NPs coated by RBC-Ms yielded even, spherical and monodisperse NPs (Figure 5Aiv). Thus, the flow cytometry results together with the SEM images indicate that the extracted RBC-Ms can be used to successfully coat MOFHb/PDA-NPs.

Following on, the $\mathrm{MOF}^{\mathrm{Hb}} / \mathrm{M}-\mathrm{NPs}$ were examined to assess the completeness of the membrane coverage by conducting an aggregation assay based on Strep-BT conjugation. ${ }^{60}$ In this study, biotinylated NPs (MOFHb/BT-NPs) which readily aggregate upon direct exposure to free Step in solution were prepared (Figure 5Bi). In particular, PDA-coated MOFHb/PDA-NPs were functionalized with BT-NHS since it reacts in a straight forward manner with the primary amines of the PDA layer rendering biotinylated $\mathrm{MOF}^{\mathrm{Hb}} / \mathrm{BT}-\mathrm{NPs}$. Figure 5Bii shows how, in the absence of RBC-M, the MOF ${ }^{\mathrm{Hb}} / \mathrm{BT}-\mathrm{NPs}$ displayed a hydrodynamic size of $\sim 500 \mathrm{~nm}$ as shown by DLS measurements. Upon incubation of $\mathrm{MOF}^{\mathrm{Hb}} / \mathrm{BT}-\mathrm{NPs}$ with free Strep, the size increased up to $\sim 900$ $\mathrm{nm}$, indicating aggregation of the system as a result of the NPs bridging mechanism of the BTStrep interaction. We would like to note that the quantitative change of hydrodynamic diameter following PDA coating (i.e., a hydrodynamic size of $\sim 220 \mathrm{~nm}$ and $\sim 500 \mathrm{~nm}$ for uncoated $\mathrm{MOF}^{\mathrm{Hb}}$ NPs and PDA-coated MOFHb/BT-NPs, respectively) could be misleading. As previously reported, the black colour produced by PDA coating could adsorb the laser light, thus affecting the accuracy 
of the DLS measurements. ${ }^{61,62}$ However, it is still nonetheless possible to qualitatively compare the size of the different samples since they all have experienced the same PDA coating procedure.

Given that a uniform coating by the RBC-Ms will prevent surface-attached BT from interacting with Strep, the completeness of RBC-M coating was evaluated using biotinylated $\mathrm{MOF}$ Hb/BT-NPs incubated with increasing amounts of RBC-M. Specifically, MOFHb/BT-NPs were mixed with different amounts of RBC-Ms (i.e., extracted from $17 \mu \mathrm{L}$ to $400 \mu \mathrm{L}$ of whole blood per mg of starting MOF-NPs) followed by sonication and extrusion. The resulting RBC-M-coated $\mathrm{MOF}^{\mathrm{Hb}} / \mathrm{BT} / \mathrm{M}-\mathrm{NPs}$ where then incubated in a Strep solution and their aggregation (or the lack of) was assessed by DLS. Figure 5B shows how, for low RBC-M amounts, significant aggregation was detected (i.e., an increase in size from $\sim 500 \mathrm{~nm}$ to $\sim 850 \mathrm{~nm}$ for RBC-M extracted from only $17 \mu \mathrm{L}$ of whole blood). In contrast, for RBC-M amounts extracted from $200 \mu \mathrm{L}$ of whole blood or higher, the addition of Strep failed to induce any considerable size increase among the $\mathrm{MOF}^{\mathrm{Hb}} / \mathrm{BT} / \mathrm{M}-\mathrm{NPs}$. This blockage of the Strep-induced aggregation indicates that the surfaces of the $\mathrm{MOF}^{\mathrm{Hb}} / \mathrm{BT} / \mathrm{M}-\mathrm{NPs}$ were fully covered upon mixing with RBC-M extracted from at least 200 $\mu \mathrm{L}$ of blood.

3.3.3. Protein adsorption studies. Recognition and clearance by the MPS, takes place following accumulation of opsonins onto the carriers surface. ${ }^{63}$ Thus, the stealth properties of the NPs as a result of the PEG and RBC-M coatings were first assessed in terms of inhibition of protein adsorption. IgG and BSA were selected as model proteins since they are two of the most abundant proteins in blood. While IgG acts as a potent opsonin, albumin is believed to have a dysopsonic effect. However, albumin can be easily replaced by opsonic proteins. ${ }^{64}$ The adsorption of fluorescently labelled BSA-FITC and IgG-FITC onto the different NPs (i.e., MOFHb-NPs, $\mathrm{MOF}^{\mathrm{Hb}} / \mathrm{PDA}-\mathrm{NPs}, \mathrm{MOF}^{\mathrm{Hb}} / \mathrm{PEG}-\mathrm{NPs}$ and $\mathrm{MOF}^{\mathrm{Hb}} / \mathrm{M}-\mathrm{NPs}$ ) following $4 \mathrm{~h}$ of incubation at $37^{\circ} \mathrm{C}$, was evaluated by flow cytometry. The results, which were normalized to the MFI of MOFHb-NPs incubated with BSA-FITC and IgG-FITC, are shown in Figure 6. While coating with PDA resulted on a $\sim 80 \%$ decrease in $\mathrm{nMFI}$ for BSA-FITC, only a $\sim 25 \%$ decrease was observed for IgGFITC. This fact could be attributed to the negative charge rendered by the PDA coating, which could repel the adsorption of the negatively charged BSA-FITC. ${ }^{65}$ Following PEG coating, a $\sim 80 \%$ and $\sim 79 \%$ decrease in nMFI was detected for MOFHb/PEG-NPs in the presence of BSA-FITC and IgG-FITC, respectively. These results are in agreement with previously reported studies using the 
same PEG-based polymer, ${ }^{36,39,40,66}$ confirming again the ability of PLL-g-PEG to act as a steric barrier hindering the diffusion and adsorption of proteins onto the surface of the nanocarriers. Coating with RBC-M displayed a similar effect than PEGylation for BSA-FITC since a $\sim 80 \%$ decrease in nMFI was also detected for $\mathrm{MOF}^{\mathrm{Hb}} / \mathrm{M}-\mathrm{NPs}$ in the presence of that protein. The results were slightly different for IgG-FITC and a higher decrease in nMFI as compared to the PEGylated counterparts was observed (i.e., 75 and 85\% decrease in nMFI for MOF $\mathrm{Hb} / \mathrm{PEG}-\mathrm{NPs}$ and $\mathrm{MOF}^{\mathrm{Hb}} / \mathrm{M}-\mathrm{NPs}$, respectively). Thus, all in all, these results indicate that coating with RBC-M, results in equally good resistance to protein adsorption as compared to PEGylation.

3.3.4. Cell uptake/association studies. The stealth properties of the NPs depending on the different terminating coatings were further evaluated by their ability in avoiding/minimizing cell internalization. RAW 264.7 mice macrophages and HUVEC were the cells of choice. While macrophages are phagocytic cells of the MPS, endothelial cells are the cells lining in our vasculature and, therefore, any intravenously administered nanocarrier will get in contact with them. To compare the cell uptake/association, the different NPs were fabricated employing fluorescently labelled Hb-FITC. The different NPs (i.e., MOFHb-FITC-NPs, MOFHb-FITC/PDA-NPs, $\mathrm{MOF}^{\mathrm{Hb}-F I T C} / \mathrm{PEG}-\mathrm{NPs}$ and MOFHb-FITC/M-NPs) were incubated at a 100:1 NPs-to-cell ratio for $4 \mathrm{~h}$ at $37{ }^{\circ} \mathrm{C}$. The CUE, which corresponds to the percentage of cells with a fluorescence intensity higher than the autofluorescence level of the cells, was evaluated by flow cytometry for the two cell lines (Figure 7A). The results show how the three different coatings (i.e., PDA, PEG and RBC-M) resulted on a significant decrease in CUE for both RAW 264.7 and HUVEC cells as compared to the uncoated counterparts. However, while such a decrease in CUE was rather slight for RAW 264.7 cells ( $\sim 10-15 \%$ decrease for the three different coatings), it was quite pronounced for HUVEC cells. Specifically, for HUVEC cells, a decrease in CUE of 35\% for PDA-coated MOFHb-FITC/PDA-NPs and 50\% for both PEG- and RBC-M-coated NPs was observed. Figure 7B shows the FI readings measured upon lysing the cells following $4 \mathrm{~h}$ incubation with the NPs at the same NPs-to-cell ratio. The results, which have been normalized to the FI readings upon incubation of the uncoated $\mathrm{MOF}^{\mathrm{Hb}-\mathrm{FITC}}-\mathrm{NPs}(\mathrm{nFI})$, are in agreement with the CUE results. While only $\sim 10$ $20 \%$ decrease in nFI could be observed for RAW 264.7 cells for the three studied coatings, a marked decrease in nFI was detected in HUVEC cells. In particular, PDA coating resulted in a $\sim 55 \%$ decrease in nFI while both PEG- and RBC-M-coatings lead to $\sim 70 \%$ reduction in $\mathrm{nFI}$. Thus, all in all, a limited effect both in CUE and nFI could be observed for RAW 264.7 cells for the three 
studied coatings. In contrast, the significant and similar blockage of the cell uptake for the two stealth coatings detected for HUVEC cells is well in agreement with the protein adsorption studies. Interestingly, PDA-coating also resulted in diminished cell uptake both in terms of CUE but also when assessing the nFI of the internalized cells. We attribute these results to the fact that following PDA coatings the charge of the NPs changes from positive $(\zeta=13.7 \pm 1.9 \mathrm{mV}$ for MOFHb-FITC

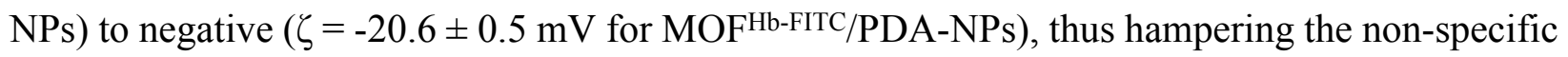
interactions with cell binding sites and diminishing the cell-uptake efficiency. ${ }^{67}$

\subsection{Biocompatibility Studies}

The biocompatibility of the NPs with the three different coatings was assessed in terms of cell viability and hemocompatibility studies.

3.4.1. Cell viability. The in vitro cytotoxicity of MOF-NPs, $\mathrm{MOF}^{\mathrm{Hb}}-\mathrm{NPs}, \mathrm{MOF}^{\mathrm{Hb}} / \mathrm{PDA}-\mathrm{NPs}$, $\mathrm{MOF}^{\mathrm{Hb}} / \mathrm{PEG}-\mathrm{NPs}$ and $\mathrm{MOF}^{\mathrm{Hb}} / \mathrm{M}-\mathrm{NPs}$ was assessed by conducting cell viability assays for the two studied cell lines at a 100:1 NPs-to-cell ratio following $4 \mathrm{~h}$ of incubation at $37^{\circ} \mathrm{C}$. Figure 8A shows no decrease in the normalized cell viability readings (nCV) for the three studied coatings and cell lines. Interestingly, although not statistically significant, an increase of $\sim 10 \%$ in nCV was observed for RAW 264.7 cells incubated with PDA-coated MOF ${ }^{\mathrm{Hb}} / \mathrm{PDA}-\mathrm{NPs}$ as compared to cells only. This is not surprising since previous works have reported enhanced cell viability for PDA coatings as a result of the large amount of amine and hydroxyl groups. ${ }^{40,68}$

3.4.2. Hemocompatibility. The evaluation of the impact of the NPs depending on the surface coatings on human blood cells was evaluated by a haemolysis assay. The haemolysis rate following incubation of the NPs with blood cells at a 100:1 of NPs-to-cell ratio, was evaluated by quantifying the amount of free $\mathrm{Hb}$ in solution. Figure $8 \mathrm{Bi}$ shows that while uncoated $\mathrm{MOF}^{\mathrm{Hb}}-\mathrm{NPs}$ result on a haemolysis rate of $\sim 8 \%$; the three different coatings $\left(\mathrm{MOF}^{\mathrm{Hb}} / \mathrm{PDA}-\mathrm{NPs}, \mathrm{MOF}^{\mathrm{Hb}} / \mathrm{PEG}-\mathrm{NPs}\right.$ and $\mathrm{MOF}^{\mathrm{Hb}} / \mathrm{M}-\mathrm{NPs}$ ) promote a decrease in haemolysis rate well below $5 \%$. This is an important fact since, according to ISO/TR 7406, the biomaterials are considered non-hemolytic for haemolysis rates lower than $5 \% .{ }^{69}$ The $\sim 8 \%$ haemolysis rate induced by $\mathrm{MOF}^{\mathrm{Hb}}-\mathrm{NPs}$ can attributed to their positive charge. The electrostatic interactions between cell membrane and NPs could promote the disturbance of cell membrane and thus resulting in a higher haemolysis rate. Figure 8Bii shows photographic images of the suspensions of the blood cells and the different NPs including a 
negative (isotonic HEPES buffer, 0\% lysis) and a positive (MQ, 100\% lysis) control group. As expected by the haemolysis rate results, only the positive control group showed haemoglobin leakage with obvious red colour. Interestingly, while bright red pellets can be observed for the control groups and for MOF-NPs and $\mathrm{MOF}^{\mathrm{Hb}}$-NPs treated groups, dark pellets were collected for the groups with NPs containing a PDA coating (i.e., $\mathrm{MOF}^{\mathrm{Hb}} / \mathrm{PDA}-\mathrm{NPs}$ but also $\mathrm{MOF}^{\mathrm{Hb}} / \mathrm{PEG}-\mathrm{NPs}$ and $\mathrm{MOF}^{\mathrm{Hb}} / \mathrm{M}-\mathrm{NPs}$ which have an underlying PDA coating). Such a darker colour indirectly indicates the successful modification by PDA. Additionally, the blood cells retained their shape after incubation with the different NPs (Figure S2, Supporting Information).

\subsection{Functional performance}

The ability to carry oxygen is one of the most important functions of $\mathrm{Hb}$. The oxygen binding and releasing properties of the NPs depending on their surface coatings (i.e., MOFHb_NPs,

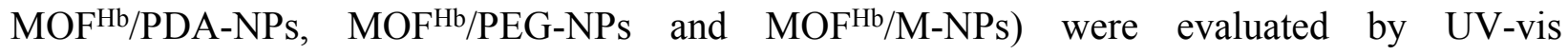
spectroscopy following several $\mathrm{O}_{2} / \mathrm{N}_{2}$ cycles. Figure 9 shows the initial characteristic peaks of oxy- $\mathrm{Hb}$ for the first $\mathrm{O}_{2}$ cycle at $\sim 412 \mathrm{~nm}$ (Soret peak), $\sim 541$ and $\sim 578 \mathrm{~nm}$ (red lines) for all the studied samples independent of the surface coating. Importantly, following flowing with $\mathrm{N}_{2}$ gas, a shift in the wavelengths towards the characteristic deoxy-Hb peaks could also be observed for all the different NPs. In particular, a red shift of the Soret peak to $\sim 428 \mathrm{~nm}$, the disappearance of the peaks at $\sim 541$ and $\sim 578 \mathrm{~nm}$ and appearance of the peak at $\sim 564 \mathrm{~nm}$ (green lines) was detected independently of the surface coating. This change in the wavelengths upon $\mathrm{O}_{2}$ and $\mathrm{N}_{2}$ gas treatment was observed for two additional cycles thus highlighting the ability of the different NPs in binding and releasing $\mathrm{O}_{2}$ in a continuous manner over multiple rounds in a similar fashion as our biological RBCs.

All in all, these results demonstrate that loading Hb into MOF-NPs, surface modification with PDA and subsequent functionalization with PEG or RBC-M, did not hamper the $\mathrm{O}_{2}$-carrying ability of $\mathrm{Hb}$, which is the most important feature for HBOCs.

\section{Conclusion}

In this work, we have presented a novel biomimetic HBOC with a high Hb loading, stability and preserved functionality. To do so, we have prepared mesoporous MOF-based NPs which are 
monodisperse and spherical with a diameter of around $220 \mathrm{~nm}$, which could avoid extravasation through the blood vessel wall and consequently circumvent vasoconstriction. Coating with RBC$\mathrm{M}$ endows $\mathrm{MOF}^{\mathrm{Hb}}$-NPs with low-fouling properties in terms of decreased protein adsorption and cell uptake, which are comparable to our previously reported PEGylation strategy. Moreover, the RBC-M-coated $\mathrm{MOF}^{\mathrm{Hb}}$-NPs showed good biocompatibility and hemocompatibility while also being able to reversibly bind and release oxygen, which is the most important feature for HBOCs. In summary, this novel biomimetic HBOCs with high $\mathrm{Hb}$ content and stability can provide a safe and efficient oxygen supply thus fulfilling the requirements for the next generation of blood surrogates. 


\section{FIGURES}

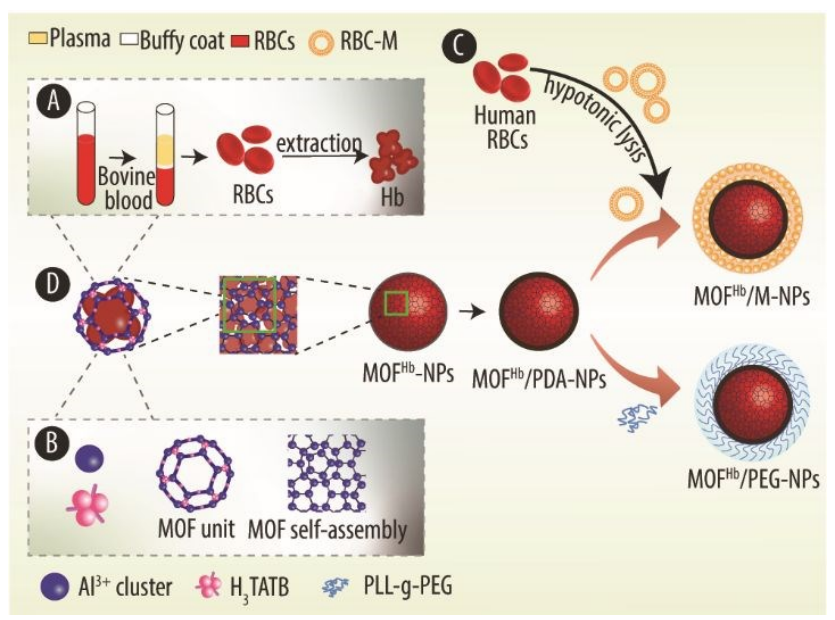

Scheme 1 Illustration of the assembly process. A) Haemoglobin ( $\mathrm{Hb})$ is extracted from bovine red blood cells (RBCs); B) Components and crystalline structure of the metal organic framework (MOF) platform; C) Membrane of RBCs (RBC-M) is extracted from human RBCs; D) Hb is loaded into empty MOF-based nanoparticles (MOF-NPs) by post-encapsulation rendering $\mathrm{MOF}^{\mathrm{Hb}}$ NPs. MOF ${ }^{H b}-N P s$ are endorsed with stealth layer employing PEGylation or RBC-M coating. 

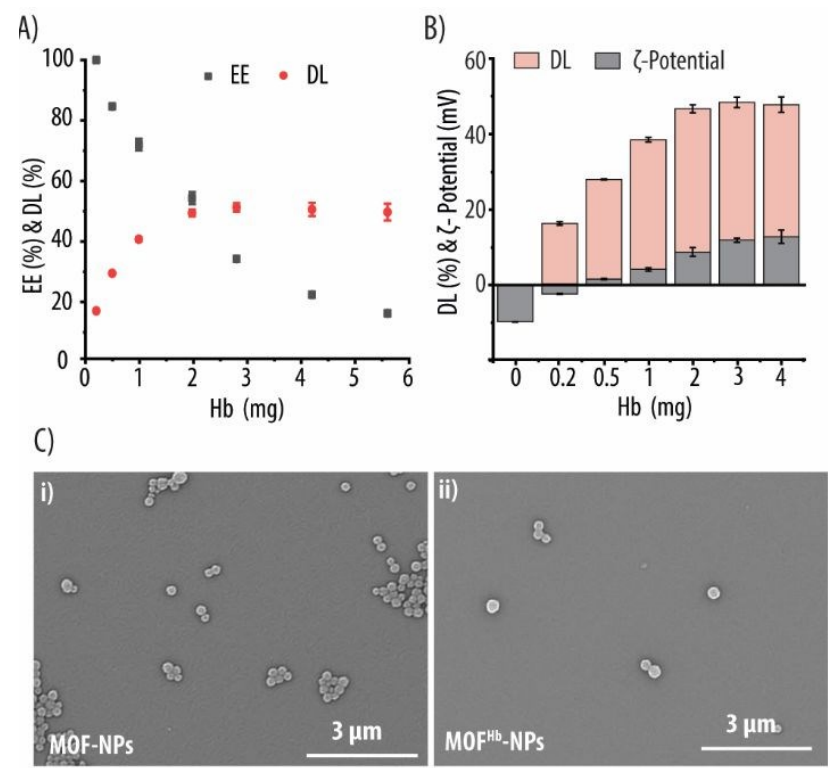

Fig. 1 A) Entrapment efficiency (EE) and drug loading (DL) of haemoglobin (Hb) into metal organic framework (MOF)-based nanoparticles (MOF-NPs) at various initial input amounts per mg of MOF-NPs. B) Zeta-potential of Hb loaded MOF-NPs (MOF ${ }^{\mathrm{Hb}}-\mathrm{NPs}$ ) for the different DLs. C) Scanning electron microscopy images of empty MOF-NPs and MOF ${ }^{\mathrm{Hb}}-\mathrm{NPs}$ in suspension (i and ii). 

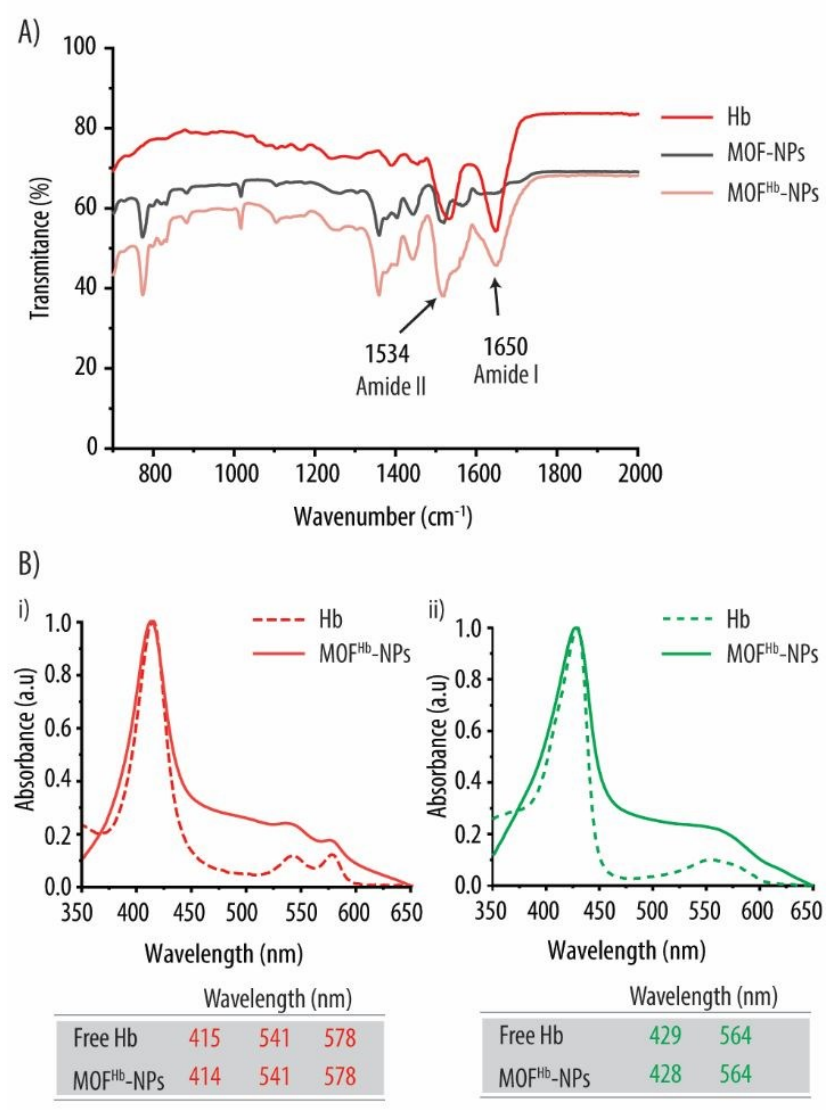

Fig. 2 A) Fourier-transform infrared (FTIR) spectra of empty metal organic framework (MOF)based nanoparticles (MOF-NPs) and haemoglobin (Hb)-loaded MOF-NPs ( $\mathrm{MOF}^{\mathrm{Hb}}-\mathrm{NPs}$ ) as compared to native $\mathrm{Hb}$. B) UV-vis absorption spectra of native $\mathrm{Hb}$ and $\mathrm{MOF}^{\mathrm{Hb}}-\mathrm{NPs}$ before i) and after purging with nitrogen gas ii). 

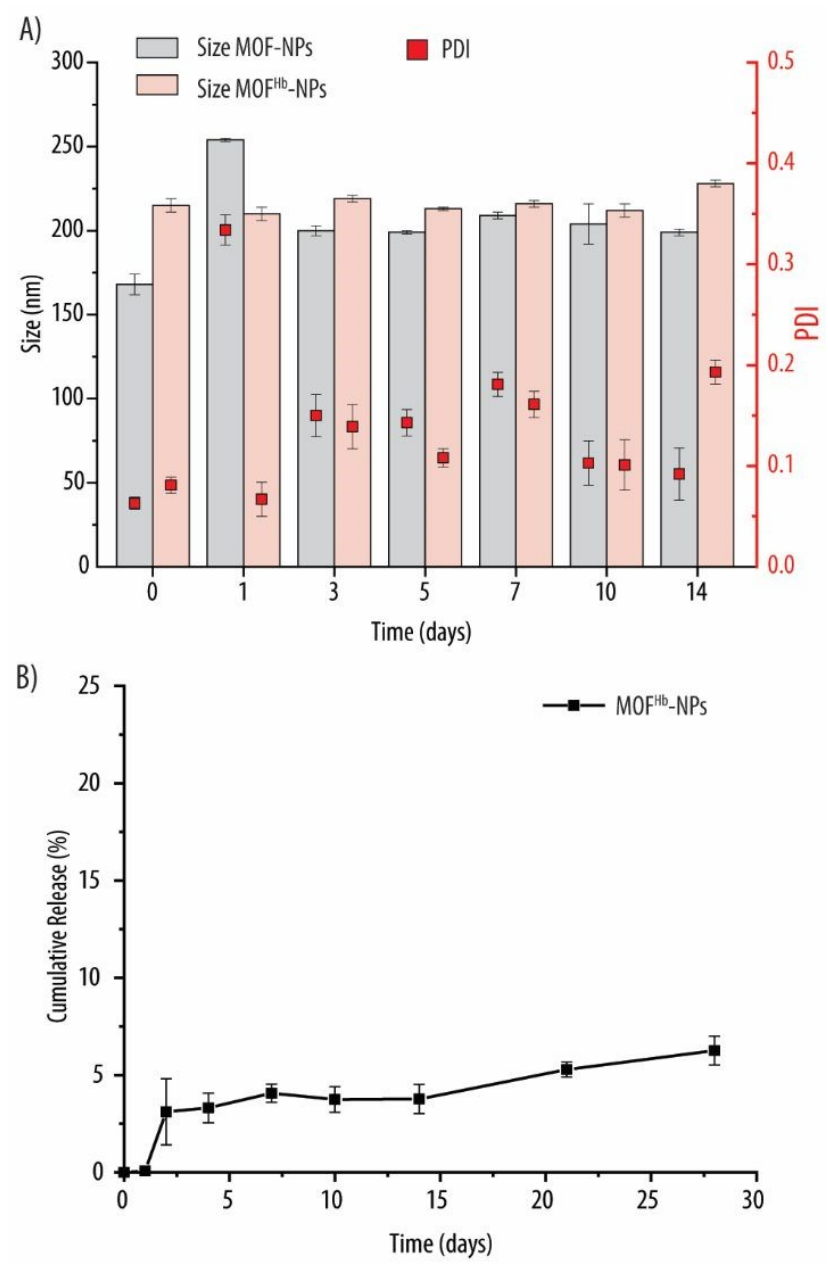

Fig. 3 A) Size and polydispersity index (PDI) of empty metal organic framework (MOF)-based nanoparticles (MOF-NPs) and haemoglobin (Hb)-loaded MOF-NPs (MOFHb-NPs) stored at $4{ }^{\circ} \mathrm{C}$ for 14 days; B) Cumulative release of $\mathrm{Hb}$ from $\mathrm{MOF}^{\mathrm{Hb}}-\mathrm{NPs}$ stored at $4{ }^{\circ} \mathrm{C}$ for 28 days. 


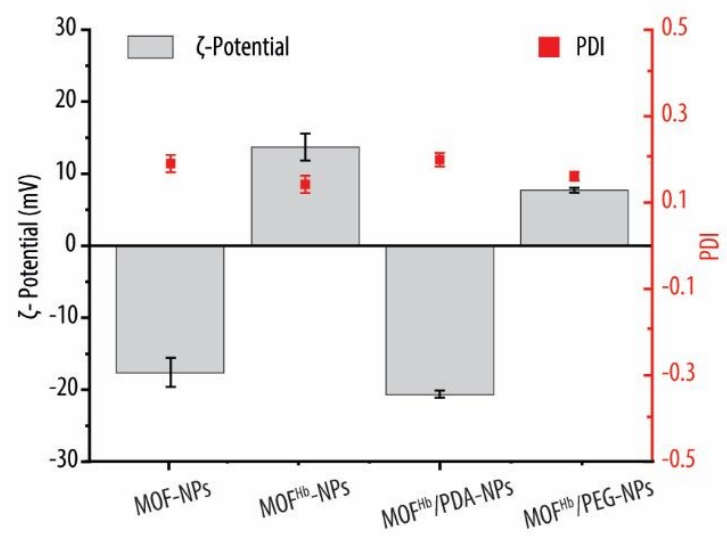

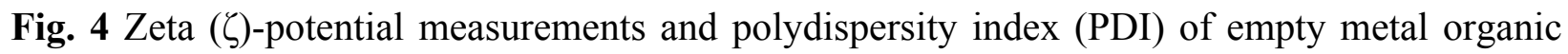
framework (MOF)-based nanoparticles (MOF-NPs) and haemoglobin ( $\mathrm{Hb}$ )-loaded MOF-NPs (MOFHb-NPs) with a polydopamine (PDA) (MOFHb/PDA-NPs) or a PEG (MOFHb/PEG-NPs) coating layer. 
A)

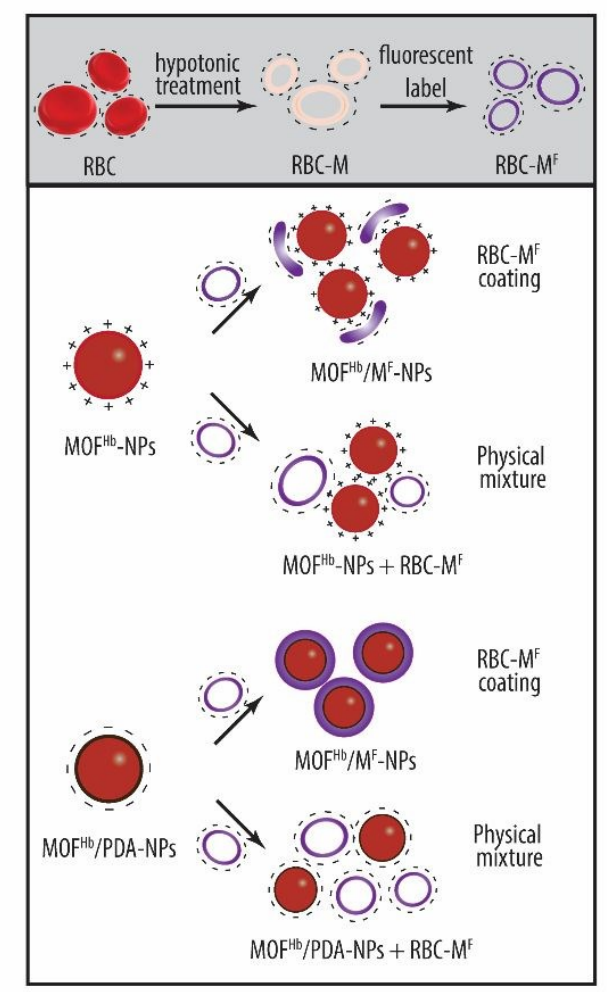

B)

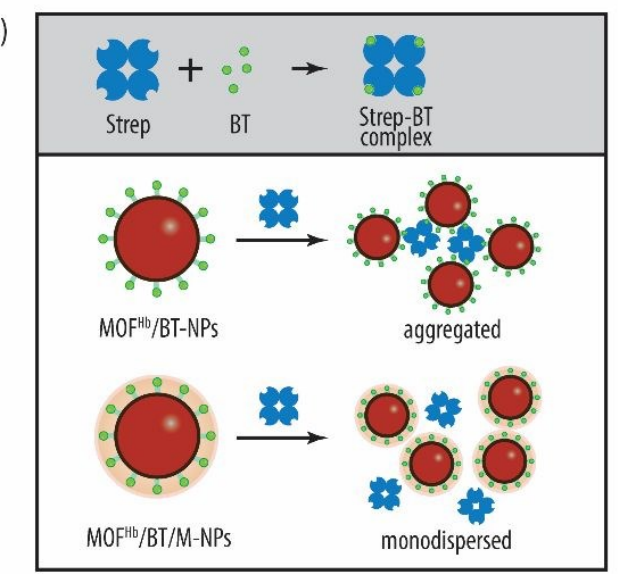

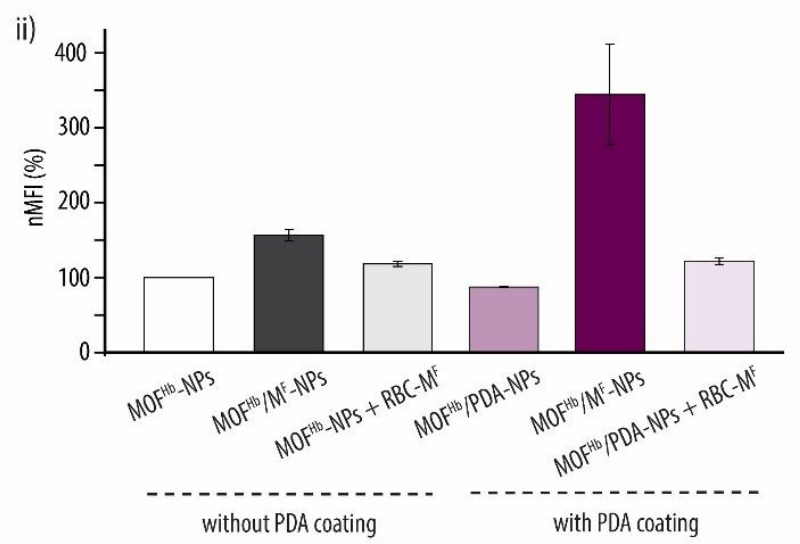

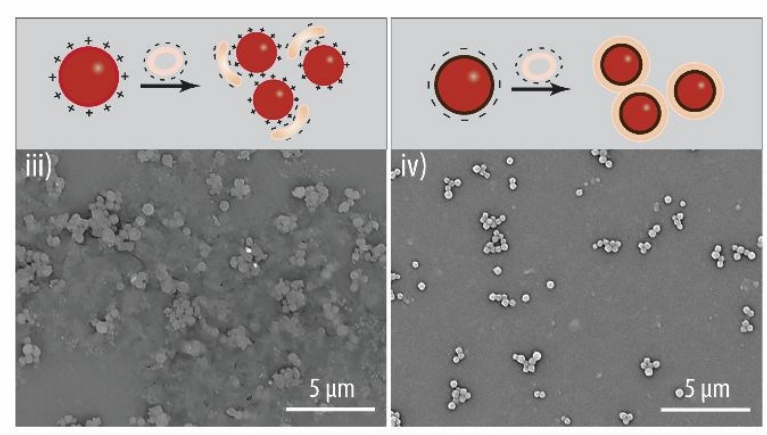

ii)

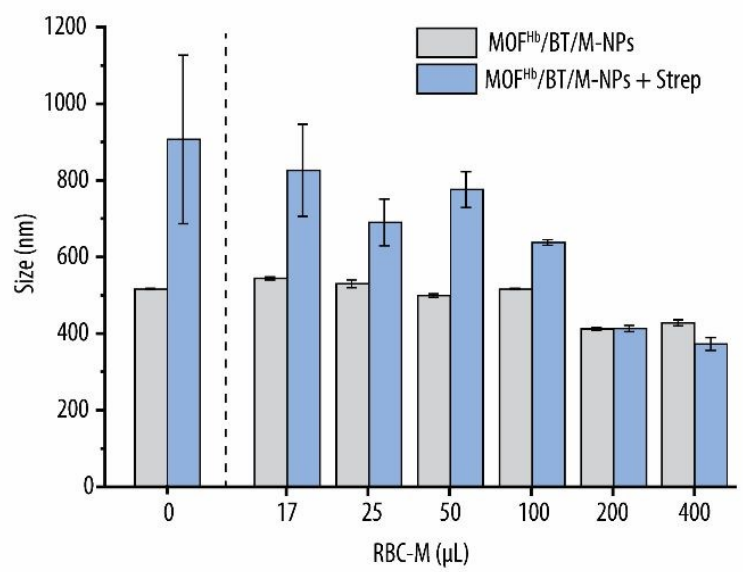

Fig. 5 A) i) Red blood cells membranes (RBC-M) are extracted and fluorescently labelled to render RBC-M $\mathrm{M}^{\mathrm{F}}$. Next, they are used to functionalize haemoglobin $(\mathrm{Hb})$-loaded metal organic framework (MOF)-based nanoparticles ( $\left.\mathrm{MOF}^{\mathrm{Hb}}-\mathrm{NPs}\right)$. Both uncoated (MOF $\left.{ }^{\mathrm{Hb}}-\mathrm{NPs}\right)$ and polydopamine (PDA) coated (MOF ${ }^{\mathrm{Hb}} / \mathrm{PDA}-\mathrm{NPs}$ ) NPs are considered. ii) Normalized mean fluorescence intensity (nMFI) readings of the NPs with the different coatings: Hb-loaded $\mathrm{MOF}^{\mathrm{Hb}}-\mathrm{NPs}$, RBC-M $\mathrm{M}^{\mathrm{F}}$-coated $\mathrm{MOF}^{\mathrm{Hb}} / \mathrm{M}^{\mathrm{F}}-\mathrm{NPs}$ and the physical mixture of $\mathrm{MOF}^{\mathrm{Hb}}-\mathrm{NPs}$ and $\mathrm{RBC}-\mathrm{M}^{\mathrm{F}}$. Scanning electron 
microscopy images of the physical mixture of $\mathrm{MOF}^{\mathrm{Hb}}-\mathrm{NPs}$ (iii) and RBC-M and the RBC-Mcoated MOFHb/M-NPs (iv). B) i) Streptavidin (Strep)-biotin (BT) conjugation results in the StrepBT complex. MOFHb/PDA-NPs were functionalized with BT to render MOFHb/BT-NPs which aggregate in the presence of Strep. $\mathrm{MOF}^{\mathrm{Hb}} / \mathrm{BT}-\mathrm{NPs}$ are coated with $\mathrm{RBC}-\mathrm{M}$ to render $\mathrm{MOF}^{\mathrm{Hb}} / \mathrm{BT} / \mathrm{M}-\mathrm{NPs}$ which remain monodisperse in the presence of Strep. ii) Size distribution of $\mathrm{MOF}^{\mathrm{Hb}} / \mathrm{BT} / \mathrm{M}-\mathrm{NPs}$ prepared with different amounts of RBC-M in the absence (grey bars) or presence (blue bars) of Strep. 


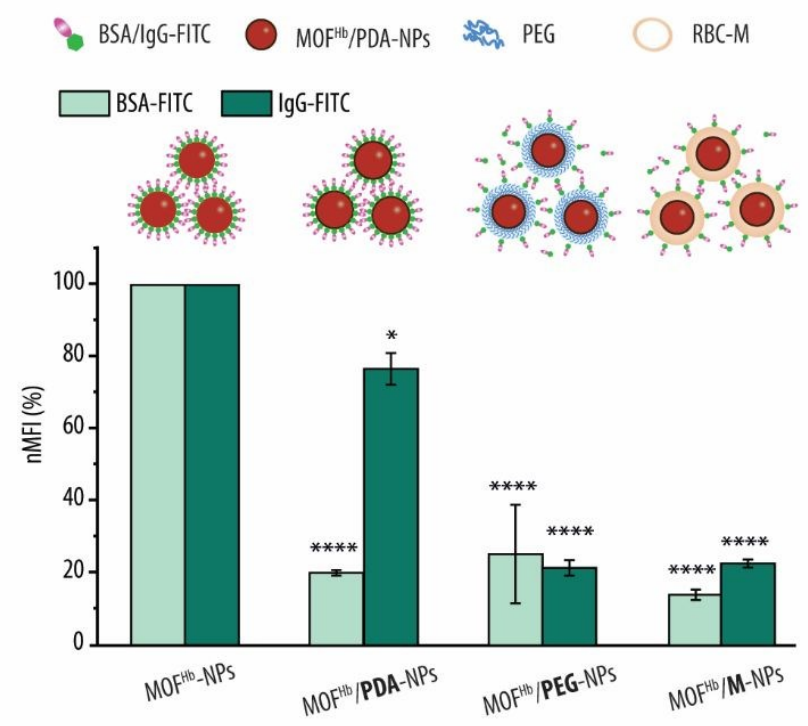

Fig. 6 Normalized mean fluorescence intensity (nMFI) of haemoglobin (Hb)-loaded metal organic framework (MOF)-based nanoparticles ( $\mathrm{MOF}^{\mathrm{Hb}}-\mathrm{NPs}$ ) incubated in the presence of fluorescently labelled bovine serum albumin (BSA-FITC) or immunoglobulin G (IgG-FITC). Different types of $\mathrm{MOF}^{\mathrm{Hb}}$-NPs are considered: uncoated: $\mathrm{MOF}^{\mathrm{Hb}}-\mathrm{NPs}$; polydopamine (PDA)-coated: MOFHb/PDANPs; PEG-coated: MOFHb/PEG-NPs; or red blood cell-membrane (RBC-M) coated: MOFHb/MNPs. ${ }^{*} \mathrm{p} \leq 0.05 ; * * * * \mathrm{p} \leq 0.0001$. 


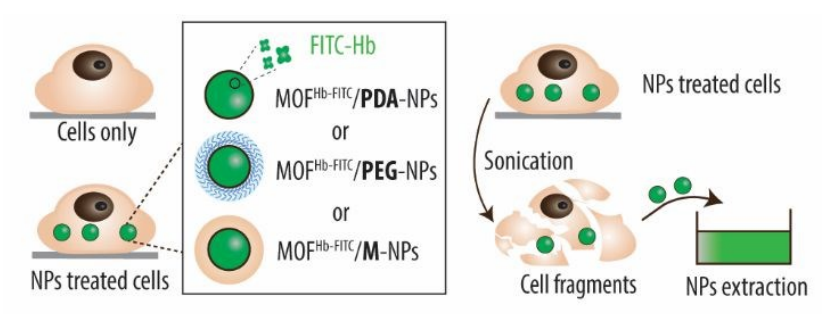

A)

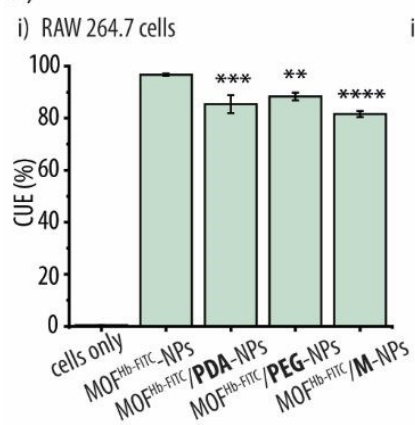

ii) HUVEC cells

B)
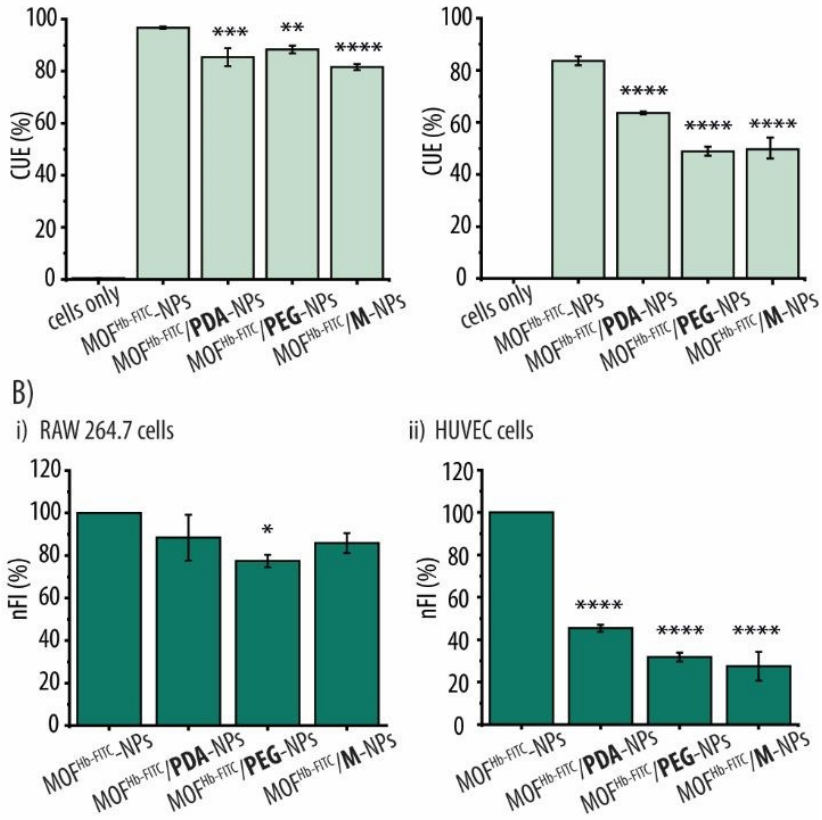

ii) HUVEC cells

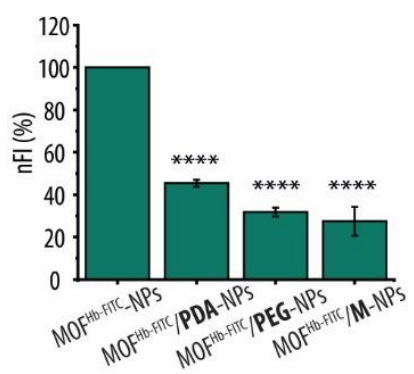

Fig. 7 A) Cell uptake efficiency (CUE) and B) normalized fluorescence intensity (nFI) of RAW 264.7 (i) and HUVEC (ii) cells incubated with haemoglobin (Hb)-loaded metal organic framework (MOF)-based nanoparticles ( $\left.\mathrm{MOF}^{\mathrm{Hb}}-\mathrm{NPs}\right)$. Different types of $\mathrm{MOF}^{\mathrm{Hb}}-\mathrm{NPs}$ are considered: uncoated: $\mathrm{MOF}^{\mathrm{Hb}}-\mathrm{NPs}$; polydopamine (PDA)-coated: $\mathrm{MOF}^{\mathrm{Hb}} / \mathrm{PDA}-\mathrm{NPs} ; \quad$ PEG-coated: MOF ${ }^{\mathrm{Hb}} / \mathrm{PEG}-\mathrm{NPs}$; or red blood cell-membrane coated: $\mathrm{MOF}^{\mathrm{Hb}} / \mathrm{M}-\mathrm{NPs} .{ }^{*} \mathrm{p} \leq 0.05 ;{ }^{* *} \mathrm{p} \leq 0.001$, $* * * \mathrm{p} \leq 0.0005, * * * * \mathrm{p} \leq 0.0001$. 


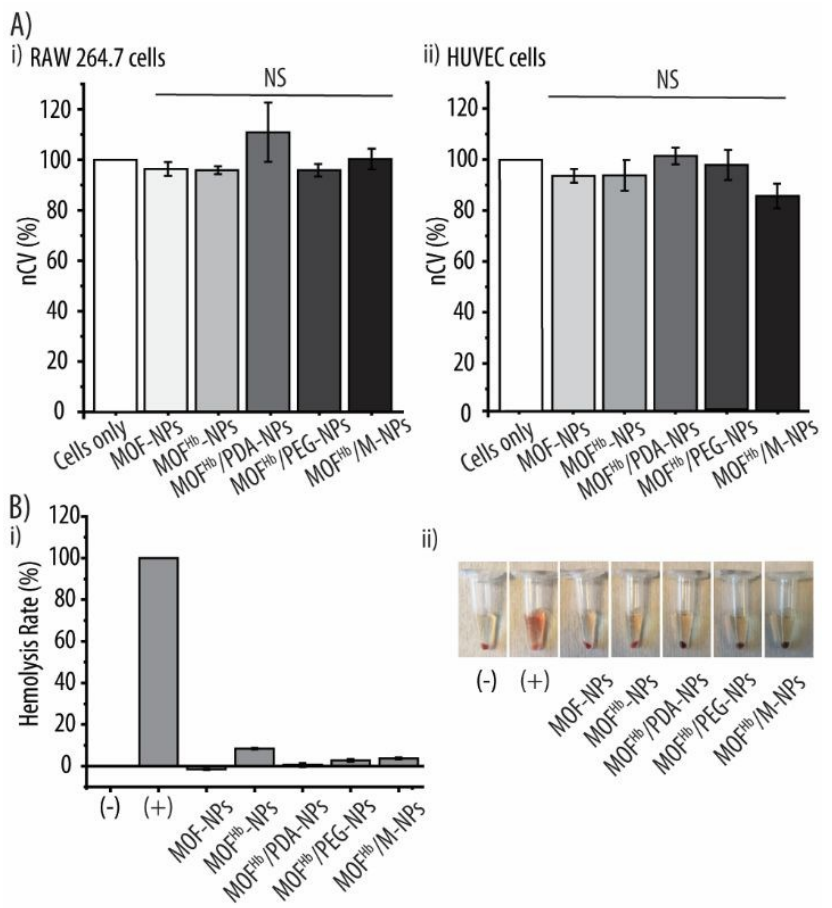

Fig. 8 A) Normalized cell viability (nCV) readings of RAW 264.7 (i) and HUVEC (ii) cells following incubation for $4 \mathrm{~h}$ with empty metal organic framework (MOF)-based nanoparticles (MOF-NPs) and haemoglobin (Hb)-loaded MOF-NPs (MOF $\mathrm{Hb}_{-N P s}$ ). B) Haemolysis rate (i) and photographic images (ii) of the of the negative control (-), positive control (+) and both MOF-NPs and $\mathrm{MOF}^{\mathrm{Hb}}$-NPs incubated with blood cells for $4 \mathrm{~h}$. Different types of $\mathrm{MOF}^{\mathrm{Hb}}-\mathrm{NPs}$ are considered: uncoated: MOFHb-NPs; polydopamine (PDA)-coated: MOFHb/PDA-NPs; PEG-coated:

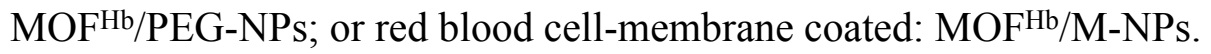



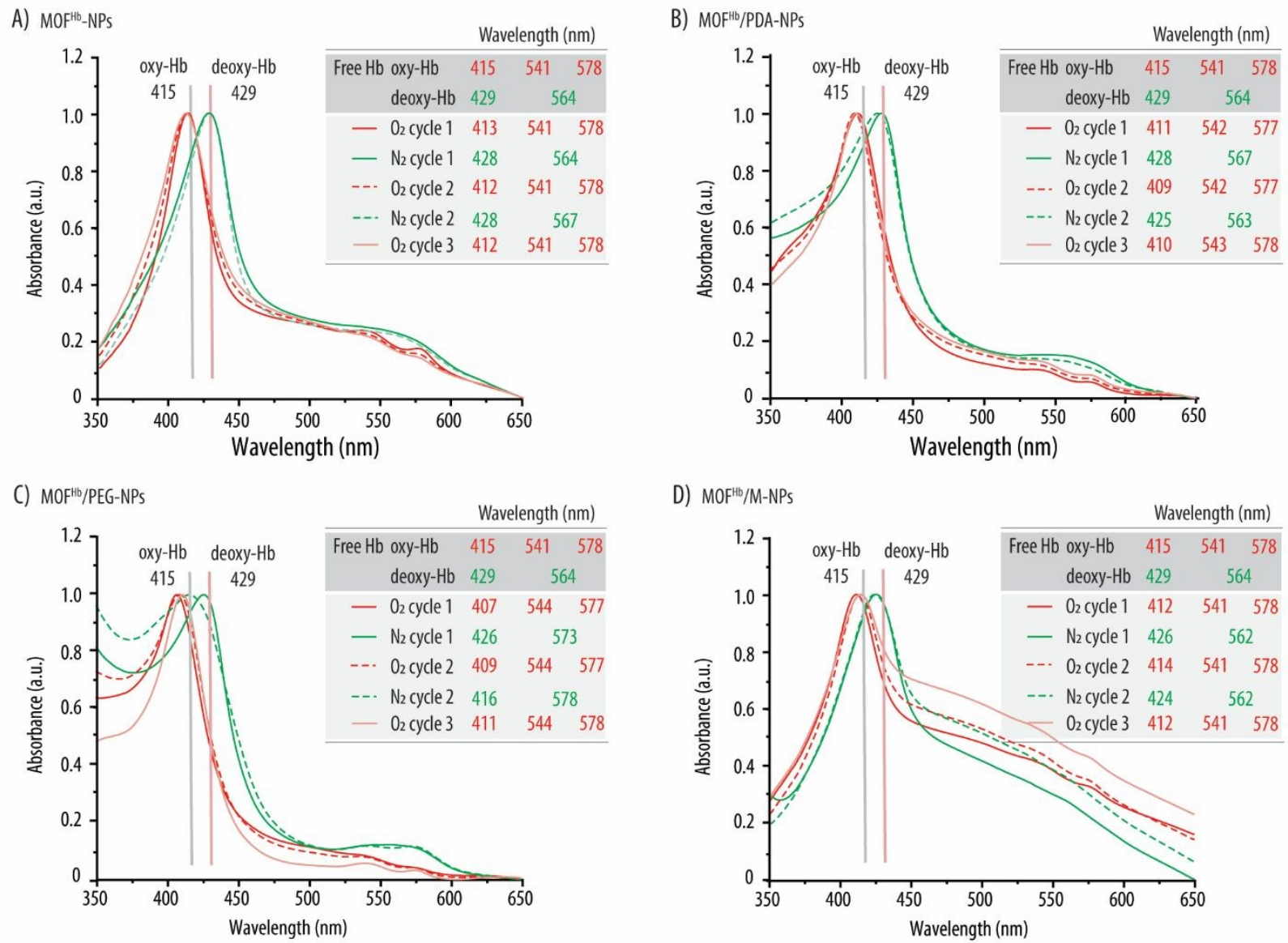

Fig. $9 \mathrm{UV}-$ vis absorption spectra of oxygenated (oxy-Hb) and deoxygenated (deoxy-Hb) haemoglobin $(\mathrm{Hb})$ after successively feeding with oxygen $\left(\mathrm{O}_{2}\right)$ or nitrogen $\left(\mathrm{N}_{2}\right)$ gas different types of metal organic framework (MOF)-based nanoparticles (MOF-NPs): A) uncoated Hb-loaded

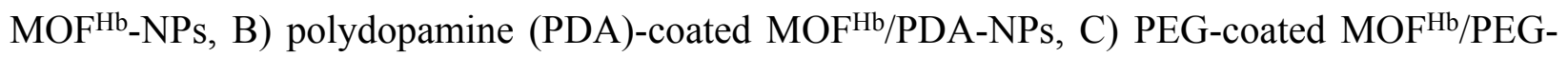
NPs and D) red blood cell-membrane-coated MOFHb/M-NPs. 


\section{ASSOCIATED CONTENT}

\section{Supporting Information}

AUTHOR INFORMATION

\section{Corresponding Author}

*leri@dtu.dk

\section{Funding Sources}

This work was supported by the Danish Council for Independent Research [Grant No. 611100298B and 0130-00009B].

\section{ACKNOWLEDGMENT}

This work was supported by the Danish Council for Independent Research [Grant No. 611100298B and 0130-00009B]. 


\section{REFERENCES}

1 Q. Wang, R. Zhang, M. Lu, G. You, Y. Wang, G. Chen, C. Zhao, Z. Wang, X. Song, Y. Wu, L. Zhao and Z. H. Zhou, Biomacromolecules, 2017, 18, 1333-1341.

2 S. M. C. Horwitz, K. Kelleher, P. M. T. Thomas Boyce, A. Webb, A. Meier-Hellmann, G. Nollet, D. Peres-Bota, J. L. Vincent, J.-F. Baron, K. Reinhart, L. Gattinoni, L. Thijs, A. Webb, A. Meier-Hellmann, G. Nollet, D. Peres-Bota and A. B. C. Investigators, 2002, 288, 1499-1507.

3 H. G. Klein and D. J. Anstee, Mollison's blood transfusion in clinical medicine, John Wiley \& Sons, 2014.

4 H. Sakai, K. Sou, H. Horinouchi, K. Kobayashi and E. Tsuchida, Artif. Organs, 2009, 33, $139-145$.

5 L. T. Goodnough, M. G. Scott and T. G. Monk, Clin. Orthop. Relat. Res., 1998, 357, 89100.

6 S. Kaneda, T. Ishizuka, H. Goto, T. Kimura, K. Inaba and H. Kasukawa, Artif. Organs, 2009, 33, 146-152.

7 V. R. Yadav, G. Rao, H. Houson, A. Hedrick, S. Awasthi, P. R. Roberts and V. Awasthi, Eur. J. Pharm. Sci., 2016, 93, 97-106.

8 S. Rameez, H. Alosta and A. F. Palmer, Bioconjug. Chem., 2008, 19, 1025-1032.

9 Y. Jia, Y. Cui, J. Fei, M. Du, L. Dai, J. Li and Y. Yang, Adv. Funct. Mater., 2012, 22, 14461453.

10 J. Zhao, C.-S. Liu, Y. Yuan, X.-Y. Tao, X.-Q. Shan, Y. Sheng and F. Wu, Biomaterials, 2007, 28, 1414-1422.

11 S. Peng, J. Liu, Y. Qin, H. Wang, B. Cao, L. Lu and X. Yu, ACS Appl. Mater. Interfaces, $2019,11,35604-35612$. 
12 J. S. Qin, S. Yuan, C. Lollar, J. Pang, A. Alsalme and H. C. Zhou, Chem. Commun., 2018, 54, 4231-4249.

13 A. J. Howarth, Y. Liu, P. Li, Z. Li, T. C. Wang, J. T. Hupp and O. K. Farha, Nat. Rev. Mater., 2016, 1, 1-15.

14 S. Yuan, L. Feng, K. Wang, J. Pang, M. Bosch, C. Lollar, Y. Sun, J. Qin, X. Yang, P. Zhang, Q. Wang, L. Zou, Y. Zhang, L. Zhang, Y. Fang, J. Li and H. C. Zhou, Adv. Mater., 2018, 1704303, 1-35.

15 M. Wu and Y. Yang, Adv. Mater., 2017, 29, 1606134.

16 J. Yang and Y. Yang, View, 2020, 1, e20.

17 J. Yang and Y. Yang, Small, 2020, 16, 1906846.

18 M. A. Luzuriaga, R. P. Welch, M. Dharmarwardana, C. E. Benjamin, S. Li, A. Shahrivarkevishahi, S. Popal, L. H. Tuong, C. T. Creswell and J. J. Gassensmith, ACS Appl. Mater. Interfaces, 2019, 11, 9740-9746.

19 X. Lian, Y. Fang, E. Joseph, Q. Wang, J. Li, S. Banerjee, C. Lollar, X. Wang and H.-C. Zhou, Chem. Soc. Rev., 2017, 46, 3386-3401.

20 M. B. Majewski, A. J. Howarth, P. Li, M. R. Wasielewski, J. T. Hupp and O. K. Farha, CrystEngComm, 2017, 19, 4082-4091.

21 F. Wu, J. Ye, Y. Cao, Z. Wang, T. Miao and Q. Shi, Luminescence, 2020, 35, 440-446.

22 W. Wang, L. Wang, Y. Huang, Z. Xie and X. Jing, Chem. - An Asian J., 2016, 11, 750-756.

23 D. Feng, T. F. Liu, J. Su, M. Bosch, Z. Wei, W. Wan, D. Yuan, Y. P. Chen, X. Wang, K. Wang, X. Lian, Z. Y. Gu, J. Park, X. Zou and H. C. Zhou, Nat. Commun., 2015, 6, 1-8.

24 H. P. Erickson, Biol. Proced. Online, 2009, 11, 32.

25 R. S. Franco, Transfus. Med. hemotherapy, 2012, 39, 302-307. 
26 T. Ishida, M. Ichihara, X. Wang, K. Yamamoto, J. Kimura, E. Majima and H. Kiwada, J. Control. Release, 2006, 112, 15-25.

27 K. Środa, J. Rydlewski, M. Langner, A. Kozubek, M. Grzybek and A. F. Sikorski, Cell. Mol. Biol. Lett, 2005, 10, 37-47.

28 T. T. Hoang Thi, E. H. Pilkington, D. H. Nguyen, J. S. Lee, K. D. Park and N. P. Truong, Polymers (Basel)., 2020, 12, 298.

29 N. d'Avanzo, C. Celia, A. Barone, M. Carafa, L. Di Marzio, H. A. Santos and M. Fresta, Adv. Ther., 2020, 3, 1900170.

30 R. H. Fang, Y. Jiang, J. C. Fang and L. Zhang, Biomaterials, 2017, 128, 69-83.

31 C.-M. J. Hu, R. H. Fang and L. Zhang, Adv. Healthc. Mater., 2012, 1, 537-547.

32 K. Knop, R. Hoogenboom, D. Fischer and U. S. Schubert, Angew. Chemie Int. Ed., 2010, 49, 6288-6308.

33 C.-M. J. Hu, L. Zhang, S. Aryal, C. Cheung, R. H. Fang and L. Zhang, Proc. Natl. Acad. Sci. U. S. A., 2011, 108, 10980-5.

34 L. Rao, L.-L. L. L. Bu, J. H. J.-H. Xu, B. Cai, G.-T. G. T. Yu, X. Yu, Z. He, Q. Huang, A. Li, S.-S. S. S. Guo, W.-F. W. F. Zhang, W. Liu, Z.-J. Z. J. Sun, H. Wang, T.-H. T. H. Wang and X.-Z. X. Z. Zhao, Small, 2015, 11, 6225-6236.

35 B. T. Luk, R. H. Fang, C.-M. J. Hu, J. A. Copp, S. Thamphiwatana, D. Dehaini, W. Gao, K. Zhang, S. Li and L. Zhang, Theranostics, 2016, 6, 1004-1011.

36 M. J. York-Duran, P. K. Ek, M. Godoy-Gallardo and L. Hosta-Rigau, Colloids Surf., B, 2018, 171, 427-436.

37 G. L. Kenausis, J. Vörös, D. L. Elbert, N. Huang, R. Hofer, L. Ruiz-Taylor, M. Textor, J. A. Hubbell and N. D. Spencer, J. Phys. Chem. B, 2000, 104, 3298-3309.

38 W. G. Zijlstra and A. Buursma, Comp. Biochem. Physiol., Part B: Biochem. Mol. Biol., 
1997, 118, 743-749.

39 M. J. York-Duran, M. Godoy-Gallardo, M. M. T. Jansman and L. Hosta-Rigau, Biomater. Sci., 2019, 7, 4813-4826.

40 X. Liu, M. M. T. Jansman, P. W. Thulstrup, A. C. Mendes, I. S. Chronakis and L. HostaRigau, Macromol. Biosci., 2020, 20, 1900293.

41 Y. Chen, V. Lykourinou, C. Vetromile, T. Hoang, L.-J. Ming, R. W. Larsen and S. Ma, J. Am. Chem. Soc., 2012, 134, 13188-13191.

42 I. Lalezari, P. Lalezari, C. Poyart, M. Marden, J. Kister, B. Bohn, G. Fermi and M. F. Perutz, Biochemistry, 1990, 29, 1515-1523.

43 M. Danaei, M. Dehghankhold, S. Ataei, F. Hasanzadeh Davarani, R. Javanmard, A. Dokhani, S. Khorasani and M. R. Mozafari, Pharmaceutics, 2018, 10, 57.

44 M. M. T. Jansman and L. Hosta-Rigau, Adv. Colloid Interface Sci., 2018, 260, 65-84.

45 J. Park, D. Feng and H.-C. Zhou, J. Am. Chem. Soc., 2015, 137, 1663-1672.

46 J. Tu, J. Bussmann, G. Du, Y. Gao, J. A. Bouwstra and A. Kros, Int. J. Pharm., 2018, 543, $169-178$.

47 J. Hu, Q. Wang, Y. Wang, G. You, P. Li, L. Zhao and H. Zhou, J. Colloid Interface Sci., 2020, 571, 326-336.

48 P.-A. A. Oldenborg, T. Harada, D. A. Christian, D. A. Pantano, R. K. Tsai, D. E. Discher, A. Zheleznyak, Y.-F. F. Fang, C. F. F. Lagenaur, H. D. D. Gresham and F. P. P. Lindberg, Science, 2000, 288, 2051-4.

49 R. H. Fang, A. V. Kroll, W. Gao and L. Zhang, Adv. Mater., 2018, 30, 1706759.

50 Q. Jiang, Z. Luo, Y. Men, P. Yang, H. Peng, R. Guo, Y. Tian, Z. Pang and W. Yang, Biomaterials, 2017, 143, 29-45.

51 J. Xie, Q. Shen, K. Huang, T. Zheng, L. Cheng, Z. Zhang, Y. Yu, G. Liao, X. Wang and C. 
Li, ACS Nano, 2019, 13, 5268-5277.

52 J. Cui, Y. Wang, A. Postma, J. Hao, L. Hosta-Rigau and F. Caruso, Adv. Funct. Mater., 2010, 20, 1625-1631.

53 J. Cui, Y. Yan, G. K. Such, K. Liang, C. J. Ochs, A. Postma and F. Caruso, Biomacromolecules, 2012, 13, 2225-2228.

54 H. Lee, S. M. Dellatore, W. M. Miller and P. B. Messersmith, Science (80-. )., 2007, 318, 426-430.

55 O. Baidukova, Q. Wang, S. Chaiwaree, D. Freyer, A. Prapan, R. Georgieva, L. Zhao and H. Bäumler, Artif. Cells, Nanomedicine, Biotechnol., 2018, 46, S693-S701.

56 Q. Wang, R. Zhang, G. You, J. Hu, P. Li, Y. Wang, J. Zhang, Y. Wu, L. Zhao and H. Zhou, Artif. Cells, Nanomedicine, Biotechnol., 2018, 46, 484-492.

57 C. Yu, X. Huang, D. Qian, F. Han, L. Xu, Y. Tang, N. Bao and H. Gu, Chem. Commun., 2018, 54, 4136-4139.

58 L. Hosta-Rigau, M. J. York-Duran, T. S. Kang and B. Städler, Adv. Funct. Mater., 2015, 25, 3860-3869.

59 R. H. Fang, C. M. J. Hu and L. Zhang, Expert Opin. Biol. Ther., 2012, 12, 385-389.

60 B. T. Luk, C.-M. Jack Hu, R. H. Fang, D. Dehaini, C. Carpenter, W. Gao and L. Zhang, Nanoscale, 2013, 6, 2730-2737.

61 B. Maxit, tc, 2009, 10, 6s.

62 R. van der Westen, L. Hosta-Rigau, D. S. Sutherland, K. N. Goldie, F. Albericio, A. Postma and B. Städler, Biointerphases, 2012, 7, 8.

63 L. Thiele, J. E. Diederichs, R. Reszka, H. P. Merkle and E. Walter, Biomaterials, 2003, 24, 1409-1418.

64 N. Bertrand and J.-C. C. Leroux, J. Control. Release, 2012, 161, 152-163. 
65 S. Pasche, J. Vörös, H. J. Griesser, N. D. Spencer and M. Textor, J. Phys. Chem. B, 2005, 109, 17545-17552.

66 B. M. B. M. Teo, R. Van Der Westen, L. Hosta-Rigau and B. Städler, Biochim. Biophys. Acta - Gen. Subj., 2013, 1830, 4838-4847.

67 M. P. Calatayud, B. Sanz, V. Raffa, C. Riggio, M. R. Ibarra and G. F. Goya, Biomaterials, 2014, 35, 6389-6399.

68 R. Luo, L. Tang, S. Zhong, Z. Yang, J. Wang, Y. Weng, Q. Tu, C. Jiang and N. Huang, ACS Appl. Mater. Interfaces, 2013, 5, 1704-1714.

69 M. Lu, C. Zhao, Q. Wang, G. You, Y. Wang, H. Deng, G. Chen, S. Xia, J. Zhao, B. Wang, X. Li, L. Shao, Y. Wu, L. Zhao and H. Zhou, Colloids Surf., B, 2016, 139, 171-179. 


\title{
Haemoglobin-Loaded Metal Organic Framework- Based Nanoparticles Camouflaged With a Red Blood Cell Membrane as Potential Oxygen Delivery
} Systems

Xiaoli Liu, ${ }^{\dagger}$ Michelle M. T. Jansman, ${ }^{\dagger}$ and Leticia Hosta-Rigau ${ }^{\dagger, *}$

$\dagger$ DTU Health Tech, Centre for Nanomedicine and Theranostics, Technical University of Denmark, Nils Koppels Allé, B423, 2800 Kgs. Lyngby, Denmark

KEYWORDS

Haemoglobin-based oxygen carriers; Metal-organic framework, Poly(dopamine), Red blood cell membrane; Stealth Coatings; Surface modification

\begin{abstract}
Transfusion of donor red blood cells (RBCs) is a crucial methodology required for the treatment of acute trauma, anaemia or for surgical procedures. Due to the many limitations of donor blood, numerous strategies have been explored to develop haemoglobin $(\mathrm{Hb})$-based oxygen carriers to be used as oxygen delivery systems. However, since free Hb suffers from a lack of stability and short circulation times in blood, an encapsulation platform is needed. Herein, we entrap Hb within a type of metal organic framework (MOF)-based nanoparticles (MOF-NPs). By doing so, Hb is protected from misfolding and denaturation, which is a crucial aspect to preserve its excellent oxygen binding and releasing properties. Furthermore, the porous structure of MOF-NPs allows for the diffusion of small molecules (i.e., oxygen) in and out of the system. Our results show that the Hb-loaded MOF-NPs (MOFHb-NPs) are monodisperse and show a small hydrodynamic diameter of $\sim 220 \mathrm{~nm}$. Importantly, the structure and functionality of encapsulated $\mathrm{Hb}$ are well
\end{abstract}


preserved. To achieve long circulation in the blood stream, we functionalize $\mathrm{MOF}^{\mathrm{Hb}}$-NPs with naturally derived RBC-membranes and compared the stealth properties of the membrane-coated $\mathrm{MOF}^{\mathrm{Hb}}$-NPs to our previously reported PEGylation strategy. Protein adsorption and cell uptake studies demonstrate that both coatings are able to significantly decrease the adsorption of proteins and also diminish their uptake by macrophages and endothelial cells. Furthermore, both types of coatings render $\mathrm{MOF}^{\mathrm{Hb}}-\mathrm{NPs}$ with good biocompatibility and oxygen binding and releasing properties. Overall, this study presents a novel oxygen carrier system which might find applications as a blood surrogate.

\section{Introduction}

Transfusion of packed red blood cells (RBCs) is a crucial clinical procedure widely applied during surgery, natural or man-made disasters (e.g., plane crashes, earthquakes) or battlefield wounds. ${ }^{1}$ Additionally, RBCs transfusions are also required for the treatment of anaemia, haemoglobin $(\mathrm{Hb})$ disorders or for patients receiving antitumor therapy. ${ }^{2,3}$ However, the transfusion of donor RBCs often encounters several difficulties which include risk of bacterial or virus transmission (e.g., HIV, hepatitis or malaria), severe shortage of blood inventory due to RBCs short half-life or logistical constraints. Furthermore, despite rigorous typing and cross matching, mismatched transfusions still occur. Therefore, the development of blood surrogates free from the abovementioned risks has attracted a great deal of attention in the fields of biotechnology and biomedicine.

Being $\mathrm{Hb}$ the main component of RBCs, accounting for their high oxygen-carrying capacity, a lot of effort has been devoted to the development of Hb-based oxygen carriers (HBOCs). However, despite Hb's excellent ability to transport and transfer oxygen and re-stablish oxygen homeostasis in tissues, free $\mathrm{Hb}$ molecules cannot be administered as blood substitutes. Outside RBCs, the $\mathrm{Hb}$ tetramer breaks down into dimers, which results in short circulation times but also in severe adverse effects including renal toxicity, vasoconstriction and haemorrhagic lesions. ${ }^{4,5}$

Therefore, in recent years, several strategies for encapsulating $\mathrm{Hb}$ within different platforms have been explored. Such approaches could provide a suitable environment to maintain Hb's functionality while, at the same time, preventing the dissociation of the Hb tetramer. Among 
others, $\mathrm{Hb}$ has been encapsulated within liposomes, ${ }^{6,7}$ polymersomes ${ }^{8}$ or polymer particles. ${ }^{9,10}$ However, despite the tremendous progress achieved, it is still a challenge to entrap $\mathrm{Hb}$ within a well-defined structure preserving its secondary structure while also enabling the free diffusion of small molecules (i.e., oxygen but also small reducing agents) in an out of the system. Furthermore, difficulties in prolonging their circulation times in the bloodstream are also hampering the transition of these $\mathrm{Hb}$ encapsulating platforms into the clinic. ${ }^{11}$

Metal-organic frameworks (MOFs), which consist of metal ions or clusters connected by organic linkers, are new type of self-assembled materials displaying several unique properties. ${ }^{12-14}$ They feature well-defined, crystalline pore structures with large surface areas and structural flexibility, since they can be fine-tuned by the right choice of organic linkers and metallic compounds. Recently, MOF-based nanoparticles (MOF-NPs), have been widely employed for biomedical applications ${ }^{15-17}$ as a result of their ability to encapsulate different types of biomolecules including vaccines, ${ }^{18}$ enzymes ${ }^{19,20}$ and DNA. ${ }^{21}$ MOF-NPs are also particularly well suited to construct HBOCs. Due to their high void space, they make it possible to encapsulate large amounts of cargo (i.e., $\mathrm{Hb}$ ) which is required to fulfil the high demands of oxygen transport. Additionally, Hb's secondary structure will be preserved since, by matching the pore size, they allow to encapsulate single $\mathrm{Hb}$ molecules within predefined cavities. This is an important aspect since, misfolding or denaturation, will alter Hb's excellent oxygen binding and releasing properties. Moreover, MOFNPs also facilitate the selective transport of small molecules (i.e., $\mathrm{O}_{2}$ but also reducing agents present in plasma) through the protective porous coating. Due to these advantages, Hb has been recently conjugated onto the surface of MOF-NPs by post-modification ${ }^{22}$ and encapsulated within the cages of the so-called zeolitic imidazole framework-8 MOF-NPs. ${ }^{11}$ Herein, we employ the water-stable porous coordination network (PCN)-333(Al) MOF which is based on trivalent metal species (i.e., $\mathrm{Al}^{3+}$ ) and exhibits one of the highest void volumes and largest cages. ${ }^{23}$ Taking into account Hb's large size $(6 \times 6 \times 5 \mathrm{~nm}),{ }^{24} \mathrm{PCN}-333(\mathrm{Al})$ is one of the few reported MOFs that can act as single-molecule traps for $\mathrm{Hb}$, thus minimizing $\mathrm{Hb}$ 's aggregation and leaching. ${ }^{23}$

Since biological RBCs can survive for up to 120 days within the blood stream, ${ }^{25}$ achieving long in vivo circulation times is another key feature when developing oxygen-carriers. Once in the blood stream, uptake by the mononuclear phagocyte system (MPS) is one of the major hurdles that almost all intravenously administered carriers need to overcome. ${ }^{26,27}$ The functionalization of 
nanosized carriers with polyethylene glycol (PEG), is currently considered the gold standard approach to extend their circulation lifetimes. However, PEG immunogenicity is an increasingly recognized issue. The administration of PEGylated drugs or nanoparticles can lead to the production of anti-PEG antibodies, their subsequent recognition by the MPS in the spleen and liver and their following clearance from the circulation. ${ }^{28}$ Thus, alternatives to PEGylation to prolong the nanocarriers circulation time are highly sought after. ${ }^{28,29}$

Biological RBCs are nature's long-circulating vehicles, and their limited immune cell clearance is mainly governed by their cell membranes where a collection of "self-marker" biomolecules are embedded into their lipid bilayer. ${ }^{30,31}$ Thus, a powerful emerging strategy to improve biocompatibility by reducing immunogenicity, is the coating of the nanocarriers by cellular membranes extracted from biological RBCs. ${ }^{32-35}$ Thus, in this work, we i) encapsulate Hb within PCN-333(Al) MOF-based NPs and evaluate the preservation of Hb's structure and functionality, ii) camouflage the resulting Hb-loaded MOF-NPs with biomimetic and naturally derived RBCmembranes (RBC-Ms), iii) evaluate the stealth properties of the RBC-M coating in terms of protein adsorption and cell uptake studies, iv) compare the RBC-M coating to our previously reported PEGylation strategy and, finally, v) confirm preservation oxygen-binding and releasing properties of the coated Hb-loaded MOF-NPs. With such a study, we hope to provide a new kind of oxygen carriers with a high $\mathrm{Hb}$ loading capacity and potential long in vivo circulation to fulfil the demand of oxygen supply in biomedical applications.

\section{Materials and methods}

\subsection{Materials}

Fresh bovine blood (Product No. 77667) was obtained from SSI Diagnostica A/S (Hillerød, Denmark). Human blood was withdrawn from healthy donors in DTU-Health Technology at University of Denmark (Kongens Lyngby, Denmark). The blood withdrawing was performed following approval and in accordance with the guidelines from the Regional Research Ethics Committees for the Capital Region of Denmark. All donors provided their informed consent to 
participate prior collection of blood samples. All the operators received appropriate training before the handling of biological materials used in this study.

Sodium chloride $(\mathrm{NaCl})$, toluene, acetone, dopamine (DA), $N, N^{\prime}$-Dimethylformamide (DMF), aluminum chloride hexahydrate $\left(\mathrm{AlCl}_{3} \cdot 6 \mathrm{H}_{2} \mathrm{O}\right)$, trifluoroacetic acid (TFA), poly- $L$-lysine (PLL) (Mw 15 - $30 \mathrm{kDa}$ ), 4-(2-hydroxyethyl) piperazine-1-ethane-sulfonic acid (HEPES), HEPES buffer solution (1M, isotonic), phosphate buffered saline (PBS), biotin-N-hydroxysuccinimide (biotinNHS), streptavidin, bovine serum albumin (BSA), fluorescein isothiocyanate (FITC), FITClabelled immunoglobulin G (IgG-FITC), sodium dithionite (SDT), Dulbecco's Modified Eagle's Medium-high glucose (DMEM D5796), penicillin/streptomycin, fetal bovine serum (FBS), trypsin and the human umbilical vein endothelial cell line (HUVEC) were purchased from Merck Life Science A/S (Søborg, Denmark). Polycarbonate porous membrane $(1 \mu \mathrm{m})$ was purchased from GE Healthcare Life Sciences $\quad$ (Brondby, 1,1'-dioctadecyl-3,3,3',3'-tetramethylindodicarbocyanine perchlorate (DiD) was purchased from Invitrogen A/S (Taastrup, Denmark). 4,4',4''-s-triazine-2,4,6-triyl-tribenzoic acid ( $\mathrm{H}_{3} \mathrm{TATB}$ ) was purchased from ChemScene LLC (Monmouth Junction, NJ, USA). $\alpha$-Methoxy- $\omega$-carboxylic acid succinimidyl ester poly(ethylene glycol) (MeO-PEG-NHS, $\mathrm{Mw}_{\mathrm{PEG}}=2000 \mathrm{Da}$ ) was purchased from Iris Biotech GmbH (Marktredwitz, Germany). Endothelial Cell Medium (ECM) Kit supplemented with 5\% FBS and 1\% endothelial cell growth supplements was purchased from Innoprot (Derio-Biskaia, Spain). PrestoBlue Cell Viability Reagent, and Pierce Bicinchoninic Acid (BCA) Protein Assay Kit were obtained from Thermo Fisher Scientific (Waltham, MA, USA). The macrophage cell line RAW 264.7 was obtained from European Collection of Authenticated Culture Collections (ECACC, Wiltshire, UK).

HEPES buffer is composed of 10 mM HEPES ( $\mathrm{pH} 7.4$ and $\mathrm{pH} 8.5$ ) and was prepared with ultrapure water (Milli-Q (MQ), gradient A 10 system, TOC $<4$ ppb, resistance $18 \mathrm{MV} \mathrm{cm}$, EMD Millipore, USA). HEPES buffer at pH 7.4 was used in all the studies, unless otherwise clarified. The prepared HEPES buffer solutions were used in all the studies except when working with cells were an isotonic HEPES buffer solution from Merck Life Science was used.

BSA was fluorescently labelled with FITC (BSA-FITC) as previously reported. ${ }^{36}$ Briefly, a FITC solution ( $3.7 \mathrm{mg}$ in $300 \mu \mathrm{L}$ DMSO) was added to a BSA solution (30 mg in $6 \mathrm{~mL} 0.05 \mathrm{M}$ 
$\mathrm{NaHCO}_{3}, \mathrm{pH} 10$ ) in a dropwise fashion. After overnight incubation at room temperature (RT), the excess of FITC was thoroughly removed by dialysis against MQ water for two days. The collected solution was freeze-dried for future use. Hb was fluorescently labelled with FITC (Hb-FITC) following the same aforementioned protocol.

Poly(L-lysine (15-30 kDa))-graft[2.0]-poly(ethylene glycol (2 kDa)) (PLL-g-PEG) was synthetized following a reported procedure. ${ }^{37}$ Briefly, a MeO-PEG-NHS solution $(0.038 \mathrm{mmol}$ in $4 \mathrm{~mL}$ cold HEPES) was added to a PLL solution ( $0.143 \mathrm{mmol}$ in $500 \mu \mathrm{L}$ cold HEPES). The reaction was allowed to proceed for $4 \mathrm{~h}$ at $4{ }^{\circ} \mathrm{C}$ under constant stirring. Finally, the reaction mixture was dialyzed for 2 days against MQ water followed by freeze-drying. The NMR analysis showed a PEG grafting ratio of $50 \%$, indicating that $50 \%$ of the lysine monomers were modified with PEG. (Figure S1, Supporting Information).

\subsection{Hb extraction from bovine blood}

$\mathrm{Hb}$ was extracted from fresh bovine blood by hypotonic haemolysis following a previous study. ${ }^{38}$ Briefly, bovine RBCs were washed with an isotonic saline solution, i.e., $0.9 \% \mathrm{NaCl}(3 \times$, $15 \mathrm{~min}, 1500 \mathrm{~g}$ ). Next, the bovine RBCs were mixed with MQ water and toluene at a 1:1:0.4 ratio. Following thorough vortexing, the suspension was stored overnight at $4{ }^{\circ} \mathrm{C}$. The suspension was then spun down $(20 \mathrm{~min}, 8000 \mathrm{~g}$ ) and, following filtration through ash-free filtration paper, the stroma-free $\mathrm{Hb}$ was collected and stored at $-80{ }^{\circ} \mathrm{C}$ for future use.

\subsection{Preparation and characterization of Hb-loaded MOF-NPs (MOF $\left.{ }^{\mathrm{Hb}}-\mathrm{NPs}\right)$}

2.3.1. Preparation of MOF-NPs. $12 \mathrm{~mL}$ of an $\mathrm{AlCl}_{3} \cdot 6 \mathrm{H}_{2} \mathrm{O}$ solution ( $3 \mathrm{mg} \mathrm{mL}{ }^{-1}$ in DMF), $12 \mathrm{~mL}$ of a $\mathrm{H}_{3}$ TATB solution ( $1 \mathrm{mg} \mathrm{mL}^{-1}$ in DMF) and $40 \mu \mathrm{L}$ TFA (HPLC grade, purity $>99 \%$ ), were mixed and incubated at $95{ }^{\circ} \mathrm{C}$ for $24 \mathrm{~h}$. The resulting MOF-NPs were collected and washed in DMF $(3 \times, 20 \mathrm{~min}, 15000 \mathrm{~g})$, acetone $(3 \times, 20 \mathrm{~min}, 15000 \mathrm{~g})$ and dried in a vacuum oven for future use.

2.3.2. Preparation of $\mathbf{M O F}^{\mathbf{H b}}$-NPs. The extracted bovine $\mathrm{Hb}$ was dissolved in MQ water at a concentration of $100 \mathrm{mg} \mathrm{mL}^{-1}$. Next, the MOF-NPs were re-suspended in MQ water at a concentration of $1 \mathrm{mg} \mathrm{mL}^{-1}$. Different amounts (i.e., 2, 5, 10, 20, 30, 40 and $60 \mu \mathrm{L}$ ) of Hb solutions at the concentration of $100 \mathrm{mg} \mathrm{mL}^{-1}$ were added to $1 \mathrm{~mL}$ of the MOF-NPs suspension under 
continuous magnetic stirring at $800 \mathrm{rpm}$ for $2 \mathrm{~h}$. Finally, the samples were collected and washed in MQ water $(3 \times, 20 \mathrm{~min}, 15000 \mathrm{~g})$. The $\mathrm{Hb}$ entrapment efficiency (EE) and drug loading (DL) were determined using a BCA assay. The EE was calculated as follows: \% $\mathrm{EE}=$ (encapsulated $\mathrm{Hb}$ amount / initial amount of $\mathrm{Hb}) \times 100$. The DL was calculated as follows: $\% \mathrm{DL}=($ encapsulated $\mathrm{Hb}$ amount / total amount of $\left.\mathrm{MOF}^{\mathrm{Hb}}-\mathrm{NPs}\right) \times 100$. The $\mathrm{MOF}^{\mathrm{Hb}}-\mathrm{NPs}$ with the optimal EE and DL were chosen for the following studies.

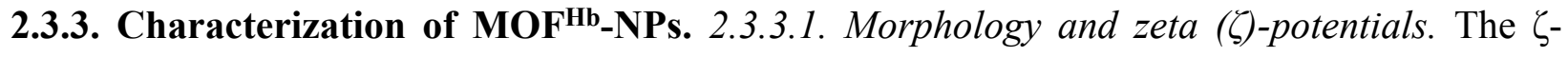
potentials of the $\mathrm{MOF}^{\mathrm{Hb}}-\mathrm{NPs}$ prepared with different initial $\mathrm{Hb}$ amounts were determined using a Zetasizer nano ZS instrument (Malvern Instruments Ltd., UK).

Scanning electron microscopy (SEM, Hitachi High-Tech HITACHI, USA) was employed to evaluate the morphology of both MOF-NPs and $\mathrm{MOF}^{\mathrm{Hb}}-\mathrm{NPs}$ with the optimal EE and DL. A drop of test sample was dried on a glass slide and mounted on a metal stub with double-sided adhesive tape. Next, the samples were coated under vacuum with gold prior to observation (Sputter Coater 208 HR, Cressington Scientific, UK). The samples were imaged at an operating voltage of $15 \mathrm{keV}$.

2.3.3.2. Fourier-transform infrared (FTIR) spectroscopy. FTIR analysis was performed using a Perkin Elmer Spectrum 100 FT-IR spectrometer (Perkin Elmer Inc., Wellesley, MA) under ambient conditions. The spectra were collected with a resolution of $4 \mathrm{~cm}^{-1}$ within the wavelength range of 400 to $4000 \mathrm{~cm}^{-1}$. Five scans per sample were measured.

2.3.3.3. UV-vis spectra of oxygenation and deoxygenation of $H b$. The UV-Vis spectra of fresh $\mathrm{Hb}$ and $\mathrm{MOF}^{\mathrm{Hb}}$-NPs dissolved/suspended in HEPES buffer were measured on a UV-2600 UV-vis Spectrophotometer (Shimadzu, Japan) in the wavelength range of 350 - $650 \mathrm{~nm}$. The deoxygenated $\mathrm{Hb}\left(\right.$ deoxy-Hb) was obtained by purging the test sample with nitrogen gas $\left(\mathrm{N}_{2}\right)$ for 10 min followed by recording the UV-vis spectrum.

\subsection{Stability over time}

The size stability of MOF-NPs and MOF $\mathrm{Hb}_{-} \mathrm{NPs}$ stored at $4{ }^{\circ} \mathrm{C}$ was determined measuring the hydrodynamic diameter by dynamic light scattering (DLS) using the Zetasizer nano ZS instrument at pre-designed time intervals (i.e. 1, 3, 5, 7, 10 and 14 days). The release behaviour of $\mathrm{Hb}$ from the $\mathrm{MOF}^{\mathrm{Hb}}$-NPs was also studied at $4{ }^{\circ} \mathrm{C}$. For that, aliquots of $1 \mathrm{mg} \mathrm{mL}^{-1}$ suspensions of $\mathrm{MOF}^{\mathrm{Hb}}$ 
NPs were prepared and stored at $4{ }^{\circ} \mathrm{C}$. At each pre-defined time point, 3 aliquots were taken out and the released amount of $\mathrm{Hb}$ in the supernatant following centrifugation (10 min, $15000 \mathrm{~g}$ ) was evaluated using a BCA assay.

\subsection{Surface modification with stealth coatings}

2.5.1. Polydopamine (PDA) coating. The as-prepared $\mathrm{MOF}^{\mathrm{Hb}}-\mathrm{NPs}$ (fabricated from $1 \mathrm{mg} \mathrm{MOF}$ NPs as starting material) were re-suspended in 0.5 mL HEPES buffer ( $\mathrm{pH} 8.5$ ) and mixed with 0.5 $\mathrm{mL}$ of a DA solution (10 mg mL $\mathrm{m}^{-1}$ in HEPES buffer, $\left.\mathrm{pH} 8.5\right) .{ }^{39,40}$ The mixture was rotated for $4 \mathrm{~h}$ at the speed of $40 \mathrm{rpm}$ at RT followed by washing in MQ water $(2 \times, 10 \mathrm{~min}, 15000 \mathrm{~g})$ to obtain PDA coated $\mathrm{MOF}^{\mathrm{Hb}}-\mathrm{NPs}\left(\mathrm{MOF}^{\mathrm{Hb}} / \mathrm{PDA}-\mathrm{NPs}\right)$.

2.5.2. PEGylation. To obtain PEGylated carriers (MOFHb/PEG-NPs), MOFHb/PDA-NPs (prepared from $1 \mathrm{mg}$ of MOF-NPs as starting material) were re-suspended in $0.5 \mathrm{~mL}$ HEPES buffer and mixed with $0.5 \mathrm{~mL}$ of a PLL- $g$-PEG solution ( $2 \mathrm{mg} \mathrm{mL}^{-1}$ in HEPES buffer). The mixture was rotated for $1 \mathrm{~h}$ at the speed of $40 \mathrm{rpm}$ at RT followed by washing with HEPES buffer $(2 \times, 20 \mathrm{~min}$, $15000 \mathrm{~g}$ ). The polydispersity index (PDI) and $\zeta$-potentials of the different NPs (i.e., MOF-NPs, $\mathrm{MOF}^{\mathrm{Hb}}$-NPs, $\mathrm{MOF}^{\mathrm{Hb}} / \mathrm{PDA}-\mathrm{NPs}$ and $\mathrm{MOF}^{\mathrm{Hb}} / \mathrm{PEG}-\mathrm{NPs}$ ) were determined employing the Zetasizer nano ZS instrument.

2.5.3. RBC-M coating. 2.5.3.1. Extraction of RBC-Ms from human blood. The RBC-M were isolated from human blood according to a previous study. ${ }^{33}$ Whole human blood was freshly collected from healthy donors. The whole blood was then spun down $\left(10 \mathrm{~min}, 1500 \mathrm{~g}, 4{ }^{\circ} \mathrm{C}\right)$ to remove the serum and the buffy coat and the resulting RBCs were then washed in ice-cold PBS (3 $\times, 15 \mathrm{~min}, 1500 \mathrm{~g}$ ). The washed RBCs were then subjected to a hypotonic medium treatment (PBS:MQ at a 1:4 v/v ratio on ice bath, $30 \mathrm{~min}$ ) for haemolysis at a 1:10 volume ratio to remove the intracellular contents. The supernatant was subsequently spun down $(4 \times, 20 \mathrm{~min}, 15000 \mathrm{~g}$ at $4{ }^{\circ} \mathrm{C}$ ) and the light-pink RBC ghost pellets were collected.

2.5.3.2. Coating with $R B C-M s$. RBC-M-coated $\left.\mathrm{NPs}_{\text {(MOF }} \mathrm{Hb} / \mathrm{M}-\mathrm{NPs}\right)$ were prepared by mixing either $\mathrm{MOF}^{\mathrm{Hb}}-\mathrm{NPs}$ or $\mathrm{MOF}^{\mathrm{Hb}} / \mathrm{PDA}-\mathrm{NPs}$ (prepared from $1 \mathrm{mg}$ of MOF-NPs as starting material and suspended in $1 \mathrm{~mL}$ of HEPES buffer) with RBC-Ms extracted from $400 \mu \mathrm{L}$ blood. The mixture was sonicated for $10 \mathrm{~s}(70 \%$ amplitude, $1 \mathrm{~s} / 1 \mathrm{~s})$ on an ice bath followed by extrusion through $1 \mu \mathrm{m}$ 
polycarbonate porous membrane to facilitate membrane fusion. An Avanti ${ }^{\circledR}$ Mini-Extruder (Avanti Polar Lipids, Inc., AL, USA) was used. Finally, the coated MOFHb/M-NPs were washed with HEPES buffer solution $(3 \times, 20 \mathrm{~min}, 15000 \mathrm{~g})$.

\subsubsection{Evaluation of the RBC-M coating. The RBC-M coating of $\mathrm{MOF}^{\mathrm{Hb}}-\mathrm{NPs}$ or $\mathrm{MOF}$} NPs was evaluated by fluorescence intensity measurements. To do that, the extracted RBC-Ms were first labelled with a lipophilic far-red fluorescent dye DiD (excitation/emission = 644/665 $\mathrm{nm})$ by adding $10 \mu \mathrm{L}$ of the $\mathrm{DiD}$ fluorophore $\left(1 \mathrm{mg} \mathrm{mL}^{-1}\right.$ in DMSO) to $1 \mathrm{~mL}$ of a RBC-M suspension. The fluorescently labelled RBC-Ms $\left(\mathrm{RBC}_{-} \mathrm{M}^{\mathrm{F}}\right)$ were used to coat both $\mathrm{MOF}^{\mathrm{Hb}}-\mathrm{NPs}$ and $\mathrm{MOF}^{\mathrm{Hb}} / \mathrm{PDA}-\mathrm{NPs}$ following the same procedure as described in section 2.5.3.2. The samples were next analysed by measuring the normalized mean fluorescence intensity (nMFI) by flow cytometry (BD Biosciences, Sparks, MD, USA). While untreated MOF $\mathrm{Hb}_{-N P s}$ and MOF ${ }^{\mathrm{Hb}} / \mathrm{PDA}-$ NPs were used as controls, the physical mixtures of $\mathrm{MOF}^{\mathrm{Hb}}-\mathrm{NPs}$ and $\mathrm{MOF}^{\mathrm{Hb}} / \mathrm{PDA}-\mathrm{NPs}$ with RBC$\mathrm{M}^{\mathrm{F}}$, respectively, without sonication and extrusion treatment, were also evaluated by flow cytometry. Each condition was evaluated in at least two independent experiments.

A RBC-M coverage assay was also conducted to identify the amount of RBC-M promoting full coverage of the $\mathrm{MOF}^{\mathrm{Hb}} / \mathrm{PDA}-\mathrm{NPs}$. For that, biotin (BT)-labelled MOF $\mathrm{Hb} / \mathrm{PDA}-\mathrm{NPs}\left(\mathrm{MOF}^{\mathrm{Hb}} / \mathrm{BT}\right.$ NPs) were prepared. Specifically, $200 \mu \mathrm{L}$ of biotin-NHS (BT-NHS, $20 \mathrm{mg} \mathrm{mL}^{-1}$ in DMSO) were added to $\mathrm{MOF}^{\mathrm{Hb}} / \mathrm{PDA}-\mathrm{NPs}$ (prepared from $12 \mathrm{mg}$ of MOF-NPs as starting material re-suspended in $12 \mathrm{~mL}$ of HEPES buffer). The BT-NHS esters reacted with amines on the PDA coating layer forming amide bonds and releasing the NHS groups. After reaction for $1 \mathrm{~h}$ at RT, the un-bound BT-NHS was removed by washing with HEPES buffer $(3 \times, 10 \mathrm{~min}, 15000 \mathrm{~g})$. Next, the BTlabelled $\mathrm{MOF}^{\mathrm{Hb}} / \mathrm{BT}-\mathrm{NPs}$ (prepared from $1 \mathrm{mg} \mathrm{mL}^{-1}$ of MOF-NPs in HEPES as the starting material) were incubated with varying amounts of RBC-Ms (i.e., extracted from 17, 25, 50, 100, 200 and $400 \mu \mathrm{L}$ of whole blood). The RBC-M coverage depending on the amount of added RBCMs, was evaluated by incubating $0.5 \mathrm{~mL}$ of coated $\mathrm{MOF}^{\mathrm{Hb}} / \mathrm{BT} / \mathrm{M}-\mathrm{NPs}$ (prepared from $1 \mathrm{mg} \mathrm{mL}^{-1}$ of MOF-NPs in HEPES as the starting material) with $4 \mu \mathrm{L}$ of streptavidin (Strep) solution (1 mg $\mathrm{mL}^{-1}$ in HEPES) for $30 \mathrm{~min}$. Particle aggregation induced by Strep-BT interactions was monitored by DLS using the Zetasizer nano ZS instrument. As controls, the corresponding RBC-M coated $\mathrm{MOF}^{\mathrm{Hb}}$ /BT-NPs without Strep addition were considered. Each condition was evaluated in at least two independent experiments. 


\subsection{Evaluation of the stealth coatings}

2.6.1. Protein adsorption studies. The stealth properties depending on the surface coatings (i.e., PDA, PEG and RBC-M) were assessed in terms of protein adsorption. Suspensions of $\mathrm{MOF}^{\mathrm{Hb}} / \mathrm{PDA}-\mathrm{NPs}, \mathrm{MOF}{ }^{\mathrm{Hb}} / \mathrm{PEG}-\mathrm{NPs}$ and $\mathrm{MOF}^{\mathrm{Hb}} / \mathrm{M}-\mathrm{NPs}$ displaying 100000 events $\mu \mathrm{L}^{-1}$ (as measured by flow cytometry), were incubated in $200 \mu \mathrm{L}$ of an IgG-FITC or BSA-FITC solution (0.5 mg mL $\mathrm{m}^{-1}$ in HEPES) at $37{ }^{\circ} \mathrm{C}$ for $4 \mathrm{~h}$ under constant shaking using a thermo-shaker (Grant Bio PHMT-PSC18 thermo-shaker, Grant Instruments Ltd, United Kingdom) at the speed of 1400 rpm. After the incubation time, the samples were washed in HEPES $(2 \times, 5 \mathrm{~min}, 15000 \mathrm{~g})$ to remove the unbound proteins. The MFI due to the adsorbed proteins onto the NPs was analysed by flow cytometry (excitation/emission $=488 / 530 \mathrm{~nm}$ ). At least 20000 events were analysed in two independent experiments.

2.6.2. Cell uptake studies. 2.6.2.1. Cell culture. DMEM cell culture medium supplemented with $10 \%(\mathrm{v} / \mathrm{v}) \mathrm{FBS}, 1 \%(\mathrm{v} / \mathrm{v})$ penicillin/streptomycin $\left(10000 \mathrm{U} \mathrm{mL}^{-1}\right.$ and $10 \mu \mathrm{g} \mathrm{m}^{-1}$, respectively) was used for culturing the mouse macrophage Raw 264.7 cell line. ECM cell culture medium supplemented with $5 \%(\mathrm{v} / \mathrm{v}) \mathrm{FBS}, 1 \%(\mathrm{v} / \mathrm{v})$ penicillin/streptomycin $\left(10000 \mathrm{U} \mathrm{mL}^{-1}\right.$ and $10 \mu \mathrm{g}$ $\mathrm{mL}^{-1}$, respectively) and $1 \%(\mathrm{v} / \mathrm{v})$ endothelial cell growth supplements was used for culturing the endothelial HUVEC cell line. All the cells were cultured in T75 flasks in a humidified incubator with $5 \% \mathrm{CO}_{2}$ supply at $37{ }^{\circ} \mathrm{C}$. The cell media was exchanged 2 - 3 times per week and the cells were sub-cultured when reaching $\sim 80 \%$ confluence. RAW 264.7 cells were detached from the culture flask using a cell scraper while HUVEC cells were detached by treatment with trypsin. Both RAW 264.7 and HUVEC cells were re-suspended in fresh cell media and added into new T75 culture flasks with appropriate amounts (a subcultivation ratio of 1:5 was used for RAW 264.7 cells and a ratio of 1:3 was used for HUVEC cells). Only cells between passages 5 and 18 (for RAW 264.7) and between passages 3 and 14 (for HUVEC) were used in all experiments.

2.6.2.2. Cell uptake/association. For cell uptake assays, 24-well plates were used and the RAW 264.7 and HUVEC cells were seeded in $1 \mathrm{~mL}$ of full cell media at a density of 180000 and 100 000 cells per well, respectively, and allowed to attach for $24 \mathrm{~h}$. Fluorescently labelled MOF $\mathrm{Hb}_{-} \mathrm{NPs}$ (MOF ${ }^{\mathrm{Hb}-F I T C}-\mathrm{NPs}$ ) were prepared using FITC-Hb instead of $\mathrm{Hb}$ following the same protocol as

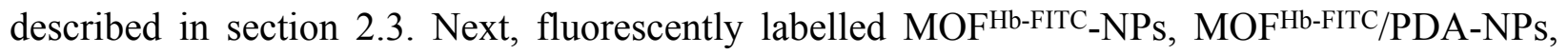


MOFHb-FITC/PEG-NPs or MOFHb-FITC/M-NPs were added to the different wells for $4 \mathrm{~h}$ at $37^{\circ} \mathrm{C}$ and $5 \% \mathrm{CO}_{2}$. A ratio of 100:1 of NPs to cells was used. After incubation, the cells were washed in PBS $(2 \times)$ and detached from the wells employing a cell scrapper (for RAW 264.7) or trypsin (for HUVEC, $100 \mu \mathrm{L}$ per well) and then collected by centrifugation (10 min, $300 \mathrm{~g})$. The cell uptake/association of the different NPs was evaluated by flow cytometry. The cellular uptake efficiency (CUE), which is determined as the percentage of cells with a mean fluorescence intensity higher than the auto fluorescence level of the cells, was assessed. Cells alone were used as controls. At least 5000 events were analysed in each running and each condition was measured in triplicate. The fluorescence intensity (FI) of the FITC-labelled NPs extracted from the same amount of cells was measured using a TECAN Spark multimode plate reader (Tecan Group Ltd., Maennendorf, Switzerland). In brief, the cells were diluted to the same amounts and then sonicated in an ice bath for $10 \mathrm{~s}(70 \%, 1 \mathrm{~s} / 1 \mathrm{~s})$. The resulting cell fragments were separated from the released NPs by spinning down the suspension $\left(5 \mathrm{~min}, 8000 \mathrm{~g}\right.$ ) at $4^{\circ} \mathrm{C}$. Finally, $200 \mu \mathrm{L}$ of the supernatants were transferred to a black 96-well plate and the FI was measured using the plate reader (excitation/emission $=490 / 525 \mathrm{~nm}$ ) and normalized $(\mathrm{nFI})$ to the FI of the cells incubated with MOFHb-FITC-NPs. Each condition was evaluated in at least three independent experiments.

\subsection{Biocompatibility studies}

2.7.1. Cell viability. The cell viability after the cell uptake study was evaluated in 96 -well plates. Cell densities of 30000 and 15000 cells per well for RAW 264.7 and HUVEC cells, respectively, in $200 \mu \mathrm{L}$ of full cell media were employed. After attachment for $24 \mathrm{~h}$, the cells were washed in PBS $(2 \times, 200 \mu \mathrm{L})$ and $200 \mu \mathrm{L}$ of the different NPs (i.e., MOF-NPs, MOF ${ }^{H b}-N P s, M^{-} F^{H b} / P^{-}$ANPs, MOF ${ }^{\mathrm{Hb}} / \mathrm{PEG}-\mathrm{NPs}$ and $\mathrm{MOF}^{\mathrm{Hb}} / \mathrm{M}-\mathrm{NPs}$ ) were added to the different wells at the same ratio used for cell uptake study (i.e., ratio of 100:1 of NPs to cells). After $4 \mathrm{~h}$ incubation, the cells were washed carefully in PBS $(3 \times, 200 \mu \mathrm{L})$ and $100 \mu \mathrm{L}$ of PrestoBlue solution $(10 \% \mathrm{v} / \mathrm{v}$ in fresh full cell media) was added to each well. Following incubation for $1 \mathrm{~h}$ at $37{ }^{\circ} \mathrm{C}$ and $5 \% \mathrm{CO}_{2}, 95 \mu \mathrm{L}$ of each supernatant were transferred to a black 96-well plate and analysed using the plate reader $($ excitation/emission $=535 / 615 \mathrm{~nm})$. Cells only were used as the positive control and PrestoBlue containing cell media only was used as the negative control. The cell viability was calculated as follows: \% cell viability $=($ experimental value - negative control value $) /($ positive control value 
- negative control value) $\times 100$. Each condition was evaluated in triplicate in at least two independent experiments.

2.7.2. Haemolysis rate. The blood compatibility of the NPs depending on the surface coating (i.e., MOF-NPs, MOF ${ }^{\mathrm{Hb}}$-NPs, MOF ${ }^{\mathrm{Hb}} / \mathrm{PDA}-\mathrm{NPs}, \mathrm{MOF}^{\mathrm{Hb}} / \mathrm{PEG}-\mathrm{NPs}$ and $\mathrm{MOF}^{\mathrm{Hb}} / \mathrm{M}-\mathrm{NPs}$ ) was evaluated by conducting a haemolysis rate test. First, whole blood collected from healthy donors was washed as described in section 2.5.3.1. Next, the blood cells collected from $1 \mathrm{~mL}$ of whole blood were suspended in $10 \mathrm{~mL}$ isotonic HEPES buffer. Suspensions of the different NPs were incubated with the diluted blood cells at a ratio of 100:1 (NPs : blood cells) using the thermo-shaker at $250 \mathrm{rpm}$ for $4 \mathrm{~h}$ at $37^{\circ} \mathrm{C}$. After incubation, $200 \mu \mathrm{L}$ of the suspensions were spun-down (10 min, $1000 \mathrm{~g}$ ) and the pellet was collected for morphology observation. For that, the pellets were re-suspended in isotonic HEPES buffer and imaged using an Axiovert 25 inverted microscope (Carl Zeiss A/S, Birkerød, Denmark). $200 \mu \mathrm{L}$ of the suspensions were spun down (10 min, $15000 \mathrm{~g}$ ), the supernatants were collected and the absorbance at $540 \mathrm{~nm}$ was measured using the plate reader. Blood cells in MQ water or isotonic HEPES buffer were used as positive and negative controls, respectively. The haemolysis rate was calculated as follows: \% haemolysis rate $=$ (experimental value - negative control value) / (positive control value - negative control value $) \times 100$. Each condition was evaluated in at least three independent experiments.

\subsection{Functional performance}

The oxygenation and deoxygenation of $\mathrm{Hb}$ within the different MOF-NPs (i.e., $\mathrm{MOF}^{\mathrm{Hb}}-\mathrm{NPs}$, $\mathrm{MOF}^{\mathrm{Hb}} / \mathrm{PDA}, \mathrm{MOF}^{\mathrm{Hb}} / \mathrm{PEG}-\mathrm{NPs}$ and $\mathrm{MOF}^{\mathrm{Hb}} / \mathrm{M}-\mathrm{NPs}$ ) was evaluated by UV-vis spectroscopy (using the $600 \mathrm{UV}$-vis Spectrophotometer) in the wavelength range of 350-650 nm. The NPs were suspended in HEPES buffer and the UV-vis spectra were recorded. Then, $\mathrm{N}_{2}$ was allowed to flow over the samples containing a pinch of oxygen scavenger SDT for $10 \mathrm{~min}$ to obtain NPs loaded with deoxy-Hb, followed by recording the UV-vis spectrum. Next, the NPs were purged with $\mathrm{O}_{2}$ for $10 \mathrm{~min}$, and NPs loaded with oxy-Hb were obtained and their UV-vis spectra recorded. Subsequently, the samples were purged with $\mathrm{N}_{2}$ and $\mathrm{O}_{2}$ and their $\mathrm{UV}$-vis spectra were recorded again. Samples from at least two independent batches have been measured.

\subsection{Statistical analysis}


A Tukey's multiple comparison test $\left(* \mathrm{p} \leq 0.05 ; * * \mathrm{p} \leq 0.001,{ }^{* * *} \mathrm{p} \leq 0.0005, * * * * \mathrm{p} \leq 0.0001\right)$ was employed using GraphPad Prism (8.1.0 (325)) software to assess the statistical differences between the different conditions. A one-way analysis of variance with a confidence level of $95 \%(\alpha=0.005)$ was employed.

\section{Results and discussion}

\subsection{Preparation and characterization of MOF-NPs and $\mathrm{MOF}^{\mathrm{Hb}}-\mathrm{NPs}$}

Water-stable MOFs containing mesocages acting as single molecule traps, show enormous potential to create HBOCs since they afford the encapsulation of single $\mathrm{Hb}$ molecules within individual cages. Such an approach will avoid the dissociation of the $\mathrm{Hb}$ tetramer while also eliminating Hb's aggregation preventing it from misfolding and denaturation. This will, in turn, preserve Hb's excellent oxygen binding and releasing properties. In particular, PCN-333(Al) exhibits large cages $(5.5 \mathrm{~nm})$ fitting the size of individual $\mathrm{Hb}$ molecules $(6 \times 6 \times 5 \mathrm{~nm})$, where the macromolecules could enter the cages while undergoing a partial conformation change. ${ }^{23,41}$ Additionally, PCN-333(Al) also displays one of the highest void volumes among the reported MOFs, which will allow for the encapsulation of the large amounts of $\mathrm{Hb}$ required to meet the high oxygen demands of our body. What is more, PCN-333(Al) also exhibits smaller cages (i.e., medium-sized and small cages of $4.2 \mathrm{~nm}$ and of $1.1 \mathrm{~nm}$, respectively), that will remain empty, thus allowing the diffusion of small compounds (i.e., oxygen but also reducing agents) in and out of the system.

Nano-sized MOF-NPs with a PCN-333(Al) crystalline structure were prepared and Hb was incorporated by post-encapsulation to render $\mathrm{MOF}^{\mathrm{Hb}}-\mathrm{NPs}{ }^{23}$ Bovine $\mathrm{Hb}$, which only requires chloride ion for native operation, was chosen. This will circumvent the complications of allosteric effectors such as 2,3-diphosphoglycerate, which are required for the native operation of human $\mathrm{Hb}^{42}$ In order to identify the optimal EE and DL, MOF-NPs were incubated with increasing amounts of $\mathrm{Hb}$. Figure 1A shows how the EE decreased upon increasing the initial $\mathrm{Hb}$ amounts, ranging from 100\% (when incubating $1 \mathrm{mg}$ of MOF-NPs with $0.2 \mathrm{mg}$ of $\mathrm{Hb}$ ) to $16.3 \%$ (when incubating $1 \mathrm{mg}$ of MOF-NPs with $6 \mathrm{mg}$ of $\mathrm{Hb}$ ). In contrast, the DL increased upon increasing the amount of $\mathrm{Hb}$ until reaching the maximum loading capacity of $\sim 50 \%$ in DL when incubating $1 \mathrm{mg}$ of MOF-NPs with $2 \mathrm{mg}$ of $\mathrm{Hb}$. Therefore, this input amount was chosen for the preparation of 
$\mathrm{MOFHb}_{-} \mathrm{NPs}$ in the subsequent studies. The $\zeta$-potential of the MOFHb-NPs upon increasing the amount of added $\mathrm{Hb}$ was also evaluated (Figure 1B). While empty MOF-NPs displayed a negative $\zeta$-potential $(-10.4 \pm 0.1 \mathrm{mV})$ as a result of the unreacted carboxyl groups of $\mathrm{H}_{3} \mathrm{TATB}$, an increase in $\zeta$-potential could be observed upon increasing the amount of added $\mathrm{Hb}$. A plateau of a $\zeta$-potential of $\sim 12.7 \pm 0.6 \mathrm{mV}$ was reached upon addition of $3 \mathrm{mg}$ of $\mathrm{Hb}$ per $1 \mathrm{mg}$ of MOF-NPs. Due to Hb's isoelectric point of 6.8, the $\mathrm{Hb}$ molecules are positively charged in a MOF-NPs solution ( $\mathrm{pH} \sim 5.6$, Table S1 in Supporting Information) which results on positive $\zeta$-potentials for MOF $\mathrm{Hb}_{-} \mathrm{NPs}_{\text {with }}$ a high DL. Both MOF-NPs and MOF ${ }^{H b}-N P s$ at a DL of 50\% were imaged by SEM in solution. Figure 1C shows that both empty MOF-NPs and $\mathrm{MOF}^{\mathrm{Hb}}-\mathrm{NPs}$ are monodisperse when resuspended in MQ water.

Preservation of Hb's structure is fundamental for oxygen transport. In this study, Hb was loaded into MOF-NPs by post-encapsulation, and only mild stirring was used to assist with the loading. The influence of the processing procedure on Hb's chemical structure was analysed by FTIR spectroscopy and, as expected, Figure 2A shows how the FTIR spectra of native $\mathrm{Hb}$ and $\mathrm{MOF}^{\mathrm{Hb}}$ NPs are almost identical. The two spectra displayed the characteristic peaks at $1650 \mathrm{~cm}^{-1}$ and 1534 $\mathrm{cm}^{-1}$, which represent the typical amide I and amide II bands of proteins and indicate that the chemical structure of $\mathrm{Hb}$ was well preserved after being loaded into MOF-NPs. While the amide I band dominated by the stretching vibrations of the $\mathrm{C}=\mathrm{O}$, shows the information of the backbone conformation and hydrogen bonding; the amide II band derives from in-plane N-H bending and $\mathrm{C}-\mathrm{N}$ stretching vibrations. As expected, the amide I and amide II bands were not present in the spectrum of empty MOF-NPs.

Preservation of $\mathrm{Hb}$ 's functionality following encapsulation to create $\mathrm{MOF}^{\mathrm{Hb}}-\mathrm{NPs}$ was demonstrated by UV-vis spectroscopy (Figure 2B). After preparation, $\mathrm{MOF}^{\mathrm{Hb}}$-NPs exhibited three main peaks at 414, 541, and $578 \mathrm{~nm}$ (solid red line), which are the characteristic absorption peaks of oxygenated $\mathrm{Hb}(\mathrm{oxy}-\mathrm{Hb})$ (dashed red line). After purging with $\mathrm{N}_{2}$, the Soret peak shifted from $414 \mathrm{~nm}$ to $428 \mathrm{~nm}$, the two peaks at 541 and $578 \mathrm{~nm}$ disappeared while the appearance of peak at $564 \mathrm{~nm}$ (solid green line); which are the characteristic peaks for deoxy-Hb in its free form (dashed green line). Such spectral changes following purging with $\mathrm{N}_{2}$ confirm the MOFHb-NPs ability to bind and release oxygen, in a similar manner than native $\mathrm{Hb}$. 


\subsection{Stability over time}

Size stability over prolonged periods of time is an important aspect to consider for storage purposes when developing nanoparticles for biomedical applications, and it is also a central factor related to their circulation behaviour in vivo. Therefore, the stability of $\mathrm{MOF}^{\mathrm{Hb}}-\mathrm{NPs}$ suspensions in MQ water stored at $4{ }^{\circ} \mathrm{C}$ for up to 14 days was studied by measuring their hydrodynamic diameter. Figure 3A shows how the size of empty MOF-NPs slightly increased from $170 \mathrm{~nm}$ to $200 \mathrm{~nm}$ after the whole storage period. In contrast, the size of the loaded $\mathrm{MOF}^{\mathrm{Hb}}-\mathrm{NPs}$ did not exhibit any substantial increase $(\sim 220 \mathrm{~nm})$ after storage for 14 days. Additionally, both MOF-NPs and $\mathrm{MOF}^{\mathrm{Hb}}$-NPs showed good monodispersity with PDI values smaller than 0.2 for the whole studied period, while a PDI of 0.2 or below indicates acceptable monodisperse NPs for medical applications. ${ }^{43}$ Since the leakage of $\mathrm{Hb}$ from HBOCs can lead to renal toxicity or vasoconstriction, amongst others, ${ }^{44} \mathrm{Hb}$ 's cumulative release over time was also evaluated. Figure 3B shows an initial burst release of $\sim 3 \%$ of $\mathrm{Hb}$ at day 2 with no further release up to 14 days. A total cumulative release of $\sim 6 \%$ could be detected after the whole studied period of 28 days. We hypothesize that the initial burst release could correspond to a small portion of $\mathrm{Hb}$ being physically attached onto the surface of $\mathrm{MOF}^{\mathrm{Hb}}-\mathrm{NPs}$, instead of being encapsulated. In contrast, we attribute the slower and more sustained $\mathrm{Hb}$ cumulative release of $\sim 3 \%$ over the last 14 -day period to the dissociation of the $\mathrm{MOF}^{\mathrm{Hb}}$-NPs porous structure, which is induced by the coordination between water molecules and the metal clusters which results in the distortion of the crystal lattices of the MOF structure. ${ }^{45}$ Such a slow leakage from the mesoporous MOF-NPs as compared to other reported HBOCs would result on a pronounced advantage for their in vivo application. As an example, a $\sim 20 \% \mathrm{Hb}$ release was detected in less than 8 days for the recently reported Hb-loaded mesoporous silica NPs. ${ }^{46}$ While, on a different study, a burst release $\sim 10 \% \mathrm{Hb}$ within only two days was recently reported for a HBOCs consisting of co-precipitated microparticles of $\mathrm{Hb}$ and manganese carbonate. ${ }^{47}$

\subsection{Surface modification with stealth coatings}

In order to fulfil the high oxygen demands of our body, successful HBOCs need to achieve long circulation in the bloodstream. However, any intravenously administered nanocarrier will unavoidably experience a highly complex environment inherently adept to recognize and eliminate external elements. Currently, the coating of the nanocarriers with PEG is the gold standard to 
suppress their uptake by the MPS and prolong their blood circulation time. ${ }^{28}$ However, recent observations of immunological responses resulting from the formation of anti-PEG antibodies, have promoted the search for alternatives to PEG. As such, coating with the membranes of RBCs has recently been proposed as a powerful alternative. By means of a surface makeup involving “self-marker" proteins but also glycans and acidic sialyl moieties, biological RBCs avoid immune responses. ${ }^{31,48}$ Thus, several drug-loaded nanocarriers have been successfully coated by RBC-M demonstrating extended circulation times. ${ }^{49-51}$ To develop a long-circulating HBOCs, we coat the as-prepared $\mathrm{MOF}^{\mathrm{Hb}}$-NPs with $\mathrm{RBC}-\mathrm{M}$ and compare this stealth coating to our previously reported PEGylation strategy. ${ }^{36,39}$

3.3.1. PEGylation. The surface modification of the $\mathrm{MOF}^{\mathrm{Hb}}-\mathrm{NPs}$ was assessed by $\zeta_{\text {-potential }}$ measurements. Figure 4 shows a negative $\zeta$-potential of $-17.6 \pm 2.0 \mathrm{mV}$ for MOF-NPs which increased to $13.7 \pm 1.9 \mathrm{mV}$ following Hb's encapsulation. Prior functionalization with PLL-gPEG, a PDA coating was deposited. While PDA coatings have been previously employed for the fabrication of several nanocarriers, ${ }^{52-54}$ in this case, such a coating is introduced to facilitate the incorporation of positively charged PLL-g-PEG by electrostatic interactions. Moreover, PDA has barely any chemical reaction with Hb's functional groups. Furthermore, we, and others, have demonstrated how PDA can minimize Hb's autoxidation into non-functional metHb. ${ }^{1,40,55-58}$ The $\mathrm{MOF}^{\mathrm{Hb}}$-NPs were incubated in a DA solution in basic conditions and, the deposition of PDA to render $\mathrm{MOF}^{\mathrm{Hb}} / \mathrm{PDA}-\mathrm{NPs}$, was confirmed by the decrease in $\zeta$-potential to $-20.6 \pm 0.5 \mathrm{mV}$. Finally, incubation in a PLL-g-PEG solution resulted in a $\zeta$-potential increase to $7.7 \pm 0.3 \mathrm{mV}$ thus rendering PEGylated MOFHb/PEG-NPs. Importantly, no changes in PDI (below 0.2) could be observed following the different coating steps, thus indicating good colloidal stability for the asprepared NPs.

3.3.2. RBC-M coating. Functionalization of nanocarriers with bio-membranes derived from $\mathrm{RBCs}$, endows the nanocarriers with high biocompatibility, immune-evasion and enables them to avoid clearance by the MPS due to their native long circulation property. ${ }^{34,59}$ Thus, RBC-Ms were extracted from fresh human blood from donors and fluorescently labelled by incubating them with the lipophilic far-red fluorescent DiD dye. The resulting $\mathrm{RBC}-\mathrm{M}^{\mathrm{F}} \mathrm{S}$ were mixed with the $\mathrm{MOF}^{\mathrm{Hb}}$

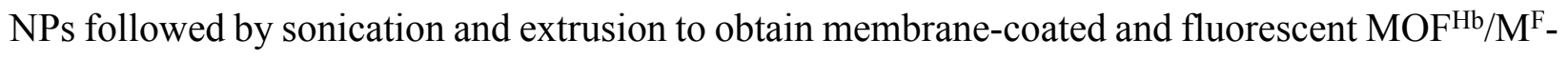
NPs. The association of the RBC-M $\mathrm{M}^{\mathrm{F}}$ with the $\mathrm{MOF}^{\mathrm{Hb}}-\mathrm{NPs}$ was first evaluated by flow cytometry. 
Since the surface charge of the nanocarriers affects the coating with RBC-Ms, ${ }^{60}$ both uncoated MOFHb_NPs (positively charged) and PDA-coated MOFHb/PDA-NPs (negatively charged) were considered. As controls, physical mixtures of RBC-MF and the NPs (both $\mathrm{MOF}^{\mathrm{Hb}}-\mathrm{NPs}_{\text {s }}$ and MOF ${ }^{\mathrm{Hb}} / \mathrm{PDA}-\mathrm{NPs}$ ) without sonication and extrusion were considered (Figure 5Ai). The MFI readings due to the DiD-labelled $\mathrm{RBC}-\mathrm{Ms}$ were normalized to uncoated $\mathrm{MOF}^{\mathrm{Hb}}-\mathrm{NPs}$. Figure 5Aii shows a $\sim 56 \%$ increase in nMFI (dark grey bars) when coating bare $\mathrm{MOF}^{\mathrm{Hb}}-\mathrm{NPs}$ with $\mathrm{RBC}-\mathrm{M}^{\mathrm{F}}$. However, the results were different for PDA-coated $\mathrm{MOF}^{\mathrm{Hb}} / \mathrm{PDA}-\mathrm{NPs}$, which experienced a $244 \%$ increase in nMFI (dark purple bars) which indicates a positive interaction between the $\mathrm{RBC}-\mathrm{M}^{\mathrm{F}}$ and the NPs. This result is in agreement with previous reports demonstrating that a negative surface charge is a major factor facilitating the coating by RBC-Ms. ${ }^{60}$ Importantly, the physical mixtures of the NPs and $\mathrm{RBC}-\mathrm{M}^{\mathrm{F}}$ resulted on a barely noticeable increase in nMFI. Specifically, a $\sim 20 \%$ and $\sim 25 \%$ increase in nMFI was observed in the absence (MOFHb-NPs, light grey bars) and presence (MOF ${ }^{\mathrm{Hb}} / \mathrm{PDA}-\mathrm{NPs}$, light purple bars) of a PDA layer. The $\mathrm{MOF}^{\mathrm{Hb}} / \mathrm{M}-\mathrm{NPs}$ were also characterized by SEM. MOF ${ }^{\mathrm{Hb}}-\mathrm{NPs}$ without a PDA layer shows large aggregates following coating with RBC-Ms (Figure 5Aiii) as a result of the disturbed RBC-M interaction with the NPs. In contrast, MOFHb/PDA-NPs coated by RBC-Ms yielded even, spherical and monodisperse NPs (Figure 5Aiv). Thus, the flow cytometry results together with the SEM images indicate that the extracted RBC-Ms can be used to successfully coat MOFHb/PDA-NPs.

Following on, the $\mathrm{MOF}^{\mathrm{Hb}} / \mathrm{M}-\mathrm{NPs}$ were examined to assess the completeness of the membrane coverage by conducting an aggregation assay based on Strep-BT conjugation. ${ }^{60}$ In this study, biotinylated NPs (MOFHb/BT-NPs) which readily aggregate upon direct exposure to free Step in solution were prepared (Figure 5Bi). In particular, PDA-coated MOFHb/PDA-NPs were functionalized with BT-NHS since it reacts in a straight forward manner with the primary amines of the PDA layer rendering biotinylated $\mathrm{MOF}^{\mathrm{Hb}} / \mathrm{BT}-\mathrm{NPs}$. Figure 5Bii shows how, in the absence of RBC-M, the MOF ${ }^{\mathrm{Hb}} / \mathrm{BT}-\mathrm{NPs}$ displayed a hydrodynamic size of $\sim 500 \mathrm{~nm}$ as shown by DLS measurements. Upon incubation of $\mathrm{MOF}^{\mathrm{Hb}} / \mathrm{BT}-\mathrm{NPs}$ with free Strep, the size increased up to $\sim 900$ $\mathrm{nm}$, indicating aggregation of the system as a result of the NPs bridging mechanism of the BTStrep interaction. We would like to note that the quantitative change of hydrodynamic diameter following PDA coating (i.e., a hydrodynamic size of $\sim 220 \mathrm{~nm}$ and $\sim 500 \mathrm{~nm}$ for uncoated $\mathrm{MOF}^{\mathrm{Hb}}$ NPs and PDA-coated MOFHb/BT-NPs, respectively) could be misleading. As previously reported, the black colour produced by PDA coating could adsorb the laser light, thus affecting the accuracy 
of the DLS measurements. ${ }^{61,62}$ However, it is still nonetheless possible to qualitatively compare the size of the different samples since they all have experienced the same PDA coating procedure.

Given that a uniform coating by the RBC-Ms will prevent surface-attached BT from interacting with Strep, the completeness of RBC-M coating was evaluated using biotinylated $\mathrm{MOF}$ Hb/BT-NPs incubated with increasing amounts of RBC-M. Specifically, MOFHb/BT-NPs were mixed with different amounts of RBC-Ms (i.e., extracted from $17 \mu \mathrm{L}$ to $400 \mu \mathrm{L}$ of whole blood per mg of starting MOF-NPs) followed by sonication and extrusion. The resulting RBC-M-coated $\mathrm{MOF}^{\mathrm{Hb}} / \mathrm{BT} / \mathrm{M}-\mathrm{NPs}$ where then incubated in a Strep solution and their aggregation (or the lack of) was assessed by DLS. Figure 5B shows how, for low RBC-M amounts, significant aggregation was detected (i.e., an increase in size from $\sim 500 \mathrm{~nm}$ to $\sim 850 \mathrm{~nm}$ for RBC-M extracted from only $17 \mu \mathrm{L}$ of whole blood). In contrast, for RBC-M amounts extracted from $200 \mu \mathrm{L}$ of whole blood or higher, the addition of Strep failed to induce any considerable size increase among the $\mathrm{MOF}^{\mathrm{Hb}} / \mathrm{BT} / \mathrm{M}-\mathrm{NPs}$. This blockage of the Strep-induced aggregation indicates that the surfaces of the $\mathrm{MOF}^{\mathrm{Hb}} / \mathrm{BT} / \mathrm{M}-\mathrm{NPs}$ were fully covered upon mixing with RBC-M extracted from at least 200 $\mu \mathrm{L}$ of blood.

3.3.3. Protein adsorption studies. Recognition and clearance by the MPS, takes place following accumulation of opsonins onto the carriers surface. ${ }^{63}$ Thus, the stealth properties of the NPs as a result of the PEG and RBC-M coatings were first assessed in terms of inhibition of protein adsorption. IgG and BSA were selected as model proteins since they are two of the most abundant proteins in blood. While IgG acts as a potent opsonin, albumin is believed to have a dysopsonic effect. However, albumin can be easily replaced by opsonic proteins. ${ }^{64}$ The adsorption of fluorescently labelled BSA-FITC and IgG-FITC onto the different NPs (i.e., MOFHb-NPs, $\mathrm{MOF}^{\mathrm{Hb}} / \mathrm{PDA}-\mathrm{NPs}, \mathrm{MOF}^{\mathrm{Hb}} / \mathrm{PEG}-\mathrm{NPs}$ and $\mathrm{MOF}^{\mathrm{Hb}} / \mathrm{M}-\mathrm{NPs}$ ) following $4 \mathrm{~h}$ of incubation at $37^{\circ} \mathrm{C}$, was evaluated by flow cytometry. The results, which were normalized to the MFI of MOFHb-NPs incubated with BSA-FITC and IgG-FITC, are shown in Figure 6. While coating with PDA resulted on a $\sim 80 \%$ decrease in nMFI for BSA-FITC, only a $\sim 25 \%$ decrease was observed for IgGFITC. This fact could be attributed to the negative charge rendered by the PDA coating, which could repel the adsorption of the negatively charged BSA-FITC. ${ }^{65}$ Following PEG coating, a $\sim 80 \%$ and $\sim 79 \%$ decrease in nMFI was detected for MOFHb/PEG-NPs in the presence of BSA-FITC and IgG-FITC, respectively. These results are in agreement with previously reported studies using the 
same PEG-based polymer, ${ }^{36,39,40,66}$ confirming again the ability of PLL-g-PEG to act as a steric barrier hindering the diffusion and adsorption of proteins onto the surface of the nanocarriers. Coating with RBC-M displayed a similar effect than PEGylation for BSA-FITC since a $\sim 80 \%$ decrease in nMFI was also detected for $\mathrm{MOF}^{\mathrm{Hb}} / \mathrm{M}-\mathrm{NPs}$ in the presence of that protein. The results were slightly different for IgG-FITC and a higher decrease in nMFI as compared to the PEGylated counterparts was observed (i.e., 75 and 85\% decrease in nMFI for MOF $\mathrm{Hb} / \mathrm{PEG}-\mathrm{NPs}$ and $\mathrm{MOF}^{\mathrm{Hb}} / \mathrm{M}-\mathrm{NPs}$, respectively). Thus, all in all, these results indicate that coating with RBC-M, results in equally good resistance to protein adsorption as compared to PEGylation.

3.3.4. Cell uptake/association studies. The stealth properties of the NPs depending on the different terminating coatings were further evaluated by their ability in avoiding/minimizing cell internalization. RAW 264.7 mice macrophages and HUVEC were the cells of choice. While macrophages are phagocytic cells of the MPS, endothelial cells are the cells lining in our vasculature and, therefore, any intravenously administered nanocarrier will get in contact with them. To compare the cell uptake/association, the different NPs were fabricated employing fluorescently labelled Hb-FITC. The different NPs (i.e., MOFHb-FITC-NPs, MOFHb-FITC/PDA-NPs, $\mathrm{MOF}^{\mathrm{Hb}-F I T C} / \mathrm{PEG}-\mathrm{NPs}$ and MOF ${ }^{\mathrm{Hb}-F I T C} / \mathrm{M}-\mathrm{NPs}$ ) were incubated at a 100:1 NPs-to-cell ratio for $4 \mathrm{~h}$ at $37{ }^{\circ} \mathrm{C}$. The CUE, which corresponds to the percentage of cells with a fluorescence intensity higher than the autofluorescence level of the cells, was evaluated by flow cytometry for the two cell lines (Figure 7A). The results show how the three different coatings (i.e., PDA, PEG and RBC-M) resulted on a significant decrease in CUE for both RAW 264.7 and HUVEC cells as compared to the uncoated counterparts. However, while such a decrease in CUE was rather slight for RAW 264.7 cells ( $\sim 10-15 \%$ decrease for the three different coatings), it was quite pronounced for HUVEC cells. Specifically, for HUVEC cells, a decrease in CUE of $\sim 35 \%$ for PDA-coated MOFHb-FITC/PDA-NPs and 50\% for both PEG- and RBC-M-coated NPs was observed. Figure 7B shows the FI readings measured upon lysing the cells following $4 \mathrm{~h}$ incubation with the NPs at the same NPs-to-cell ratio. The results, which have been normalized to the FI readings upon incubation of the uncoated $\mathrm{MOF}^{\mathrm{Hb}-\mathrm{FITC}}-\mathrm{NPs}(\mathrm{nFI})$, are in agreement with the CUE results. While only $\sim 10$ $20 \%$ decrease in nFI could be observed for RAW 264.7 cells for the three studied coatings, a marked decrease in nFI was detected in HUVEC cells. In particular, PDA coating resulted in a $\sim 55 \%$ decrease in $\mathrm{nFI}$ while both PEG- and RBC-M-coatings lead to $\sim 70 \%$ reduction in $\mathrm{nFI}$. Thus, all in all, a limited effect both in CUE and nFI could be observed for RAW 264.7 cells for the three 
studied coatings. In contrast, the significant and similar blockage of the cell uptake for the two stealth coatings detected for HUVEC cells is well in agreement with the protein adsorption studies. Interestingly, PDA-coating also resulted in diminished cell uptake both in terms of CUE but also when assessing the nFI of the internalized cells. We attribute these results to the fact that following PDA coatings the charge of the NPs changes from positive $(\zeta=13.7 \pm 1.9 \mathrm{mV}$ for MOFHb-FITC

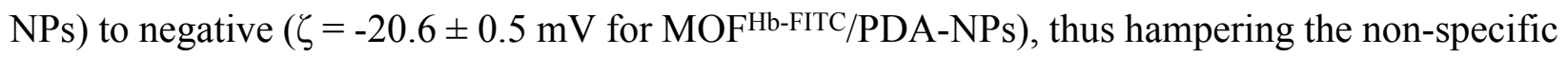
interactions with cell binding sites and diminishing the cell-uptake efficiency. ${ }^{67}$

\subsection{Biocompatibility Studies}

The biocompatibility of the NPs with the three different coatings was assessed in terms of cell viability and hemocompatibility studies.

3.4.1. Cell viability. The in vitro cytotoxicity of MOF-NPs, $\mathrm{MOF}^{\mathrm{Hb}}-\mathrm{NPs}, \mathrm{MOF}^{\mathrm{Hb}} / \mathrm{PDA}-\mathrm{NPs}$, $\mathrm{MOF}^{\mathrm{Hb}} / \mathrm{PEG}-\mathrm{NPs}$ and $\mathrm{MOF}^{\mathrm{Hb}} / \mathrm{M}-\mathrm{NPs}$ was assessed by conducting cell viability assays for the two studied cell lines at a 100:1 NPs-to-cell ratio following 4 h of incubation at $37^{\circ} \mathrm{C}$. Figure $8 \mathbf{A}$ shows no decrease in the normalized cell viability readings (nCV) for the three studied coatings and cell lines. Interestingly, although not statistically significant, an increase of $\sim 10 \%$ in nCV was observed for RAW 264.7 cells incubated with PDA-coated MOF ${ }^{\mathrm{Hb}} / \mathrm{PDA}-\mathrm{NPs}$ as compared to cells only. This is not surprising since previous works have reported enhanced cell viability for PDA coatings as a result of the large amount of amine and hydroxyl groups. ${ }^{40,68}$

3.4.2. Hemocompatibility. The evaluation of the impact of the NPs depending on the surface coatings on human blood cells was evaluated by a haemolysis assay. The haemolysis rate following incubation of the NPs with blood cells at a 100:1 of NPs-to-cell ratio, was evaluated by quantifying the amount of free $\mathrm{Hb}$ in solution. Figure $8 \mathrm{Bi}$ shows that while uncoated $\mathrm{MOF}^{\mathrm{Hb}}-\mathrm{NPs}$ result on a haemolysis rate of $\sim 8 \%$; the three different coatings $\left(\mathrm{MOF}^{\mathrm{Hb}} / \mathrm{PDA}-\mathrm{NPs}, \mathrm{MOF}^{\mathrm{Hb}} / \mathrm{PEG}-\mathrm{NPs}\right.$ and $\mathrm{MOF}^{\mathrm{Hb}} / \mathrm{M}-\mathrm{NPs}$ ) promote a decrease in haemolysis rate well below $5 \%$. This is an important fact since, according to ISO/TR 7406, the biomaterials are considered non-hemolytic for haemolysis rates lower than $5 \% .{ }^{69}$ The $\sim 8 \%$ haemolysis rate induced by $\mathrm{MOF}^{\mathrm{Hb}}-\mathrm{NPs}$ can attributed to their positive charge. The electrostatic interactions between cell membrane and NPs could promote the disturbance of cell membrane and thus resulting in a higher haemolysis rate. Figure 8Bii shows photographic images of the suspensions of the blood cells and the different NPs including a 
negative (isotonic HEPES buffer, 0\% lysis) and a positive (MQ, 100\% lysis) control group. As expected by the haemolysis rate results, only the positive control group showed haemoglobin leakage with obvious red colour. Interestingly, while bright red pellets can be observed for the control groups and for MOF-NPs and $\mathrm{MOF}^{\mathrm{Hb}}$-NPs treated groups, dark pellets were collected for the groups with NPs containing a PDA coating (i.e., $\mathrm{MOF}^{\mathrm{Hb}} / \mathrm{PDA}-\mathrm{NPs}$ but also $\mathrm{MOF}^{\mathrm{Hb}} / \mathrm{PEG}-\mathrm{NPs}$ and $\mathrm{MOF}^{\mathrm{Hb}} / \mathrm{M}-\mathrm{NPs}$ which have an underlying PDA coating). Such a darker colour indirectly indicates the successful modification by PDA. Additionally, the blood cells retained their shape after incubation with the different NPs (Figure S2, Supporting Information).

\subsection{Functional performance}

The ability to carry oxygen is one of the most important functions of $\mathrm{Hb}$. The oxygen binding and releasing properties of the NPs depending on their surface coatings (i.e., MOFHb_NPs,

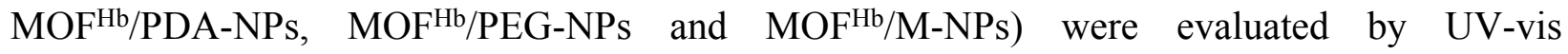
spectroscopy following several $\mathrm{O}_{2} / \mathrm{N}_{2}$ cycles. Figure 9 shows the initial characteristic peaks of oxy- $\mathrm{Hb}$ for the first $\mathrm{O}_{2}$ cycle at $\sim 412 \mathrm{~nm}$ (Soret peak), $\sim 541$ and $\sim 578 \mathrm{~nm}$ (red lines) for all the studied samples independent of the surface coating. Importantly, following flowing with $\mathrm{N}_{2}$ gas, a shift in the wavelengths towards the characteristic deoxy-Hb peaks could also be observed for all the different NPs. In particular, a red shift of the Soret peak to $\sim 428 \mathrm{~nm}$, the disappearance of the peaks at $\sim 541$ and $\sim 578 \mathrm{~nm}$ and appearance of the peak at $\sim 564 \mathrm{~nm}$ (green lines) was detected independently of the surface coating. This change in the wavelengths upon $\mathrm{O}_{2}$ and $\mathrm{N}_{2}$ gas treatment was observed for two additional cycles thus highlighting the ability of the different NPs in binding and releasing $\mathrm{O}_{2}$ in a continuous manner over multiple rounds in a similar fashion as our biological RBCs.

All in all, these results demonstrate that loading Hb into MOF-NPs, surface modification with PDA and subsequent functionalization with PEG or RBC-M, did not hamper the $\mathrm{O}_{2}$-carrying ability of $\mathrm{Hb}$, which is the most important feature for HBOCs.

\section{Conclusion}

In this work, we have presented a novel biomimetic HBOC with a high Hb loading, stability and preserved functionality. To do so, we have prepared mesoporous MOF-based NPs which are 
monodisperse and spherical with a diameter of around $220 \mathrm{~nm}$, which could avoid extravasation through the blood vessel wall and consequently circumvent vasoconstriction. Coating with RBC$\mathrm{M}$ endows $\mathrm{MOF}^{\mathrm{Hb}}$-NPs with low-fouling properties in terms of decreased protein adsorption and cell uptake, which are comparable to our previously reported PEGylation strategy. Moreover, the RBC-M-coated $\mathrm{MOF}^{\mathrm{Hb}}$-NPs showed good biocompatibility and hemocompatibility while also being able to reversibly bind and release oxygen, which is the most important feature for HBOCs. In summary, this novel biomimetic HBOCs with high $\mathrm{Hb}$ content and stability can provide a safe and efficient oxygen supply thus fulfilling the requirements for the next generation of blood surrogates. 


\section{FIGURES}

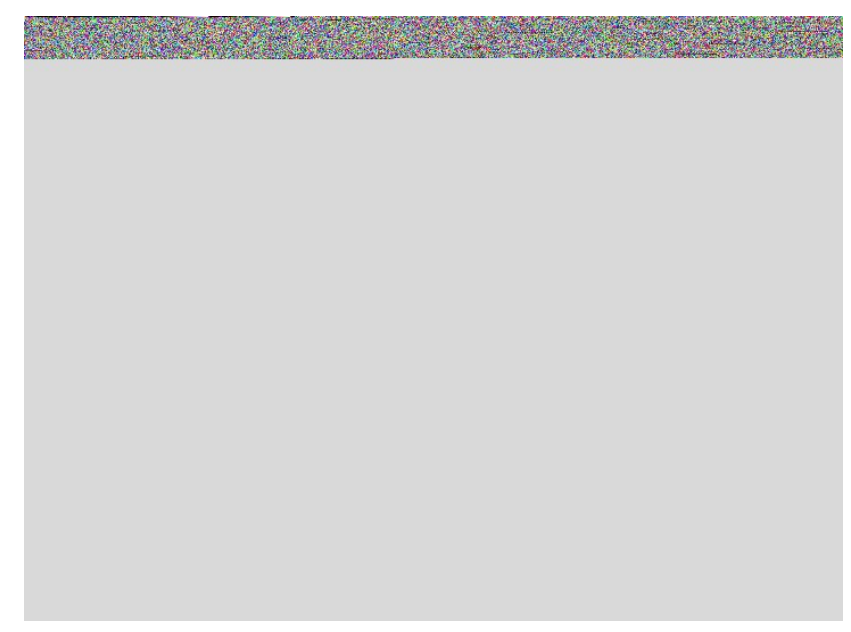

Scheme 1 Illustration of the assembly process. A) Haemoglobin ( $\mathrm{Hb})$ is extracted from bovine red blood cells (RBCs); B) Components and crystalline structure of the metal organic framework (MOF) platform; C) Membrane of RBCs (RBC-M) is extracted from human RBCs; D) Hb is loaded into empty MOF-based nanoparticles (MOF-NPs) by post-encapsulation rendering $\mathrm{MOF}^{\mathrm{Hb}}$ NPs. MOF ${ }^{H b}-N P s$ are endorsed with stealth layer employing PEGylation or RBC-M coating. 


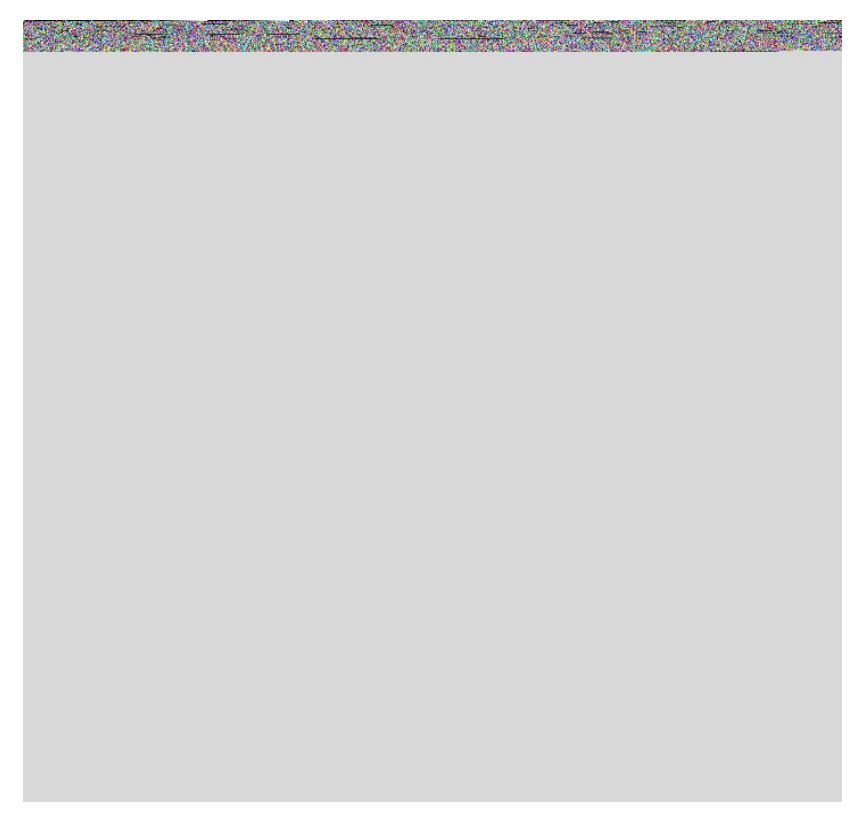

Fig. 1 A) Entrapment efficiency (EE) and drug loading (DL) of haemoglobin (Hb) into metal organic framework (MOF)-based nanoparticles (MOF-NPs) at various initial input amounts per mg of MOF-NPs. B) Zeta-potential of Hb loaded MOF-NPs (MOF ${ }^{\mathrm{Hb}}-\mathrm{NPs}$ ) for the different DLs. C) Scanning electron microscopy images of empty MOF-NPs and MOF ${ }^{\mathrm{Hb}}-\mathrm{NPs}$ in suspension (i and ii). 


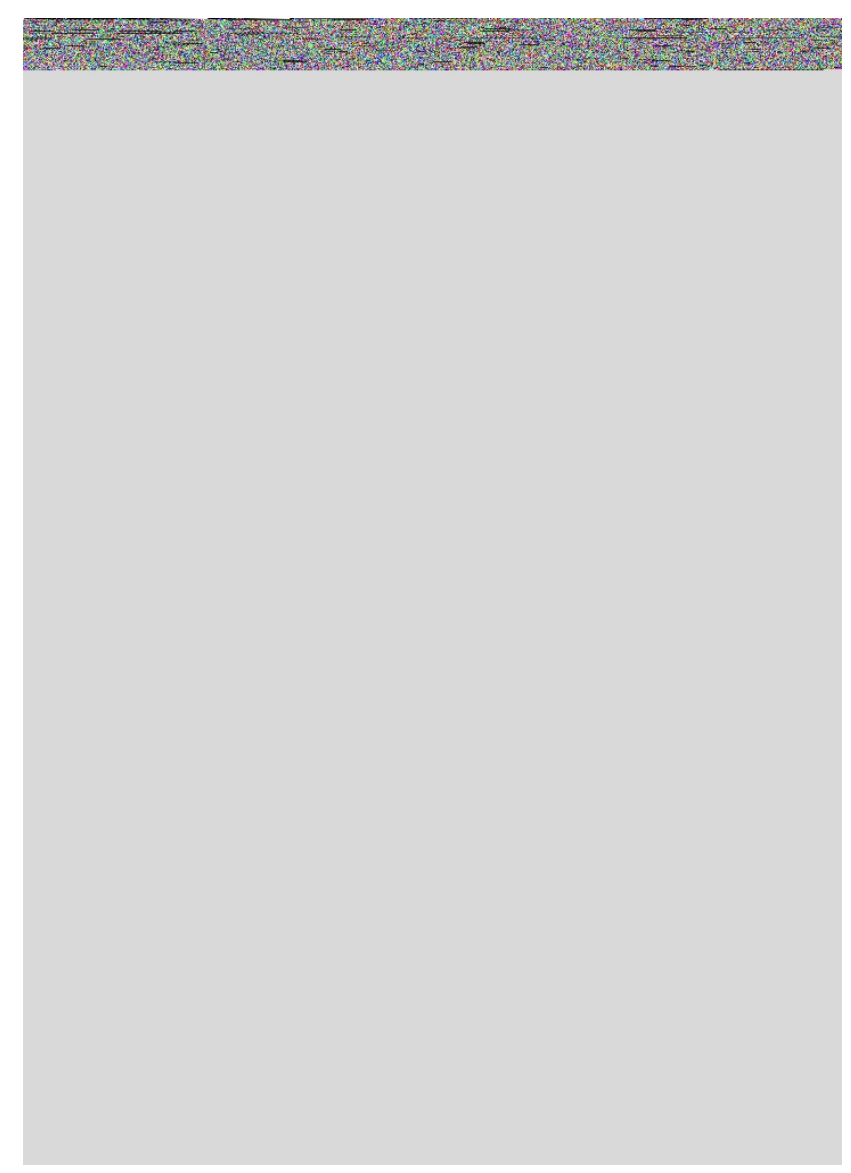

Fig. 2 A) Fourier-transform infrared (FTIR) spectra of empty metal organic framework (MOF)based nanoparticles (MOF-NPs) and haemoglobin (Hb)-loaded MOF-NPs (MOF $\left.{ }^{H b}-N P s\right)$ as compared to native $\mathrm{Hb}$. B) UV-vis absorption spectra of native $\mathrm{Hb}$ and $\mathrm{MOF}^{\mathrm{Hb}}-\mathrm{NPs}$ before i) and after purging with nitrogen gas ii). 


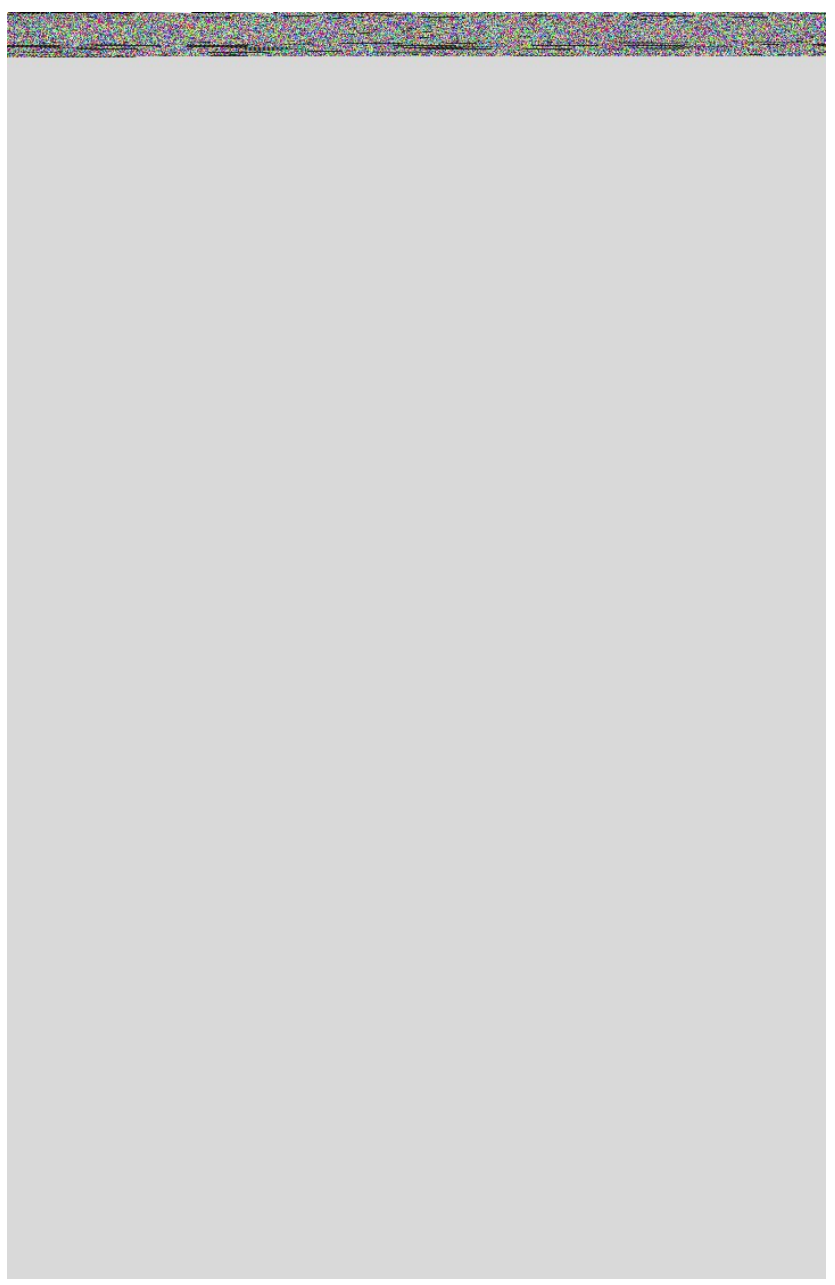

Fig. 3 A) Size and polydispersity index (PDI) of empty metal organic framework (MOF)-based nanoparticles (MOF-NPs) and haemoglobin (Hb)-loaded MOF-NPs (MOFHb-NPs) stored at $4{ }^{\circ} \mathrm{C}$ for 14 days; B) Cumulative release of $\mathrm{Hb}$ from $\mathrm{MOF}^{\mathrm{Hb}}-\mathrm{NPs}$ stored at $4{ }^{\circ} \mathrm{C}$ for 28 days. 


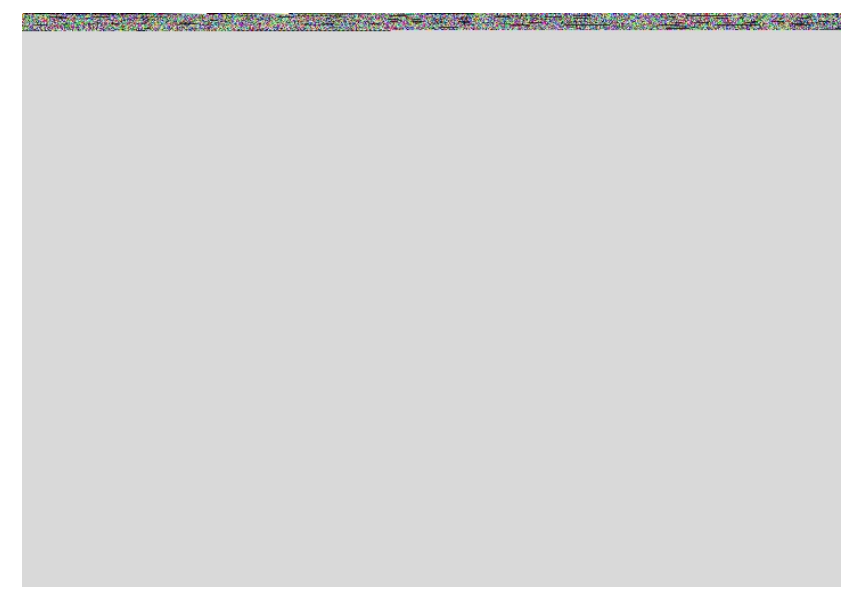

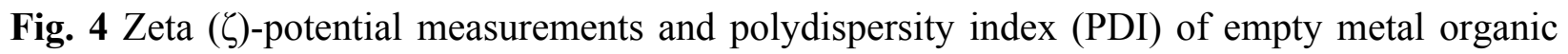
framework (MOF)-based nanoparticles (MOF-NPs) and haemoglobin ( $\mathrm{Hb}$ )-loaded MOF-NPs (MOFHb-NPs) with a polydopamine (PDA) (MOFHb/PDA-NPs) or a PEG (MOFHb/PEG-NPs) coating layer. 


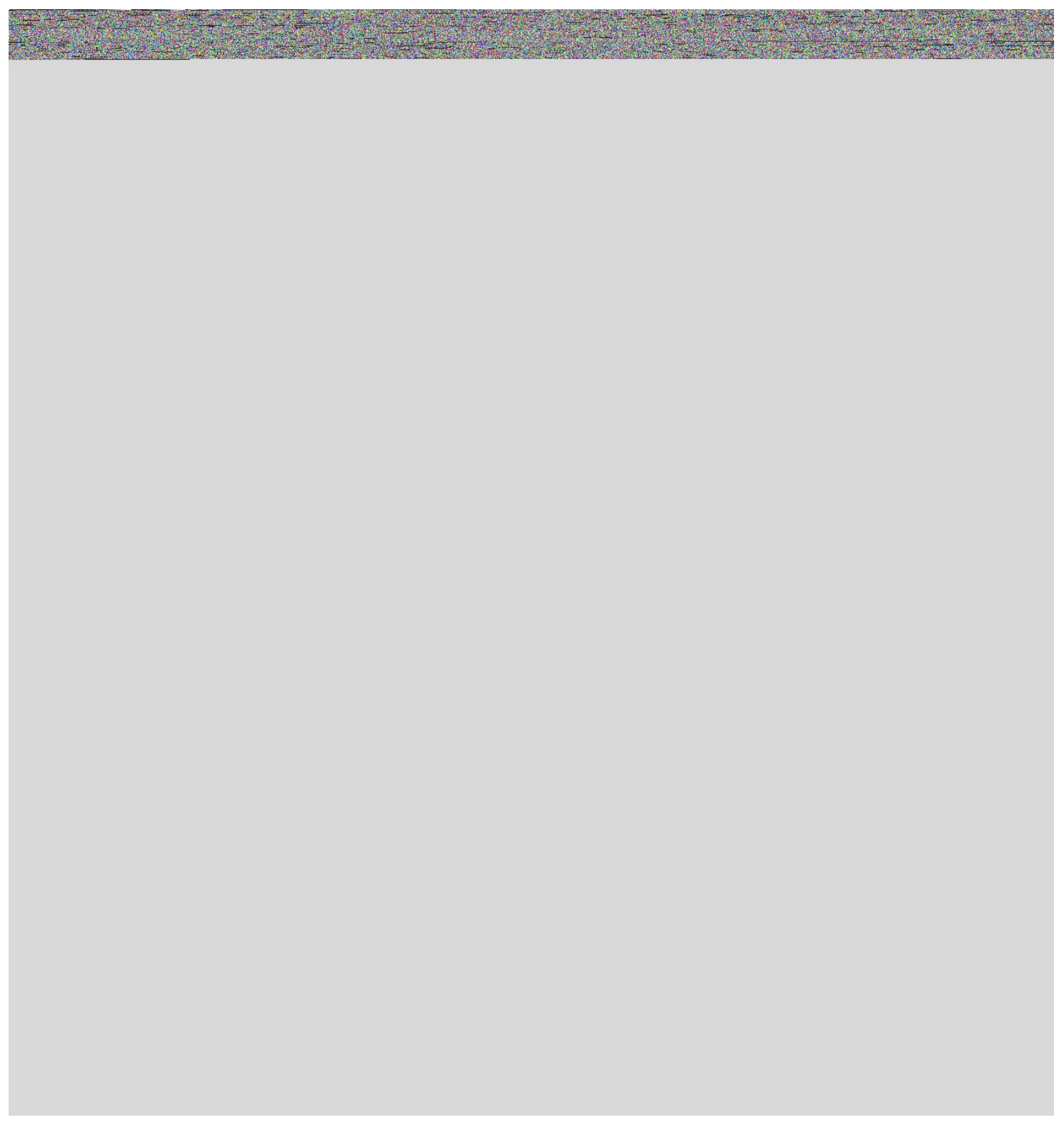

Fig. 5 A) i) Red blood cells membranes (RBC-M) are extracted and fluorescently labelled to render $\mathrm{RBC}-\mathrm{M}^{\mathrm{F}}$. Next, they are used to functionalize haemoglobin $(\mathrm{Hb})$-loaded metal organic framework (MOF)-based nanoparticles (MOF $\left.{ }^{\mathrm{Hb}}-\mathrm{NPs}\right)$. Both uncoated (MOF ${ }^{\mathrm{Hb}}-\mathrm{NPs}$ ) and polydopamine (PDA) coated (MOF ${ }^{\mathrm{Hb}} / \mathrm{PDA}-\mathrm{NPs}$ ) NPs are considered. ii) Normalized mean fluorescence intensity (nMFI) readings of the NPs with the different coatings: Hb-loaded $\mathrm{MOF}^{\mathrm{Hb}}-\mathrm{NPs}, \mathrm{RBC}-\mathrm{M}^{\mathrm{F}}$-coated $\mathrm{MOF}^{\mathrm{Hb}} / \mathrm{M}^{\mathrm{F}}-\mathrm{NPs}$ and the physical mixture of $\mathrm{MOF}^{\mathrm{Hb}}-\mathrm{NPs}$ and $\mathrm{RBC}-\mathrm{M}^{\mathrm{F}}$. Scanning electron 
microscopy images of the physical mixture of $\mathrm{MOF}^{\mathrm{Hb}}-\mathrm{NPs}$ (iii) and RBC-M and the RBC-Mcoated MOFHb/M-NPs (iv). B) i) Streptavidin (Strep)-biotin (BT) conjugation results in the StrepBT complex. MOFHb/PDA-NPs were functionalized with BT to render MOFHb/BT-NPs which aggregate in the presence of Strep. $\mathrm{MOF}^{\mathrm{Hb}} / \mathrm{BT}-\mathrm{NPs}$ are coated with $\mathrm{RBC}-\mathrm{M}$ to render $\mathrm{MOF}^{\mathrm{Hb}} / \mathrm{BT} / \mathrm{M}-\mathrm{NPs}$ which remain monodisperse in the presence of Strep. ii) Size distribution of $\mathrm{MOF}^{\mathrm{Hb}} / \mathrm{BT} / \mathrm{M}-\mathrm{NPs}$ prepared with different amounts of RBC-M in the absence (grey bars) or presence (blue bars) of Strep. 


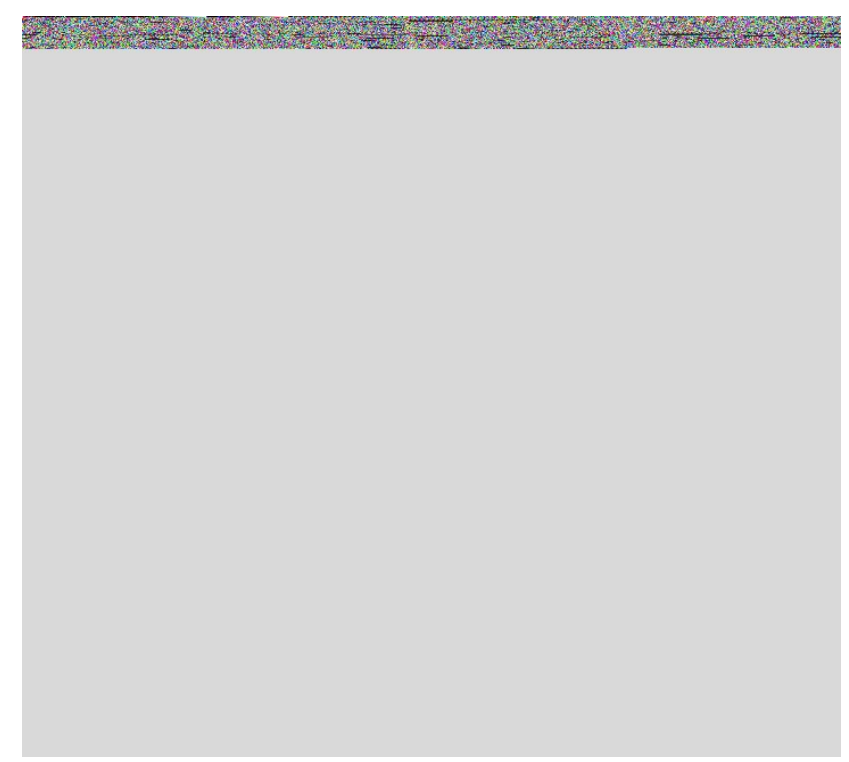

Fig. 6 Normalized mean fluorescence intensity (nMFI) of haemoglobin (Hb)-loaded metal organic framework (MOF)-based nanoparticles ( $\left.\mathrm{MOF}^{\mathrm{Hb}}-\mathrm{NPs}\right)$ incubated in the presence of fluorescently labelled bovine serum albumin (BSA-FITC) or immunoglobulin G (IgG-FITC). Different types of $\mathrm{MOF}^{\mathrm{Hb}}$-NPs are considered: uncoated: $\mathrm{MOF}^{\mathrm{Hb}}-\mathrm{NPs}$; polydopamine (PDA)-coated: MOFHb/PDANPs; PEG-coated: MOFHb/PEG-NPs; or red blood cell-membrane (RBC-M) coated: MOFHb/MNPs. $* \mathrm{p} \leq 0.05 ; * * * * \mathrm{p} \leq 0.0001$. 


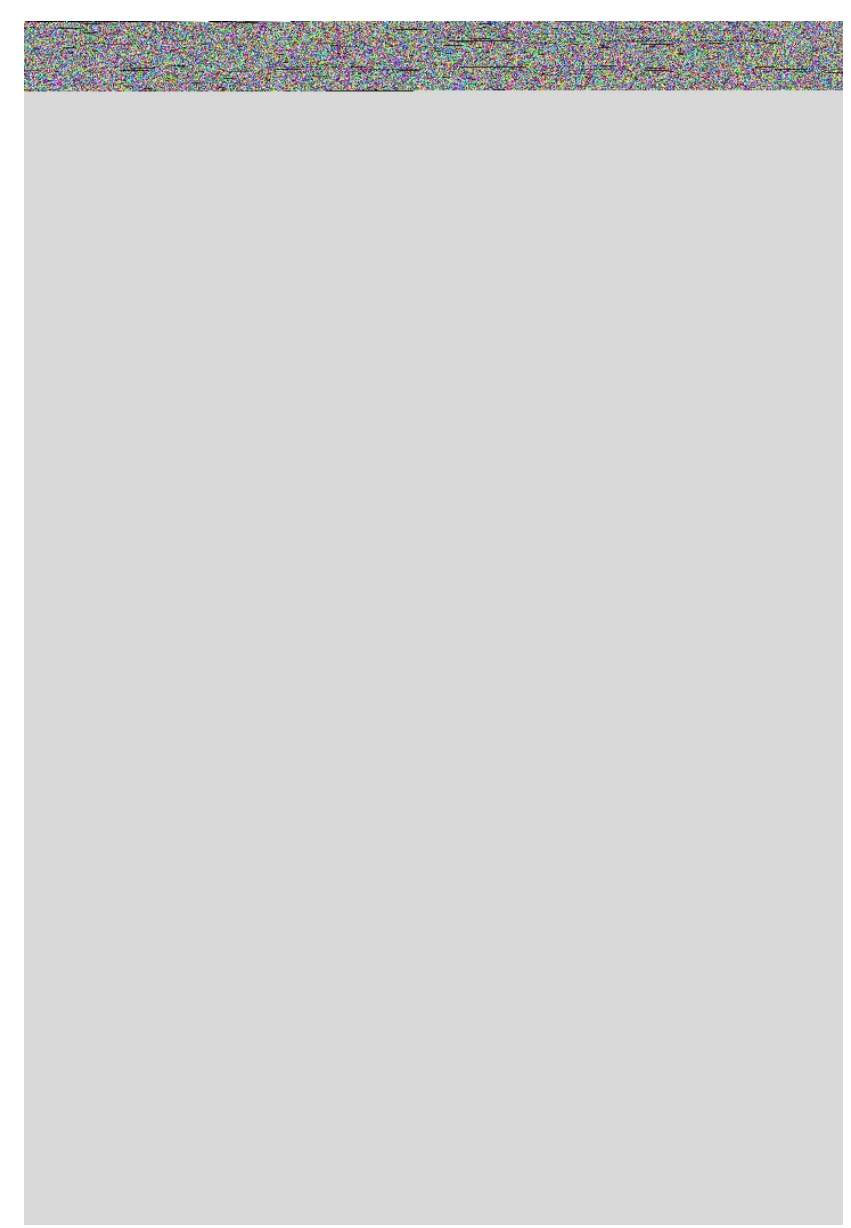

Fig. 7 A) Cell uptake efficiency (CUE) and B) normalized fluorescence intensity (nFI) of RAW 264.7 (i) and HUVEC (ii) cells incubated with haemoglobin (Hb)-loaded metal organic framework (MOF)-based nanoparticles (MOF $\left.{ }^{\mathrm{Hb}}-\mathrm{NPs}\right)$. Different types of $\mathrm{MOF}^{\mathrm{Hb}}-\mathrm{NPs}$ are considered: uncoated: $\mathrm{MOF}^{\mathrm{Hb}}-\mathrm{NPs}$; polydopamine (PDA)-coated: $\mathrm{MOF}^{\mathrm{Hb}} / \mathrm{PDA}-\mathrm{NPs}$; PEG-coated: $\mathrm{MOF}^{\mathrm{Hb}} / \mathrm{PEG}-\mathrm{NPs}$; or red blood cell-membrane coated: $\mathrm{MOF}^{\mathrm{Hb}} / \mathrm{M}-\mathrm{NPs} .{ }^{*} \mathrm{p} \leq 0.05 ; * * \mathrm{p} \leq 0.001$, $* * * \mathrm{p} \leq 0.0005, * * * * \mathrm{p} \leq 0.0001$. 


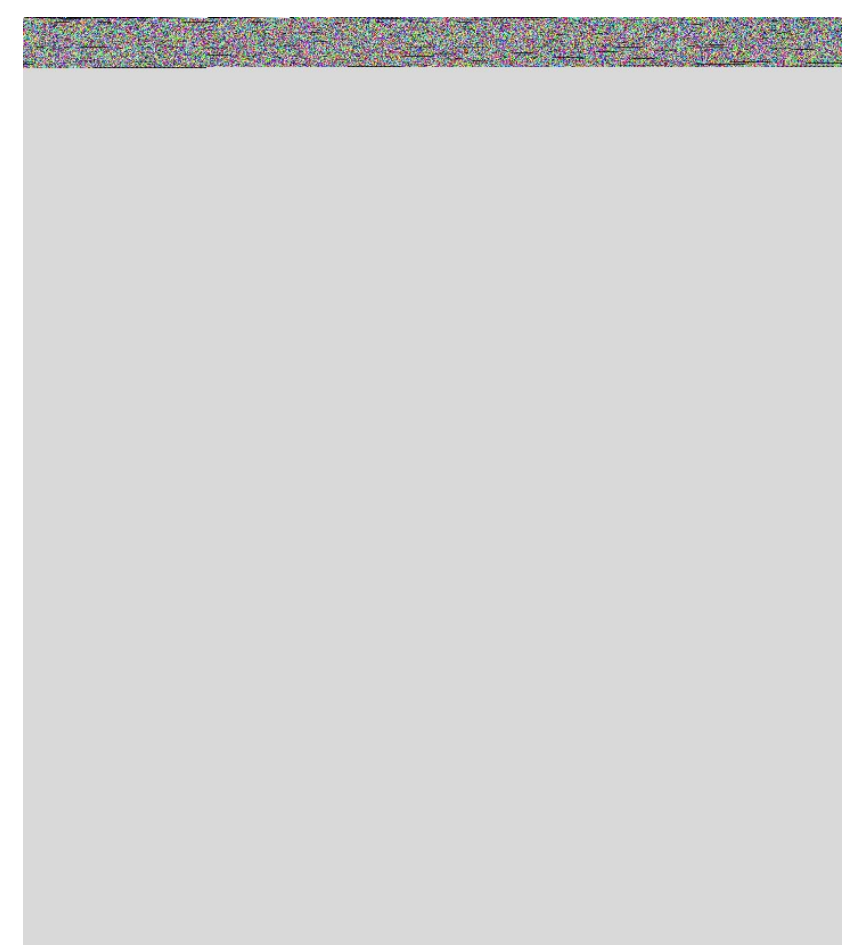

Fig. 8 A) Normalized cell viability (nCV) readings of RAW 264.7 (i) and HUVEC (ii) cells following incubation for $4 \mathrm{~h}$ with empty metal organic framework (MOF)-based nanoparticles (MOF-NPs) and haemoglobin (Hb)-loaded MOF-NPs (MOF $\mathrm{Hb}_{-N P s}$ ). B) Haemolysis rate (i) and photographic images (ii) of the of the negative control (-), positive control (+) and both MOF-NPs and $\mathrm{MOF}^{\mathrm{Hb}}$-NPs incubated with blood cells for $4 \mathrm{~h}$. Different types of $\mathrm{MOF}^{\mathrm{Hb}}-\mathrm{NPs}$ are considered: uncoated: MOFHb-NPs; polydopamine (PDA)-coated: MOFHb/PDA-NPs; PEG-coated:

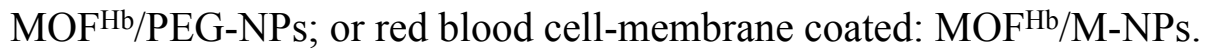




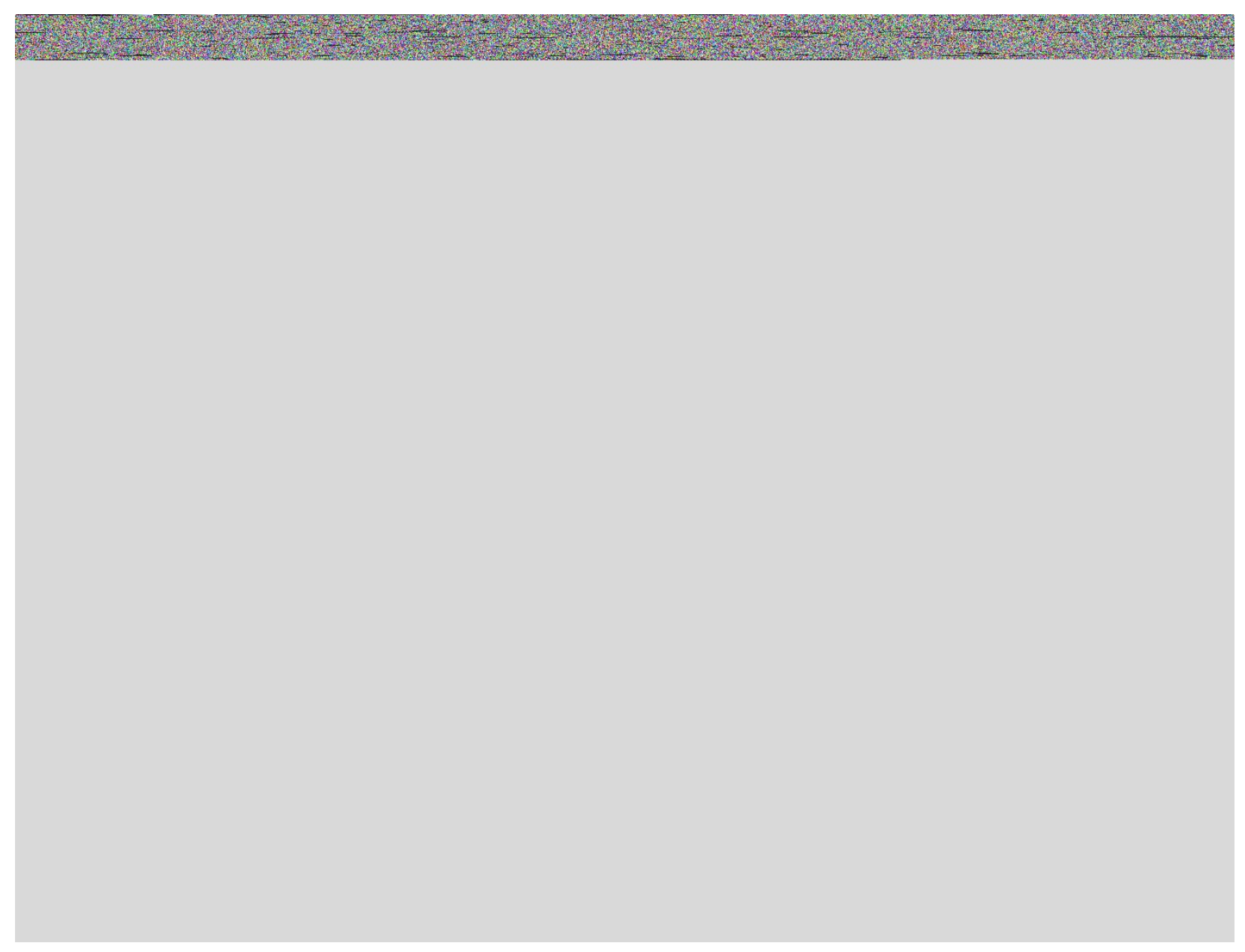

Fig. $9 \mathrm{UV}-$-vis absorption spectra of oxygenated (oxy-Hb) and deoxygenated (deoxy-Hb) haemoglobin $(\mathrm{Hb})$ after successively feeding with oxygen $\left(\mathrm{O}_{2}\right)$ or nitrogen $\left(\mathrm{N}_{2}\right)$ gas different types of metal organic framework (MOF)-based nanoparticles (MOF-NPs): A) uncoated Hb-loaded

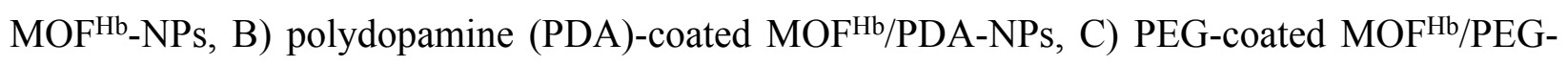
NPs and D) red blood cell-membrane-coated $\mathrm{MOF}^{\mathrm{Hb}} / \mathrm{M}-\mathrm{NPs}$. 


\section{ASSOCIATED CONTENT}

\section{Supporting Information}

\section{AUTHOR INFORMATION}

\section{Corresponding Author}

*leri@dtu.dk

\section{Funding Sources}

This work was supported by the Danish Council for Independent Research [Grant No. 611100298B and 0130-00009B].

\section{ACKNOWLEDGMENT}

This work was supported by the Danish Council for Independent Research [Grant No. 611100298B and 0130-00009B]. 


\section{REFERENCES}

1 Q. Wang, R. Zhang, M. Lu, G. You, Y. Wang, G. Chen, C. Zhao, Z. Wang, X. Song, Y. Wu, L. Zhao and Z. H. Zhou, Biomacromolecules, 2017, 18, 1333-1341.

2 S. M. C. Horwitz, K. Kelleher, P. M. T. Thomas Boyce, A. Webb, A. Meier-Hellmann, G. Nollet, D. Peres-Bota, J. L. Vincent, J.-F. Baron, K. Reinhart, L. Gattinoni, L. Thijs, A. Webb, A. Meier-Hellmann, G. Nollet, D. Peres-Bota and A. B. C. Investigators, 2002, 288, 1499-1507.

3 H. G. Klein and D. J. Anstee, Mollison's blood transfusion in clinical medicine, John Wiley \& Sons, 2014.

4 H. Sakai, K. Sou, H. Horinouchi, K. Kobayashi and E. Tsuchida, Artif. Organs, 2009, 33, $139-145$.

5 L. T. Goodnough, M. G. Scott and T. G. Monk, Clin. Orthop. Relat. Res., 1998, 357, 89100.

6 S. Kaneda, T. Ishizuka, H. Goto, T. Kimura, K. Inaba and H. Kasukawa, Artif. Organs, 2009, 33, 146-152.

7 V. R. Yadav, G. Rao, H. Houson, A. Hedrick, S. Awasthi, P. R. Roberts and V. Awasthi, Eur. J. Pharm. Sci., 2016, 93, 97-106.

8 S. Rameez, H. Alosta and A. F. Palmer, Bioconjug. Chem., 2008, 19, 1025-1032.

9 Y. Jia, Y. Cui, J. Fei, M. Du, L. Dai, J. Li and Y. Yang, Adv. Funct. Mater., 2012, 22, 14461453.

10 J. Zhao, C.-S. Liu, Y. Yuan, X.-Y. Tao, X.-Q. Shan, Y. Sheng and F. Wu, Biomaterials, 2007, 28, 1414-1422.

11 S. Peng, J. Liu, Y. Qin, H. Wang, B. Cao, L. Lu and X. Yu, ACS Appl. Mater. Interfaces, 2019, 11, 35604-35612. 
12 J. S. Qin, S. Yuan, C. Lollar, J. Pang, A. Alsalme and H. C. Zhou, Chem. Commun., 2018, 54, 4231-4249.

13 A. J. Howarth, Y. Liu, P. Li, Z. Li, T. C. Wang, J. T. Hupp and O. K. Farha, Nat. Rev. Mater., 2016, 1, 1-15.

14 S. Yuan, L. Feng, K. Wang, J. Pang, M. Bosch, C. Lollar, Y. Sun, J. Qin, X. Yang, P. Zhang, Q. Wang, L. Zou, Y. Zhang, L. Zhang, Y. Fang, J. Li and H. C. Zhou, Adv. Mater., 2018, 1704303, 1-35.

15 M. Wu and Y. Yang, Adv. Mater., 2017, 29, 1606134.

16 J. Yang and Y. Yang, View, 2020, 1, e20.

17 J. Yang and Y. Yang, Small, 2020, 16, 1906846.

18 M. A. Luzuriaga, R. P. Welch, M. Dharmarwardana, C. E. Benjamin, S. Li, A. Shahrivarkevishahi, S. Popal, L. H. Tuong, C. T. Creswell and J. J. Gassensmith, ACS Appl. Mater. Interfaces, 2019, 11, 9740-9746.

19 X. Lian, Y. Fang, E. Joseph, Q. Wang, J. Li, S. Banerjee, C. Lollar, X. Wang and H.-C. Zhou, Chem. Soc. Rev., 2017, 46, 3386-3401.

20 M. B. Majewski, A. J. Howarth, P. Li, M. R. Wasielewski, J. T. Hupp and O. K. Farha, CrystEngComm, 2017, 19, 4082-4091.

21 F. Wu, J. Ye, Y. Cao, Z. Wang, T. Miao and Q. Shi, Luminescence, 2020, 35, 440-446.

22 W. Wang, L. Wang, Y. Huang, Z. Xie and X. Jing, Chem. - An Asian J., 2016, 11, 750-756.

23 D. Feng, T. F. Liu, J. Su, M. Bosch, Z. Wei, W. Wan, D. Yuan, Y. P. Chen, X. Wang, K. Wang, X. Lian, Z. Y. Gu, J. Park, X. Zou and H. C. Zhou, Nat. Commun., 2015, 6, 1-8.

24 H. P. Erickson, Biol. Proced. Online, 2009, 11, 32.

25 R. S. Franco, Transfus. Med. hemotherapy, 2012, 39, 302-307. 
26 T. Ishida, M. Ichihara, X. Wang, K. Yamamoto, J. Kimura, E. Majima and H. Kiwada, J. Control. Release, 2006, 112, 15-25.

27 K. Środa, J. Rydlewski, M. Langner, A. Kozubek, M. Grzybek and A. F. Sikorski, Cell. Mol. Biol. Lett, 2005, 10, 37-47.

28 T. T. Hoang Thi, E. H. Pilkington, D. H. Nguyen, J. S. Lee, K. D. Park and N. P. Truong, Polymers (Basel)., 2020, 12, 298.

29 N. d'Avanzo, C. Celia, A. Barone, M. Carafa, L. Di Marzio, H. A. Santos and M. Fresta, Adv. Ther., 2020, 3, 1900170.

30 R. H. Fang, Y. Jiang, J. C. Fang and L. Zhang, Biomaterials, 2017, 128, 69-83.

31 C.-M. J. Hu, R. H. Fang and L. Zhang, Adv. Healthc. Mater., 2012, 1, 537-547.

32 K. Knop, R. Hoogenboom, D. Fischer and U. S. Schubert, Angew. Chemie Int. Ed., 2010, 49, 6288-6308.

33 C.-M. J. Hu, L. Zhang, S. Aryal, C. Cheung, R. H. Fang and L. Zhang, Proc. Natl. Acad. Sci. U. S. A., 2011, 108, 10980-5.

34 L. Rao, L.-L. L. L. Bu, J. H. J.-H. Xu, B. Cai, G.-T. G. T. Yu, X. Yu, Z. He, Q. Huang, A. Li, S.-S. S. S. Guo, W.-F. W. F. Zhang, W. Liu, Z.-J. Z. J. Sun, H. Wang, T.-H. T. H. Wang and X.-Z. X. Z. Zhao, Small, 2015, 11, 6225-6236.

35 B. T. Luk, R. H. Fang, C.-M. J. Hu, J. A. Copp, S. Thamphiwatana, D. Dehaini, W. Gao, K. Zhang, S. Li and L. Zhang, Theranostics, 2016, 6, 1004-1011.

36 M. J. York-Duran, P. K. Ek, M. Godoy-Gallardo and L. Hosta-Rigau, Colloids Surf., B, 2018, 171, 427-436.

37 G. L. Kenausis, J. Vörös, D. L. Elbert, N. Huang, R. Hofer, L. Ruiz-Taylor, M. Textor, J. A. Hubbell and N. D. Spencer, J. Phys. Chem. B, 2000, 104, 3298-3309.

38 W. G. Zijlstra and A. Buursma, Comp. Biochem. Physiol., Part B: Biochem. Mol. Biol., 
1997, 118, 743-749.

39 M. J. York-Duran, M. Godoy-Gallardo, M. M. T. Jansman and L. Hosta-Rigau, Biomater. Sci., 2019, 7, 4813-4826.

40 X. Liu, M. M. T. Jansman, P. W. Thulstrup, A. C. Mendes, I. S. Chronakis and L. HostaRigau, Macromol. Biosci., 2020, 20, 1900293.

41 Y. Chen, V. Lykourinou, C. Vetromile, T. Hoang, L.-J. Ming, R. W. Larsen and S. Ma, J. Am. Chem. Soc., 2012, 134, 13188-13191.

42 I. Lalezari, P. Lalezari, C. Poyart, M. Marden, J. Kister, B. Bohn, G. Fermi and M. F. Perutz, Biochemistry, 1990, 29, 1515-1523.

43 M. Danaei, M. Dehghankhold, S. Ataei, F. Hasanzadeh Davarani, R. Javanmard, A. Dokhani, S. Khorasani and M. R. Mozafari, Pharmaceutics, 2018, 10, 57.

44 M. M. T. Jansman and L. Hosta-Rigau, Adv. Colloid Interface Sci., 2018, 260, 65-84.

45 J. Park, D. Feng and H.-C. Zhou, J. Am. Chem. Soc., 2015, 137, 1663-1672.

46 J. Tu, J. Bussmann, G. Du, Y. Gao, J. A. Bouwstra and A. Kros, Int. J. Pharm., 2018, 543, $169-178$.

47 J. Hu, Q. Wang, Y. Wang, G. You, P. Li, L. Zhao and H. Zhou, J. Colloid Interface Sci., 2020, 571, 326-336.

48 P.-A. A. Oldenborg, T. Harada, D. A. Christian, D. A. Pantano, R. K. Tsai, D. E. Discher, A. Zheleznyak, Y.-F. F. Fang, C. F. F. Lagenaur, H. D. D. Gresham and F. P. P. Lindberg, Science, 2000, 288, 2051-4.

49 R. H. Fang, A. V. Kroll, W. Gao and L. Zhang, Adv. Mater., 2018, 30, 1706759.

50 Q. Jiang, Z. Luo, Y. Men, P. Yang, H. Peng, R. Guo, Y. Tian, Z. Pang and W. Yang, Biomaterials, 2017, 143, 29-45.

51 J. Xie, Q. Shen, K. Huang, T. Zheng, L. Cheng, Z. Zhang, Y. Yu, G. Liao, X. Wang and C. 
Li, ACS Nano, 2019, 13, 5268-5277.

52 J. Cui, Y. Wang, A. Postma, J. Hao, L. Hosta-Rigau and F. Caruso, Adv. Funct. Mater., 2010, 20, 1625-1631.

53 J. Cui, Y. Yan, G. K. Such, K. Liang, C. J. Ochs, A. Postma and F. Caruso, Biomacromolecules, 2012, 13, 2225-2228.

54 H. Lee, S. M. Dellatore, W. M. Miller and P. B. Messersmith, Science (80-. )., 2007, 318, 426-430.

55 O. Baidukova, Q. Wang, S. Chaiwaree, D. Freyer, A. Prapan, R. Georgieva, L. Zhao and H. Bäumler, Artif. Cells, Nanomedicine, Biotechnol., 2018, 46, S693-S701.

56 Q. Wang, R. Zhang, G. You, J. Hu, P. Li, Y. Wang, J. Zhang, Y. Wu, L. Zhao and H. Zhou, Artif. Cells, Nanomedicine, Biotechnol., 2018, 46, 484-492.

57 C. Yu, X. Huang, D. Qian, F. Han, L. Xu, Y. Tang, N. Bao and H. Gu, Chem. Commun., 2018, 54, 4136-4139.

58 L. Hosta-Rigau, M. J. York-Duran, T. S. Kang and B. Städler, Adv. Funct. Mater., 2015, 25, 3860-3869.

59 R. H. Fang, C. M. J. Hu and L. Zhang, Expert Opin. Biol. Ther., 2012, 12, 385-389.

60 B. T. Luk, C.-M. Jack Hu, R. H. Fang, D. Dehaini, C. Carpenter, W. Gao and L. Zhang, Nanoscale, 2013, 6, 2730-2737.

61 B. Maxit, tc, 2009, 10, 6s.

62 R. van der Westen, L. Hosta-Rigau, D. S. Sutherland, K. N. Goldie, F. Albericio, A. Postma and B. Städler, Biointerphases, 2012, 7, 8.

63 L. Thiele, J. E. Diederichs, R. Reszka, H. P. Merkle and E. Walter, Biomaterials, 2003, 24, 1409-1418.

64 N. Bertrand and J.-C. C. Leroux, J. Control. Release, 2012, 161, 152-163. 
65 S. Pasche, J. Vörös, H. J. Griesser, N. D. Spencer and M. Textor, J. Phys. Chem. B, 2005, 109, 17545-17552.

66 B. M. B. M. Teo, R. Van Der Westen, L. Hosta-Rigau and B. Städler, Biochim. Biophys. Acta - Gen. Subj., 2013, 1830, 4838-4847.

67 M. P. Calatayud, B. Sanz, V. Raffa, C. Riggio, M. R. Ibarra and G. F. Goya, Biomaterials, 2014, 35, 6389-6399.

68 R. Luo, L. Tang, S. Zhong, Z. Yang, J. Wang, Y. Weng, Q. Tu, C. Jiang and N. Huang, ACS Appl. Mater. Interfaces, 2013, 5, 1704-1714.

69 M. Lu, C. Zhao, Q. Wang, G. You, Y. Wang, H. Deng, G. Chen, S. Xia, J. Zhao, B. Wang, X. Li, L. Shao, Y. Wu, L. Zhao and H. Zhou, Colloids Surf., B, 2016, 139, 171-179. 